\title{
THE IMPACT OF PORE STRUCTURE ON CARBONATE STIMULATION TREATMENT USING VES-BASED HCL
}

\author{
A Thesis \\ by \\ TIURMA THERESA SIBARANI
}

\begin{abstract}
Submitted to the Office of Graduate and Professional Studies of Texas A\&M University

in partial fulfillment of the requirements for the degree of

MASTER OF SCIENCE
\end{abstract}

$\begin{array}{ll}\begin{array}{l}\text { Chair of Committee, } \\ \text { Committee Members, }\end{array} & \begin{array}{l}\text { Hisham A. Nasr-El-Din } \\ \text { Maria A. Barrufet } \\ \text { Mahmoud El-Halwagi }\end{array} \\ \text { Head of Department, } & \text { A. Daniel Hill }\end{array}$

August 2016

Major Subject: Petroleum Engineering

Copyright 2016 Tiurma Theresa Sibarani 


\begin{abstract}
Regular $\mathrm{HCl}$ has been used for years in carbonate stimulation treatment because it reacts rapidly with carbonate rocks. However, due to fast reaction, the acid reacts near the wellbore area and is not able to travel deeper into the formations. Viscoelastic surfactant has been added to increase acid viscosity and to lower the reaction between acid and carbonate. On the other hand, pore structures of carbonate are diverse and consist of various porosity systems such as intergranular, moldic pores, and vugs pores. The pore heterogeneity greatly impacts carbonate stimulation treatments. A pore-scale evaluation during stimulation design could lead to a more successful field treatment. This work proposes the study of viscoelastic surfactant (VES)-based hydrochloric acid ( $\mathrm{HCl})$ as a function of pore structures in carbonate rock. The results have revealed that flowing fraction, which represents pore heterogeneity, is higher in rock that has well-connected pores and lower in rock that has fairly connected pores. Preferential flow paths exist in the rock that has a lower flowing fraction. These paths lead to faster wormhole propagation, and thus less acid was required to reach breakthrough. Rock with a higher flowing fraction possesses higher fraction of the pores that allow more fluid to flow. This process caused more acid to come into contact with the carbonate rocks and more acid to be needed to reach breakthrough. The regained permeability is used to represent cleanup characteristic after acid injection. This study proves that rock with a higher degree of heterogeneity has better cleanup than rock with a lower degree of heterogeneity. It happens because heterogeneous rock has a lower flowing fraction, which corresponds to less remaining
\end{abstract}


surfactants inside the matrix. Wormholes that have fewer branches were produced in rock with a lower flowing fraction. Fewer branches correspond to a less complex wormhole pattern and a lower fractal dimension number. Moreover, it is highly recommendable that surfactants are added into acid systems to reduce acid pore volume to reach breakthrough and to form uniform wormhole patterns. 


\section{DEDICATION}

I dedicate this thesis to my mom, dad in heaven, brothers, sisters, and nieces for their continuous support and encouragement. Family is the greatest gift in the whole life. 


\section{ACKNOWLEDGEMENTS}

I would like to express my deepest gratitude and appreciation to my committee chair, Dr. Hisham A. Nasr-El-Din, for his support and guidance throughout my master program and this research. I would like to extend my appreciation to Dr. Maria A. Barrufet and Dr. Mahmoud El-Halwagi for serving as committee members.

I would like also to thank all my friends and colleagues in my research group and staff at Texas A\&M University. I also want to express my gratitude to Schlumberger for the funding of this research. 


\section{NOMENCLATURE}

C

$\mathrm{CaCl}_{2}$

$\mathrm{CaCO}_{3}$

$\mathrm{CO}_{2}$

CT

D

$\mathrm{d}_{\mathrm{f}}$

DI

$\mathrm{Fe}$

$\mathrm{HCl}$

HPMI

$\mathrm{H}_{2} \mathrm{O}$

ICP

$\mathrm{k}$

$\mathrm{KCl}$

L

$\mathrm{MgCl}_{2}$

$\mathrm{MgCO}_{3}$

NMR
Tracer concentration in the core effluent samples, $\mathrm{mg} / \mathrm{l}$

Calcium chloride

Calcium carbonate

Carbon dioxide

Computed tomography

Core diameter, inch

Fractal dimension

Deionized

Iron

Hydrochloric acid

High pressure mercury injection

Hydrogen dioxide

Inductively coupled plasma

Permeability, md

Potassium chloride

Core length, inch

Magnesium chloride

Magnesium carbonate

Nuclear magnetic resonance 


$\begin{array}{ll}\mathrm{PV}_{\mathrm{bt}} & \text { Pore volume to reach breakthrough } \\ \mathrm{q} & \text { Flow rate, } \mathrm{cm}^{3} / \mathrm{min} \\ \mathrm{rpm} & \text { Revolutions per minute } \\ \mathrm{RRT} & \text { Reservoir rock type } \\ \mathrm{Vb} & \text { Bulk volume } \\ \mathrm{VES} & \text { Viscoelastic surfactant } \\ \mathrm{vol} \% & \text { Volume percent } \\ \mathrm{Vp} & \text { Pore volume } \\ \mathrm{Wdry} & \text { Dry weight, gram } \\ \text { wt } \% & \text { Weight percent } \\ \text { Wwet } & \text { Wet weight, gram }\end{array}$

vii 


\section{TABLE OF CONTENTS}

Page

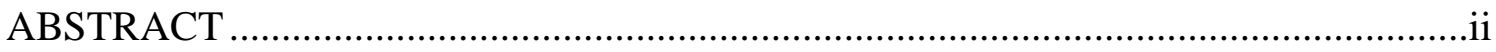

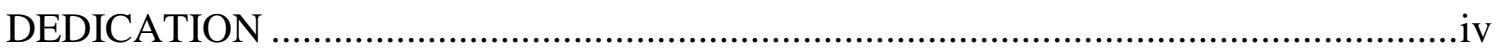

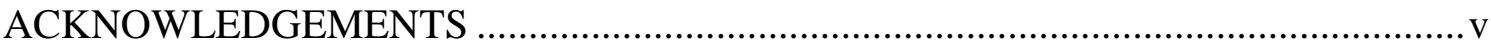

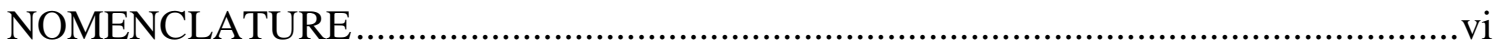

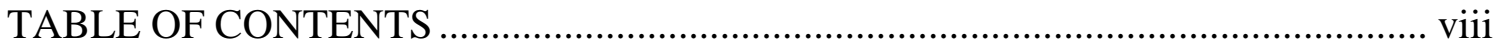

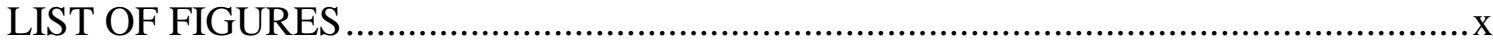

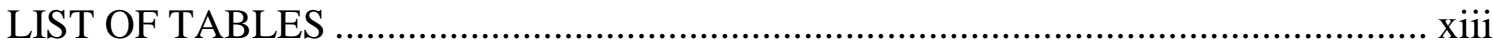

CHAPTER I INTRODUCTION AND LITERATURE REVIEW ................................. 1

CHAPTER II EXPERIMENTAL STUDY ..........................................................

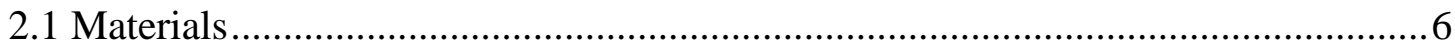

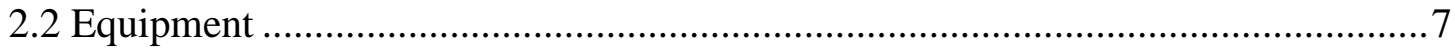

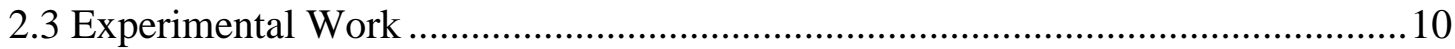

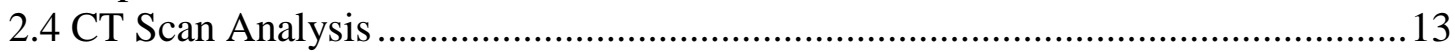

CHAPTER III EXPERIMENTAL RESULTS ....................................................... 14

3.1 Rheology Study ........................................................................................ 14

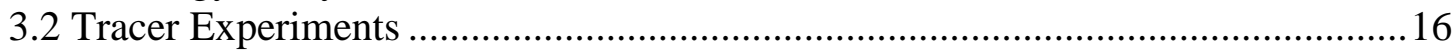

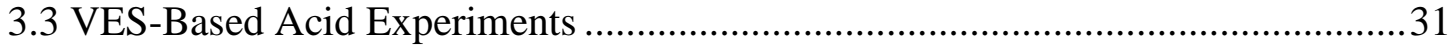

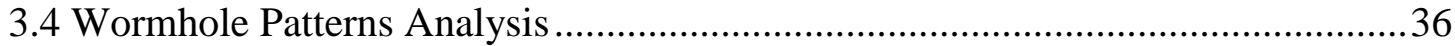

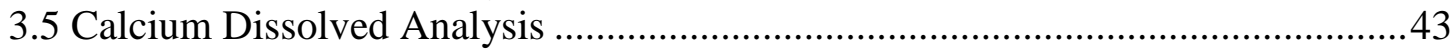

CHAPTER IV ANALYSIS AND CONCLUSIONS ..............................................49

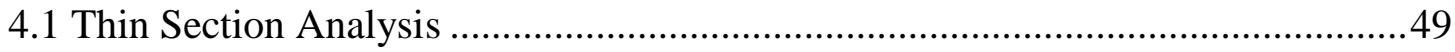

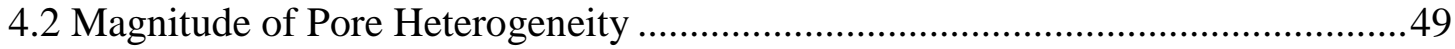

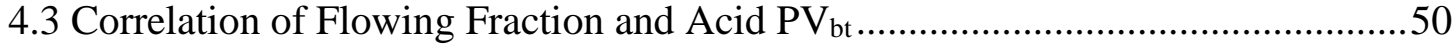

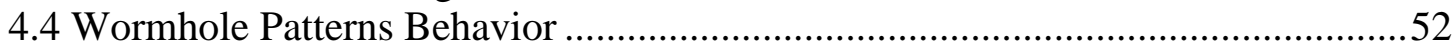

4.5 Correlation of Flowing Fraction and Wormhole Complexity ................................54

4.6 Correlation of Flowing Fraction and Cleanup Characteristic ..............................56

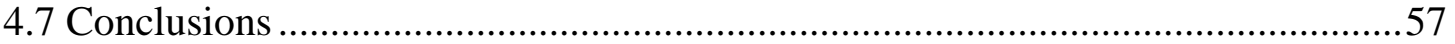




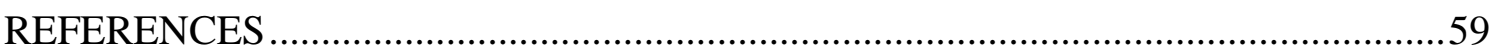




\section{LIST OF FIGURES}

Figure 1: Flowchart to quantify pore-scale heterogeneity ...........................................5

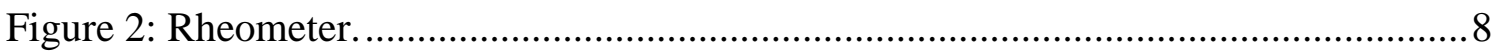

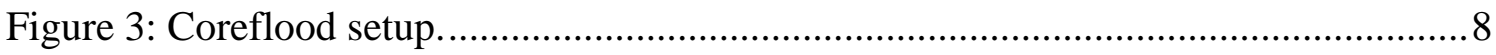

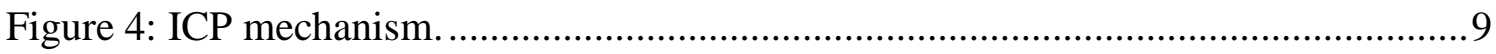

Figure 5: Optima 7000 ICP-OES spectrometer................................................

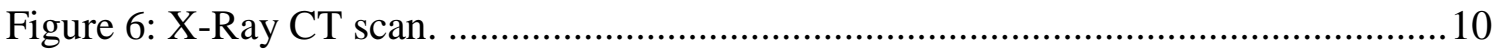

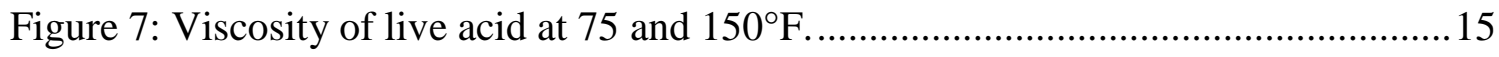

Figure 8: Viscosity at different salt concentration as a function of shear rate at $150^{\circ} \mathrm{F} .15$

Figure 9: Tracer concentration of Indiana limestone core 1. ...................................... 18

Figure 10: Tracer concentration of Indiana limestone core 2. .................................. 18

Figure 11: Tracer concentration of Indiana limestone core 3................................. 19

Figure 12: Tracer concentration of Indiana limestone core 4. ................................... 19

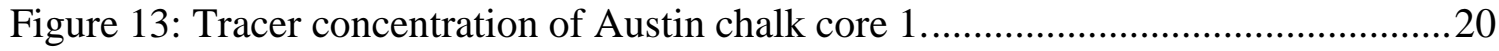

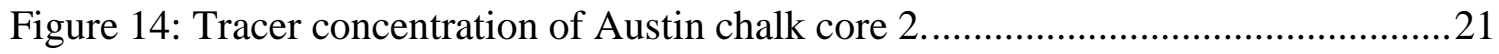

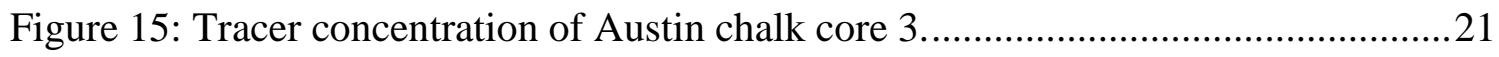

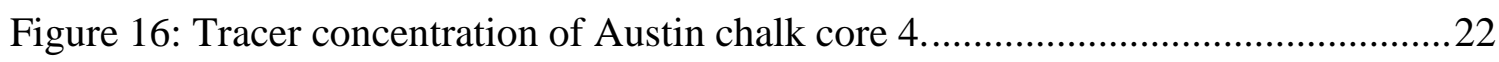

Figure 17: Tracer concentration of Edwards yellow core 1 .....................................23

Figure 18: Tracer concentration of Edwards yellow core 2.......................................23

Figure 19: Tracer concentration of Edwards yellow core 3....................................24

Figure 20: Tracer concentration of Edwards yellow core 4.......................................24

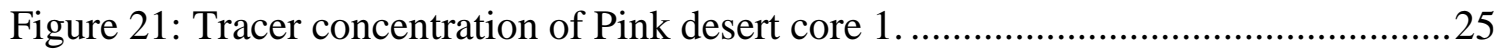

Figure 22: Tracer concentration of Pink desert core 2..........................................25 
Figure 23: Tracer concentration of Pink desert core 3 ...........................................26

Figure 24: Tracer concentration of Pink desert core 4 ..............................................26

Figure 25: Tracer concentration of Winterset limestone core 1 ..................................27

Figure 26: Tracer concentration of Winterset limestone core 2................................28

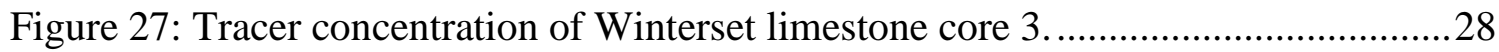

Figure 28: Tracer concentration of Winterset limestone core 4 .................................29

Figure 29: Tracer concentration of Edwards white core 1 .......................................29

Figure 30: Tracer concentration of Edwards white core 2 ...................................... 30

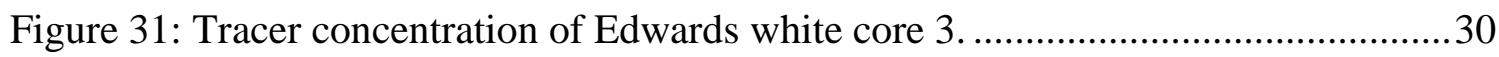

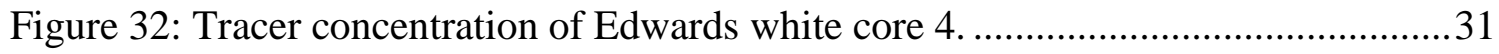

Figure 33: Pressure drop profiles of Indiana limestone. ........................................... 32

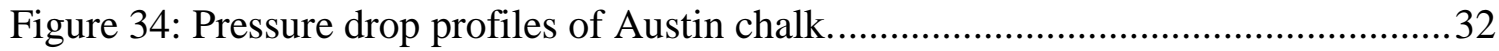

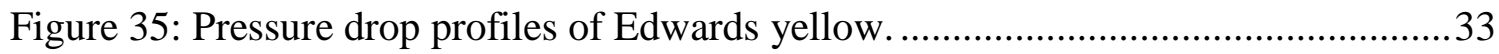

Figure 36: Pressure drop profiles of Pink desert. ..................................................... 33

Figure 37: Pressure drop profiles of Winterset limestone.........................................34

Figure 38: Pressure drop profiles of Edwards white.............................................. 34

Figure 39: Acid volume to breakthrough as a function of acid injection rates................35

Figure 40: CT scan images of Indiana limestone before acidizing. .............................37

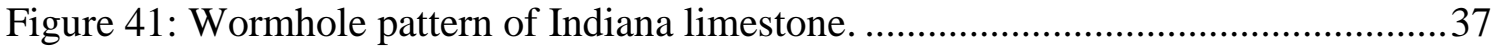

Figure 42: CT scan images of Austin chalk before acidizing. .....................................38

Figure 43: Wormhole pattern of Austin chalk. .................................................. 38

Figure 44: CT scan images of Edwards yellow before acidizing.................................39

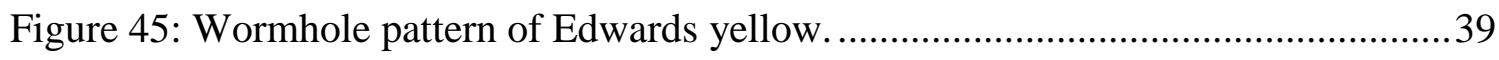

Figure 46: CT scan images of Pink desert before acidizing........................................40 
Figure 47: Wormhole pattern of Pink desert.

Figure 48: CT scan images of Winterset limestone before acidizing.

Figure 49: Wormhole pattern of Winterset limestone.

Figure 50: CT scan images of Edwards white before acidizing.

Figure 51: Wormhole pattern of Edwards white.

Figure 52: Calcium concentration in the core effluent samples of Indiana limestone.....44

Figure 53: Calcium concentration in the core effluent samples of Austin chalk.

Figure 54: Calcium concentration in the core effluent samples of Edwards yellow....

Figure 55: Calcium concentration in the core effluent samples of Pink desert. .46

Figure 56: Calcium concentration in the core effluent samples of Winterset limestone. 46

Figure 57: Calcium concentration in the core effluent samples of Edwards white .47

Figure 58: PVbt for VES-based $\mathrm{HCl}$ as a function of the flowing fraction at different acid injection.

Figure 59: Wormhole patterns that are produced with VES-based $\mathrm{HCl}$, grouped into each rock type.

Figure 60: Fractal dimension as a function of flowing fraction.

Figure 61: Regained permeability of different carbonate rock types after VES-based $\mathrm{HCl}$ injection. 


\section{LIST OF TABLES}

Page

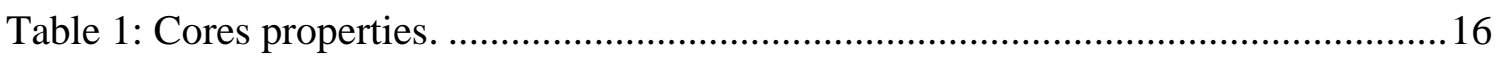

Table 2: Fractal dimension of different rock types. ............................................... 43

Table 3: Total calcium dissolved for different rock types. ......................................47

Table 4: Flowing fraction of carbonate rocks. .........................................................50 


\section{CHAPTER I}

\section{INTRODUCTION AND LITERATURE REVIEW}

The objective of acid stimulation treatment is to bypass the damage of near wellbore area to improve well productivity. The success of this treatment is determined by fluid distribution. As well, the acid placement materials do not create additional formation damage such as permeability loss. A uniform distribution is the most preferable (Gomaa et al. 2011) because the acid penetrates to the treatment zones instead of leaking away as fluid loss into other zones.

$\mathrm{HCl}$ has been used for years on carbonate acidizing due to its ability to react rapidly with carbonate and it is cost effective. Reaction of $\mathrm{HCl}$ with carbonate as below:

$$
\begin{aligned}
& 2 \mathrm{HCl}+\mathrm{CaCO}_{3} \rightarrow \mathrm{CaCl}_{2}+\mathrm{H}_{2} \mathrm{O}+\mathrm{CO}_{2} \\
& 2 \mathrm{HCl}+\mathrm{MgCO}_{3} \rightarrow \mathrm{MgCl}_{2}+\mathrm{H}_{2} \mathrm{O}+\mathrm{CO}_{2}
\end{aligned}
$$

However, due to low viscosity, the acid leakoff occured and generated branched wormholes, and the fast reaction of acid and carbonate rocks led to acid consumption before the acid flow deeper into interested zones, and produced face dissolution (Wang et al. 1993).

To overcome these issues, several acid systems have been introduced to increase the fluid viscosity in purpose to minimize leakoff, and to lower the reaction rate between acid and the carbonate rock, so that acid will penetrate deeper into the production intervals. Polymer and crosslinked-acid have been developed as the alternative. The concern is that polymer retention in the wormholes after acid treatment cause permeability loss (Lynn 
and Nasr-El-Din 2001). Crosslinked-acid is able to improve the acid viscosity and reduce acid leakoff, however, this acid system used Fe (III) as a crosslinker, and at a higher iron concentrations the acid would precipitate and created another formation damage (AlNakhli et al. 2008). In addition, this crosslinker cause more frictional pressure loss when acid is pumped through tubing (Nasr-El-Din and Samuel 2007).

VES-based acids have been developed extensively as matrix stimulation fluid to resolve these problems. Surfactant is added in to the acid system to lower reaction of acid with carbonate rock. The presence of salts and an increase in $\mathrm{pH}$ cause surfactant molecules to form rod-like micelle that increase apparent viscosity (Li et al. 2009; NasrEl-Din et al. 2006; Yu et al. 2009). The high viscosity fluid acts as a barrier to improve fluid diversion during stimulation so that fluid loss could be reduced. In addition, less friction loss occured because the acid system does not require crosslinker and in-situ gelled acid is formed in the formation when the acid reacted with carbonate rocks, hence, the acid can be pumped at a higher rate (Nasr-El-Din and Samuel 2007). After field treatment, viscosity can be reduced by breaking down surfactant gel through dilution or mixing, with hydrocarbon (oil or condensate) or mutual solvent (Yu et al. 2009; 2011).

On the other hand, carbonate formations are very complex in the porosity system. Understanding the response of each pore class to the acid stimulation treatment could lead to a more successful stimulation treatment with VES fluids. Lucia (1983) described the division of carbonate pore types: pore-space that is located between grains, called interparticle porosity. The other pore-space, called vuggy porosity, and this type of porosity is divided into two groups: (1) vugs that are interconnected through the 
interparticle pore is separate vugs, and (2) vugs that are formed due to an interconnected pore system are touching vugs.

Several studies have been conducted to investigate the response of acid with carbonate rocks at various temperatures, additives, and injection rates, but only few studies reported the effect of pore-structure on carbonate stimulation treatments. Wang et al. (1993) studied the effect of injection rate, acid concentration, rock mineralogy, and temperature on carbonate acidizing. They concluded that among all of those factors, rock mineralogy has the largest effect on carbonate acidizing. If rock mineralogy gave the most significant impact on this treatement, further detailed study is necessary to obtain an accurate well stimulation design. Ziauddin and Bize (2007) explored the effect of porescale heterogeneity, and they selected eight different carbonate rocks for their study. They classified each type of rock into a single reservoir rock type (RRT), this classification was based on porosity spatial distribution. The experimental results revealed rocks that from the same reservoir rock type showed a similar dissolution pattern, for example Austin chalk and Winterset limestone are grain dominated carbonates, and both rock types produced similar wormhole pattern. Their study helped establish the practice of rock classification based on porosity before field application.

Berthier and Fleury (2000) attempted experimental works to have a better uderstanding on carbonate pore-structure. The goal of their work is to determine the degree of heterogeneity using tracer experiments, displacement fluid by another miscible fluid that has the same viscosity. The concentration of effluent sample was increased because of fluid dispersion mechanism. For homogeneous rock, the fluid dispersion due to velocity 
gradients at the pore level, because of pore size. If the rock has large throat size that distributed in the porosity system, this curve was symmetric with a larger width, it represents weakly heterogeneous rock. In strongly heteregenous rock, the fluid was flowing in the preferential paths, tracer profile is a non symmetrical curve with long tail and early breakthrough.

Recent study from Zakaria et al. (2015) proved that pore heterogeneity has big impact on the acid reseponse during stimulation treatment. Their work consists: (1) thin section analysis to observe qualitative pore connectivity, fabric, and texture, (2) High Pressure Mercury Injection (HPMI) test to analyze pore throat size distribution, (3) Nuclear Magnetic Resonance (NMR) test to measure relaxation time distribution (T2), and (4) Tracer experiments, to quantify pore-scale heterogeneity. Their work is summarized as flowchart in Figure 1.

The results of their study proved that carbonate rocks with a higher flowing fraction required a higher $\mathrm{PV}_{\mathrm{bt}}$ than carbonate rocks with a lower flowing fraction. Regular $\mathrm{HCl}$ was used for acid treatment in their work. As mentioned earlier, due to low viscosity and rapid reaction of carbonate with the acid, the CT scan images showed that branched wormhole was generated.

The present study is a continuation of their research and attempts to investigate the performance of $\mathrm{VES}$-based $\mathrm{HCl}$ on six carbonate rocks. To lower the reaction of acid with the rock, the viscocity was increased by adding surfactant into the acid system, to achieve deeper acid penetration. This high viscosity fluid is also used to improve diversion ability to minimize acid leakoff. 


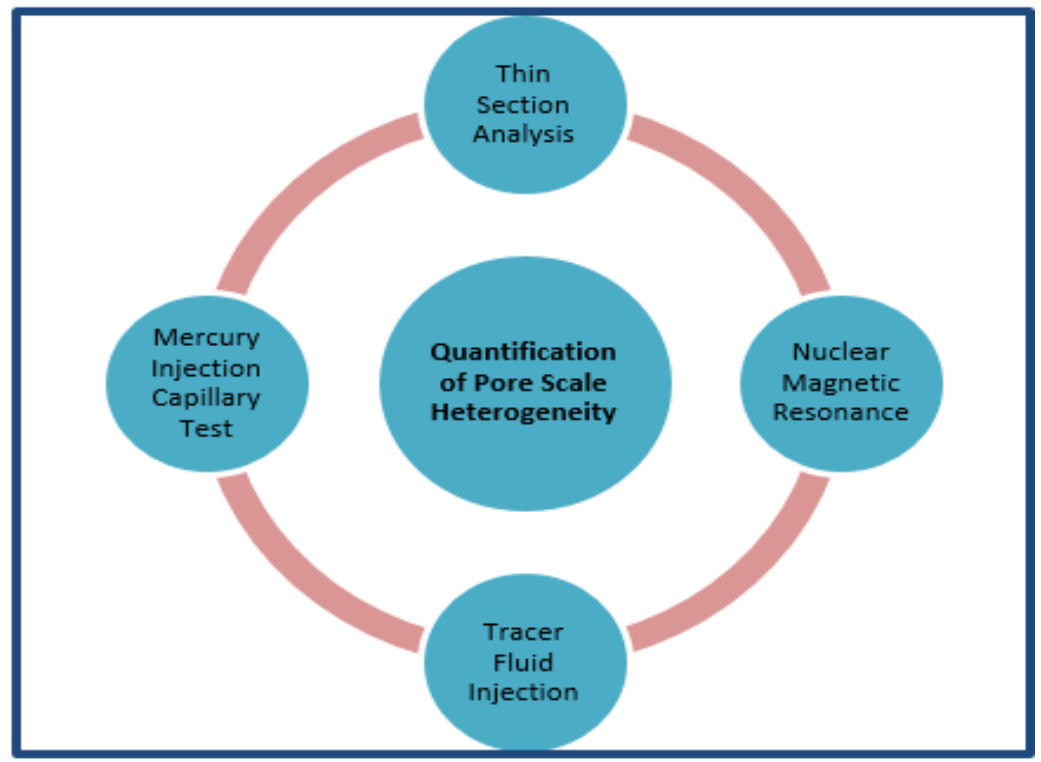

Figure 1: Flowchart to quantify pore-scale heterogeneity.

The quantification of pore heterogeneity in this work was determined by tracer experiments, in the number known as flowing fraction. The flowing fraction of each rock type was correlated to optimum $\mathrm{PV}_{\mathrm{bt}}$, and wormhole patterns were analyzed to observe the acid response into each porosity system. To achieve this objective, the work is divided into several phases: (1) to examine the magnitude of pore heterogeneity with tracer experiments, (2) to determine the optimum acid pore volume to reach breakthrough of selected carbonate rocks with coreflood experiments, (3) to investigate the wormhole pattern and its complexity for different pore-structures with CT Scan and Imagej software, and (4) to correlate the pore heterogeneity, acid response, and wormhole pattern. Eventually, if pore heterogeneity could be estimated, and then used to predict $\mathrm{PV}_{\mathrm{bt}}$ and wormhole pattern, these experimental studies could be conducted as part of stimulation design to achieve a more succesful field treatment. 


\section{CHAPTER II}

\section{EXPERIMENTAL STUDY}

The purpose of this experimental study is to achieve the objective that mentioned in the previous chapter. Series of tracer at fix injection rate, VES-based acid experiments at various injection rates, CT scan, and fractal dimension analysis were conducted to accomplish the goal.

\subsection{Materials}

Six carbonate rock types were selected for this study: Indiana limestone, Austin chalk, Edwards yellow, Pink desert, Edwards white, and Winterset limestone. The rocks were obtained from blocks, which are outcrops of the Bedford, Edwards Plateau, and Kansas formations, respectively. Cylindrical cores with dimensions of 6 in. length and 1.5 in. diameter were drilled from the blocks. Deionized (DI) water with a resisitivity 18.2 $\mathrm{M} \Omega . \mathrm{cm}$ at room temperature was used to saturate the cores and to prepare all solutions.

The tracer fluid, $8 \mathrm{wt} \%$ potassium chloride $(\mathrm{KCl})$ was prepared by diluting $\mathrm{KCl}$ (ACS reagent, > 99\%) in DI water. The acid solution was VES-based HCl. The live acid was prepared to have $15 \mathrm{wt} \% \mathrm{HCl}$ by mixing $\mathrm{DI}$ water, corrosion inhibitor (1-(1naphthylmethyl) quinolinium chloride, formic acid, aromatic ketones, oxyalkylated alcohols, propan-2-ol), and inhibitor aid agent (formic acid) at a moderate mixing speed. Then $\mathrm{HCl}$ (ACS reagent grade $36.8 \mathrm{wt} \%$ ) was added slowly to the solution, followed by methanol. Lastly, VES (fatty acid amidoalkyl betaine) was added with continuous stirring 
at $300 \mathrm{rpm}$ for nearly 2 minutes. Spent acid represent acid with various salt concentrations, was prepared by dissolving salt (calcium chloride, $\mathrm{CaCl}_{2}$ ) in DI water. The appropriate amount of $\mathrm{CaCl}_{2}$ was prepared based on the percentage of spent acid. In this work, three spent acids were prepared: $10 \mathrm{wt} \% \mathrm{HCl}$ (where $5 \mathrm{wt} \%$ was spent), $5 \mathrm{wt} \% \mathrm{HCl}$ (where 10 wt\% was spent), and completely spent acid (assuming all acid reacted with the rock). Corrosion inhibitor, inhibitor aid, methanol, and VES were added to this spent acid and incorporated via stirring.

\subsection{Equipment}

VES is a non-Newtonian fluid, where shear rate affects its viscosity behavior. To understand behavior of this fluid, viscosity was measured using Grace M5600 High Pressure High Temperature (HPHT) Rheometer at 300 psi and temperature $75^{\circ} \mathrm{F}$ and $150^{\circ} \mathrm{F}$ (Figure 2). The coreflood setup used in the experiments is shown in Figure 3. Back pressure of 1200 psi was applied during coreflood to keep $\mathrm{CO}_{2}$ in the solution. Confining/overburden pressure of $2000 \mathrm{psi}$ was applied during the experiments. Computer was connected pressure transducer to monitor and record pressure drop during the whole experiments. Fluids were injected in to the core using syringe pump (Teledyne ISCO D500) with maximum operational pressure of 2000 psi. 


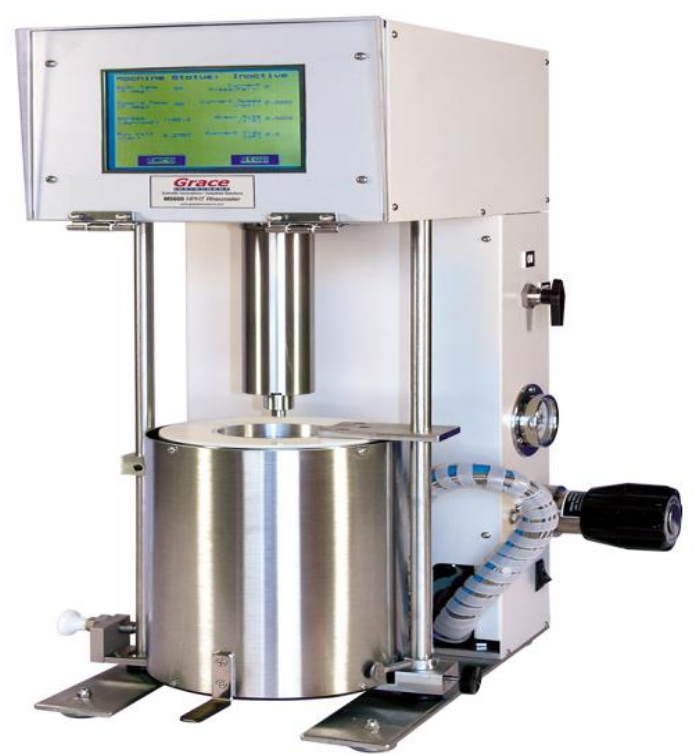

Figure 2: Rheometer.

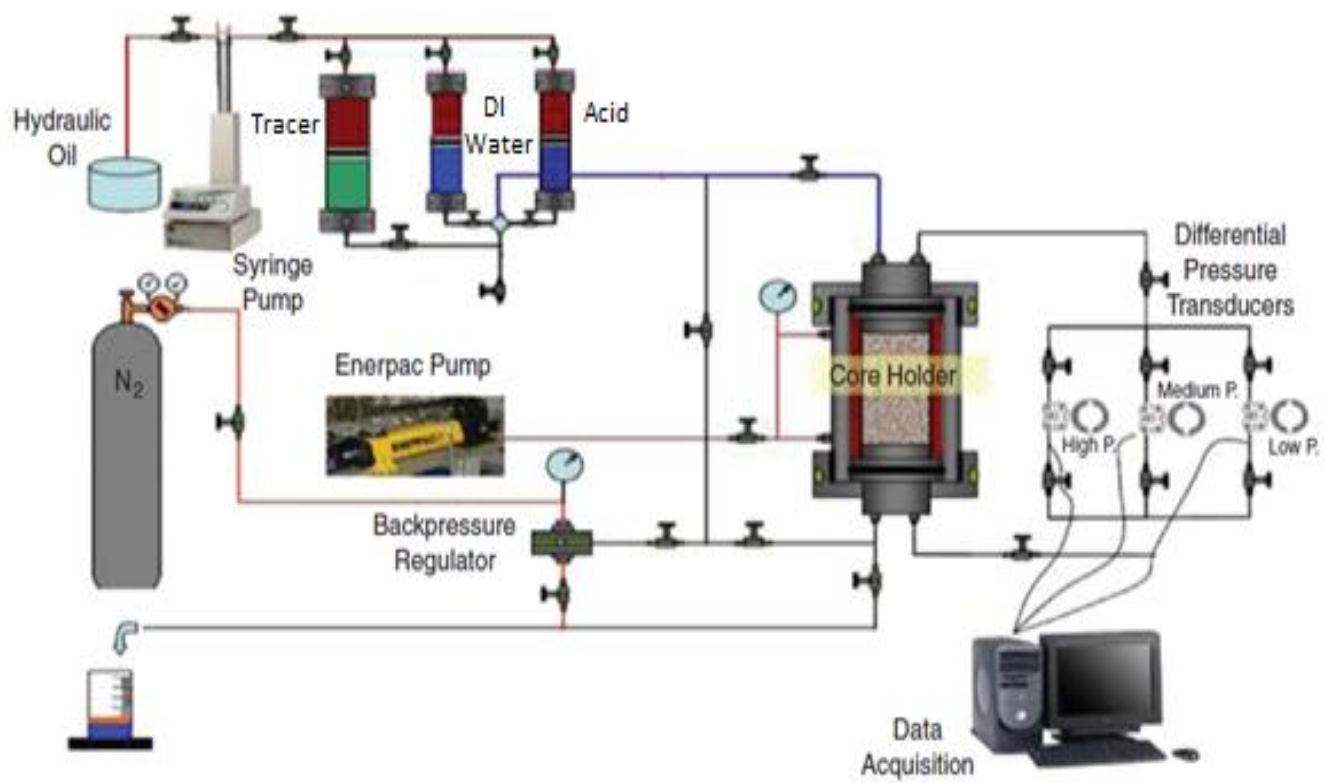

Figure 3: Coreflood setup.

The mechanism of optical emission spectroscopy measurements is using optical emission of excited atoms to determine element concentration. Sample solution are 
vaporized and atomized by plasma. The intensity of analyte atoms is compared with known concentration of standard solution. The concentration of each sample is computed by interpolating of calibration line of standard solution. The mechanism of these measurements illustrated in Figure 4. Inductively Coupled Plasma Optical Emission Spectrometry (ICP-OES, Optima 7000) that used to analyze effluent samples from coreflood experiments is shown in Figure 5.

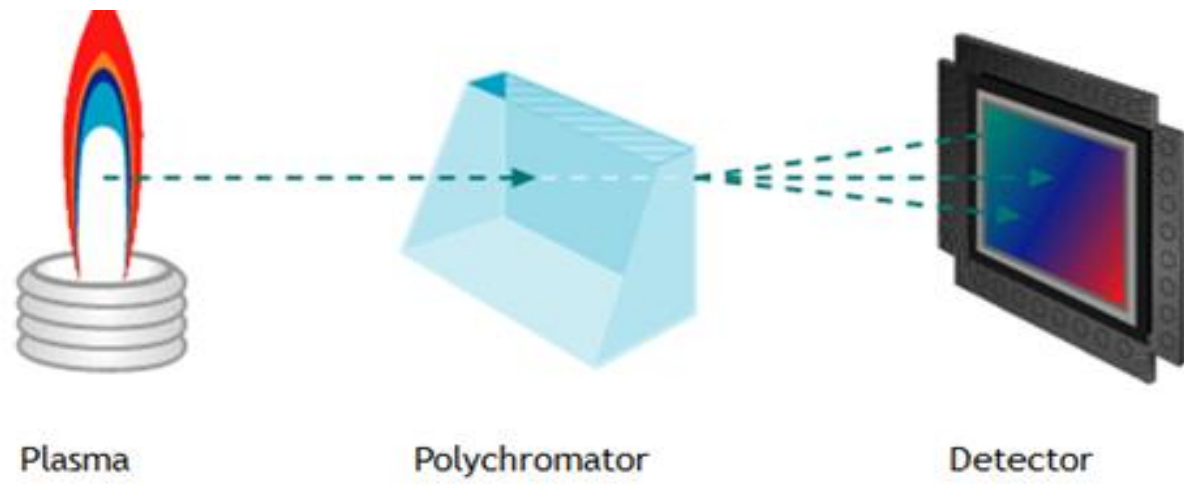

Figure 4: ICP mechanism.

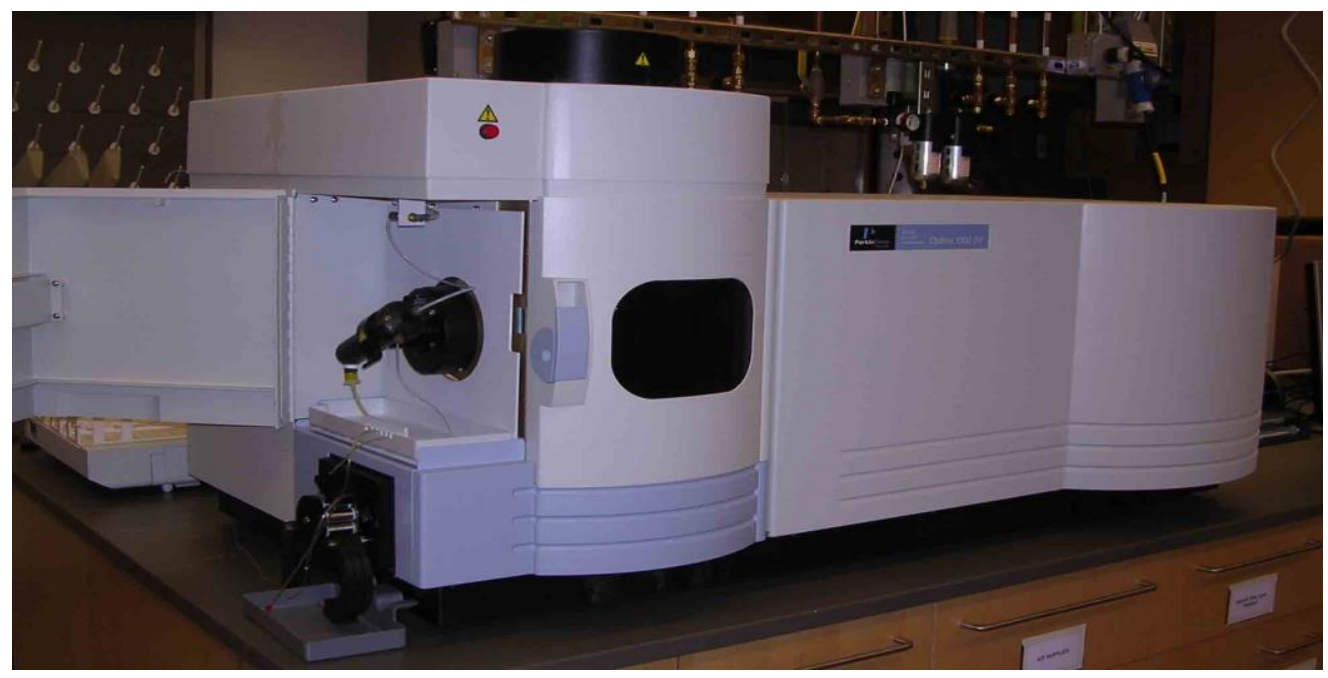

Figure 5: Optima 7000 ICP-OES spectrometer. 


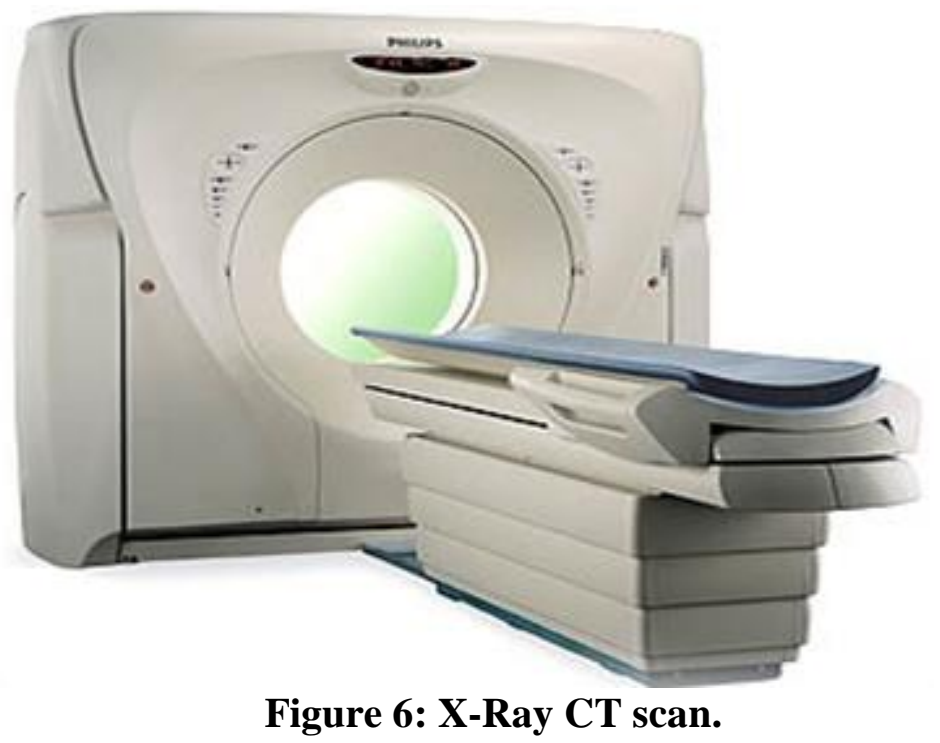

X-Ray Computed Tomography (CT) scan is conducted before acid injection to see spatial distribution of porosity and to make sure there is no fracturing occurs during core preparation, so the permeability are purely from the core itself. The CT scan after acid injection is used to examine the wormhole pattern.

\subsection{Experimental Work}

Cylindrical cores were dried in the oven at $250^{\circ} \mathrm{F}$ for 4 hours and dry weight was measured. Then cores were saturated with deionized water under vaccum for 24 hours and wet weight was measured. Pore volume was calculated based the difference of dry weight and wet weight measurements.

$$
V_{p}=\frac{W_{w e t}-W_{d r y}}{\rho}
$$

$V_{p}$ : Pore volume, $\mathrm{cm}^{3} ; \rho$ : Deionized water density, $\mathrm{g} / \mathrm{cm}^{3}$

Porosity was calculated from calculated pore volume and bulk volume. 


$$
\text { Porosity (\%) }=\frac{V_{p}}{V b} \times 100 \%
$$

Cylindrical core was inserted in core holder and deionized water was injected at room temperature wih flow rates $15 \& 20 \mathrm{~cm}^{3} / \mathrm{min}$ for higher permeability cores and $3 \& 5$ $\mathrm{cm}^{3} / \mathrm{min}$ for low permeability cores. Pressure drop was monitored untill it stable and permeability was calculated using Darcy's formula for laminar flow as below:

$$
k=122.8 \frac{q L \mu}{\Delta p d^{2}}
$$

k: permeability, md; L: core length, inch, d: core diameter, inch; q: flow rate, $\mathrm{cm}^{3} / \mathrm{min} ; \mu$ : dynamic viscosity, cp; $\Delta p$ : psia.

VES-based $\mathrm{HCl}$ was prepared by adding $0.6 \mathrm{vol} \%$ of corrosion inhibitor and 2 vol\% of inhibitor aid into DI water. $\mathrm{HCl}$ was added to solution slowly then methanol and VES. VES had to be added at a moderate rate to minimize foam generation. A high shear rate provided for a high-viscosity solution. This acid preparation method was chosen because of the absence of $\mathrm{CO}_{2}$, to minimize foaming (Nasr-El-Din et al. 2008). The trapped air generated during preparation can affect the rheology measurements; therefore, before viscosity was measured, the trapped air was removed using a centfrifuge.

Six of carbonate rock types were used to investigate the effect of pore-structure in matrix stimulation treatment. The design of experimental works are described as below. 24 Tracer Coreflood Experiments on Limestone:

- Temperature: $75^{\circ} \mathrm{F}$.

- Tracer injection rate: $5 \mathrm{~cm}^{3} / \mathrm{min}$.

- Tracer concentration in all experiments: $8 \mathrm{wt} \%$. 
24 VES-Based $\mathrm{HCl}$ Coreflood Experiments on Limestone:

- Temperature: $150^{\circ} \mathrm{F}$.

- Acid Injection Rate: $1 ; 2.5 ; 5 ; 7$ or $10 \mathrm{~cm}^{3} / \mathrm{min}$.

- $\mathrm{HCl}$ concentration in all experiments: $15 \mathrm{wt} \%$.

Cores with low permeability (Winterset limestone and Edward white) have higher pressure drop compare to other rocks, hence need high injection pressure that exceeded syring pump allowable working pressure. Because of this, maximum acid injection rate for these rock types was limited to $7 \mathrm{~cm}^{3}$. The procedures to measure concentration of effluent samples are below:

- Switch on the exhaust.

- Open nitrogen and argon tanks and observe the pressure.

- Make sure there are enough gas during analysis.

- Open the air valve.

- Switch the OES on.

- Close the peristaltic pump.

- Select method that is used for the analysis.

- Initialize plasma and wait for 30-40 minutes to stabilize.

- Calibrate blank (DI water).

- Calibrate standard solution (5, 15, and $30 \mathrm{ppm})$.

- Make sure calibration coefficient close to 1 (linear).

- Analyze each sample $\left(\mathrm{Ca}^{2+}\right.$ for acid samples and $\mathrm{K}^{+}$for tracer samples).

- If the concentration of sample was beyond 0-30 ppm, re-analyze the sample. 


\subsection{CT Scan Analysis}

Fractal dimension in this study was used to examine the complexity of wormhole patterns. The wormhole images were obtained from CT Scan. The magnitude of this complexity represented by fractal dimension number, that was obtained from ImageJ software (Karperien 2004) for this work. This number presenting a scaling rule to compare number of new parts and scale. This number was calculated from ratio of the log of the number of new parts to the log of scale. The image from CT scan as an input for the software, was converted to binary contour. The binary image was used to generate new segments, and these segments were counted as new parts that were used in the calculation. The log scale was determined from the size of the segments that were replaced by the new parts. The fractal dimension of 1 represents the index for a straight line, and 2 represents of surface. The fractal dimension of any irregular line or joint profile lies between 1 and 2. 


\section{CHAPTER III}

\section{EXPERIMENTAL RESULTS}

\subsection{Rheology Study}

Understanding the effect of shear rate is important because VES is a nonNewtonian shear-thinning fluid, which shear rate affects its viscosity behavior and could change the structure of the solution. As surfactant molecules are subjected to various degrees of shearing in the mixing tanks, pumps, and in the formation. The rheology measurements started at a shear rate of $1 \mathrm{~s}^{-1}$ up to $935 \mathrm{~s}^{-1}$. Figure 7 shows that apparent viscosity at room temperature $\left(75^{\circ} \mathrm{F}\right)$ was lower than at $150^{\circ} \mathrm{F}$ at various shear rates. The increase in viscosity at higher temperature could be due to restructuring of VES molecules in the micelle, and these micelle molecules entangle and give the solution its shearthinning behavior. The entangle molecules made VES-based $\mathrm{HCl}$ a self-viscosified fluid, so it does not need metallic crosslinker, hence less frictional pressure loss occurs during acid injection through tubing. Reducing the pressure loss is cost effective to minimize horsepower during field treatments.

As acid reacted with carbonate rocks, the $\mathrm{pH}$ of the solution and salt $\left(\mathrm{CaCl}_{2}\right)$ concentration in the fluid increased. Calcium ions carry positive charge and amphoteric surfactants have negative charge in neutralized acid. The presence of positive and negative charges in the acid system creates strong electrostatic attraction that will align micelle structures, to enhance the viscosity. The increase in viscosity could lead to better diversion 
ability. Viscosity measurements of VES-based $\mathrm{HCl}$ were conducted for different salt concentrations (Figure 8).

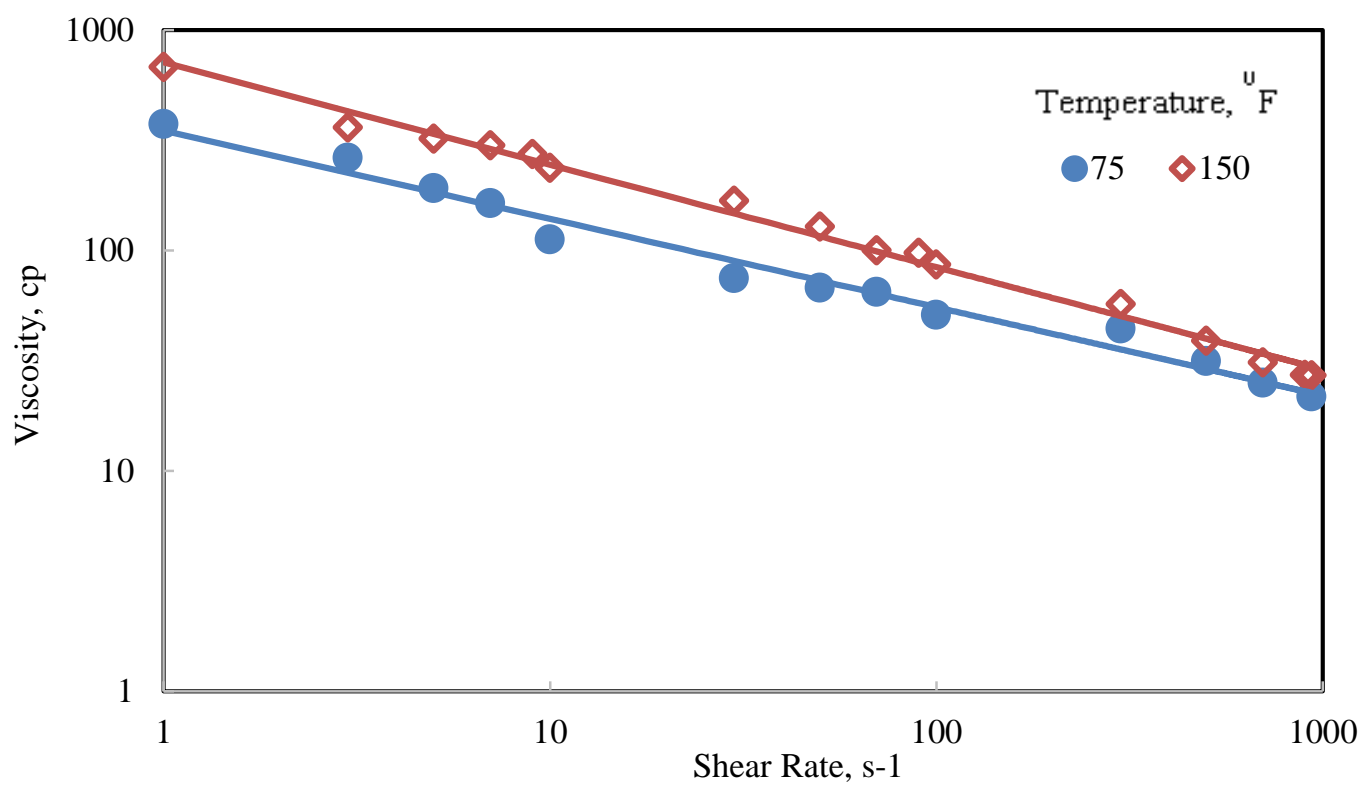

Figure 7: Viscosity of live acid at 75 and $150^{\circ} \mathrm{F}$.

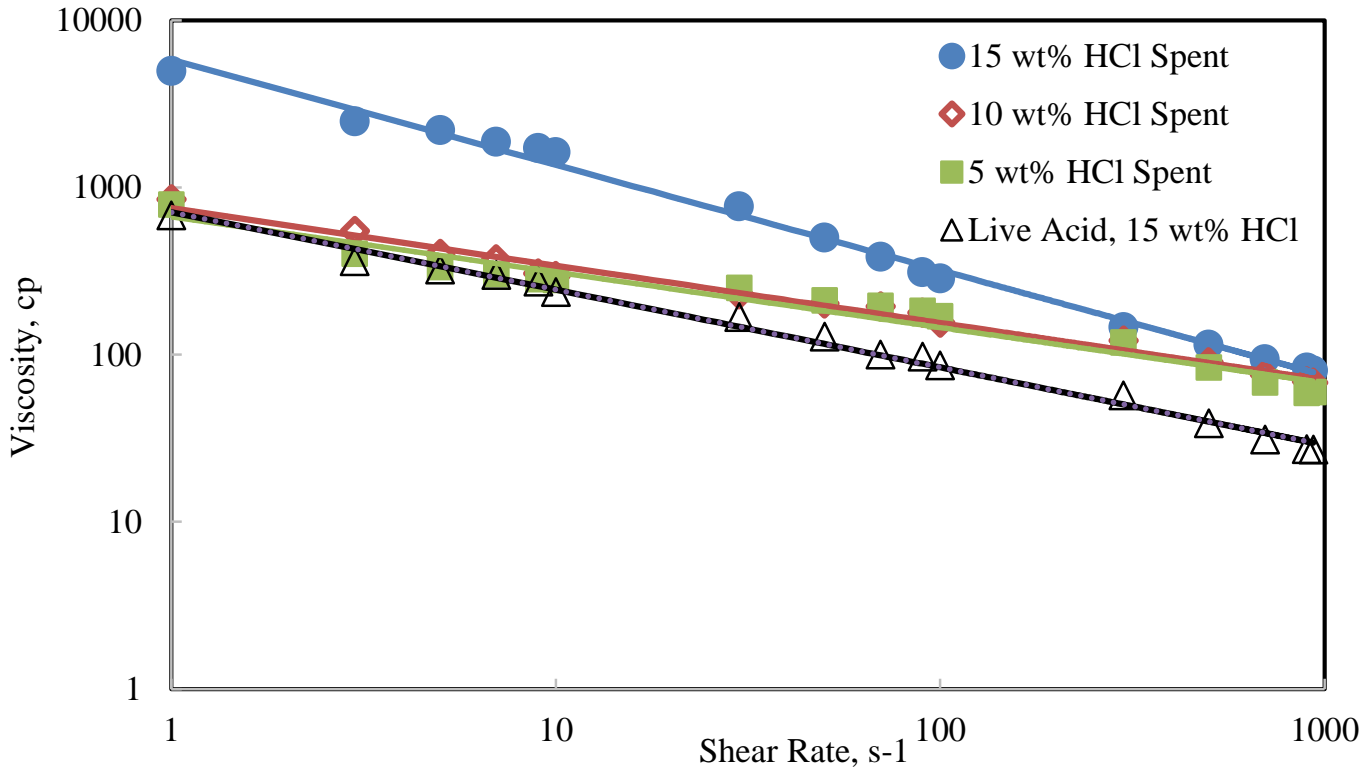

Figure 8: Viscosity at different salt concentration as a function of shear rate at $150^{\circ} \mathbf{F}$. 
Table 1: Cores properties.

\begin{tabular}{|c|c|c|c|c|}
\hline Rock Type & $\begin{array}{c}\text { Pore Volume } \\
\left(\mathrm{cm}^{3}\right)\end{array}$ & $\begin{array}{c}\text { Injection Rate } \\
\left(\mathrm{cm}^{3} / \mathrm{min}\right)\end{array}$ & $\begin{array}{c}\text { Porosity } \\
(\text { vol \% })\end{array}$ & $\begin{array}{c}\text { Initial Permeability } \\
(\mathrm{md})\end{array}$ \\
\hline Indiana limestone 1 & 26.6 & 1 & 16.3 & 155 \\
\hline Indiana limestone 2 & 26.8 & 2.5 & 16.4 & 153 \\
\hline Indiana limestone 3 & 26.5 & 5 & 16.2 & 151 \\
\hline Indiana limestone 4 & 26.9 & 10 & 16.5 & 155 \\
\hline Austin chalk 1 & 39.5 & 1 & 24.2 & 26 \\
\hline Austin chalk 2 & 40.5 & 2.5 & 24.8 & 25 \\
\hline Austin chalk 3 & 39.1 & 5 & 23.9 & 25 \\
\hline Austin chalk 4 & 42.0 & 10 & 25.7 & 24 \\
\hline Edwards yellow 1 & 49.3 & 1 & 30.2 & 78 \\
\hline Edwards yellow 2 & 47.0 & 2.5 & 28.8 & 72 \\
\hline Edwards yellow 3 & 49.5 & 5 & 30.3 & 74 \\
\hline Edwards yellow 4 & 46.9 & 10 & 28.7 & 76 \\
\hline Pink desert 1 & 49.9 & 1 & 30.6 & 64 \\
\hline Pink desert 2 & 46.7 & 2.5 & 28.7 & 66 \\
\hline Pink desert 3 & 49.4 & 5 & 30.3 & 69 \\
\hline Pink desert 4 & 48.9 & 10 & 30.0 & 75 \\
\hline Winterset limestone 1 & 35.4 & 1 & 21.7 & 3.5 \\
\hline Winterset limestone 2 & 35.5 & 2.5 & 21.7 & 3.8 \\
\hline Winterset limestone 3 & 37.5 & 5 & 22.9 & 5 \\
\hline Winterset limestone 4 & 39.8 & 7 & 24.4 & 5.4 \\
\hline Edwards white 1 & 32.3 & 1 & 19.8 & 2.5 \\
\hline Edwards white 2 & 30.7 & 2.5 & 18.8 & 2.5 \\
\hline Edwards white 3 & 31.6 & 5 & 19.3 & 3.6 \\
\hline Edwards white 4 & 32.0 & 7 & 19.6 & 3.3 \\
\hline
\end{tabular}

Six different carbonate rocks with different pore structures were selected for this study. The cores that have similar properties (porosity and permeability) were chosen for each rock type.

\subsection{Tracer Experiments}

Flowing fraction which was obtained from tracer experiments was used to quantify pore-scale heterogeneity. $\mathrm{K}^{+}$concentration (time function) from the effluent samples was measured using ICP. Normalized concentration, $\mathrm{K}^{+}$concentration from effluent core 
samples $(\mathrm{C})$ over the initial $\mathrm{K}^{+}$concentration in the injected tracer fluid $\left(\mathrm{C}_{\mathrm{o}}\right)$ was plotted against the cumulative volume injected. The fluid concentration (C) at the outlet was gradually increased due to dispersion, mass transfer, and dead-end pores. Berthier and Fleury (2000) showed that the dispersion due to velocity gradients at the pore level, in the case of homogeneous rocks, creates a symmetrical profile. In the case of rocks with large pore-throat size distribution, the dispersion curve might be symmetric with a larger width, the characteristic of weakly heterogeneous rocks. In the case of strongly heterogeneous rocks, deeply penetrable paths already exist, creating strong asymmetry with early breakthrough and long tail features. The tailing profile occured with the rock that has higher heterogeneity because mass transfer within dead end pores, and early reakthrough happened due to inaccessible pores. Asymmetry profile representing the presence of deadend and inaccessible pores (Skauge et al. 2006).

Tracer profiles for Indiana limestone showed in Figure 9 through Figure 12. This rock type needs about 1 cumulative injected volume of tracer to obtain 0.5 dimensionless effluent concentrations $\left(\mathrm{C} / \mathrm{C}_{\mathrm{o}}\right)$, or it can be said that flowing fraction $(f)$ of Indiana limestone is $f=1$. Based on study of Berthier and Fleury (2000), these tracer profiles are symmetrical, correspond to homogeneous rock. 


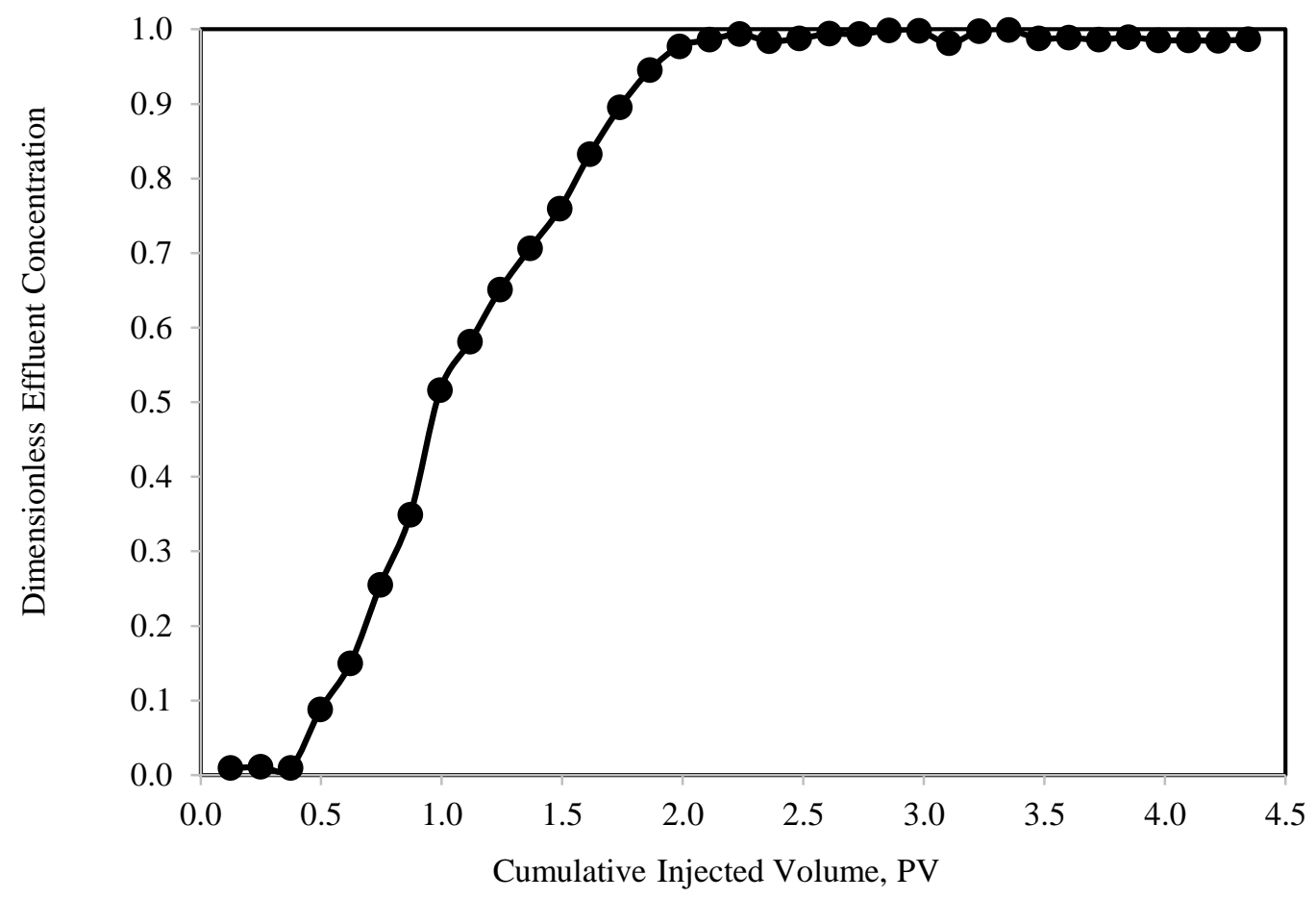

Figure 9: Tracer concentration of Indiana limestone core 1.

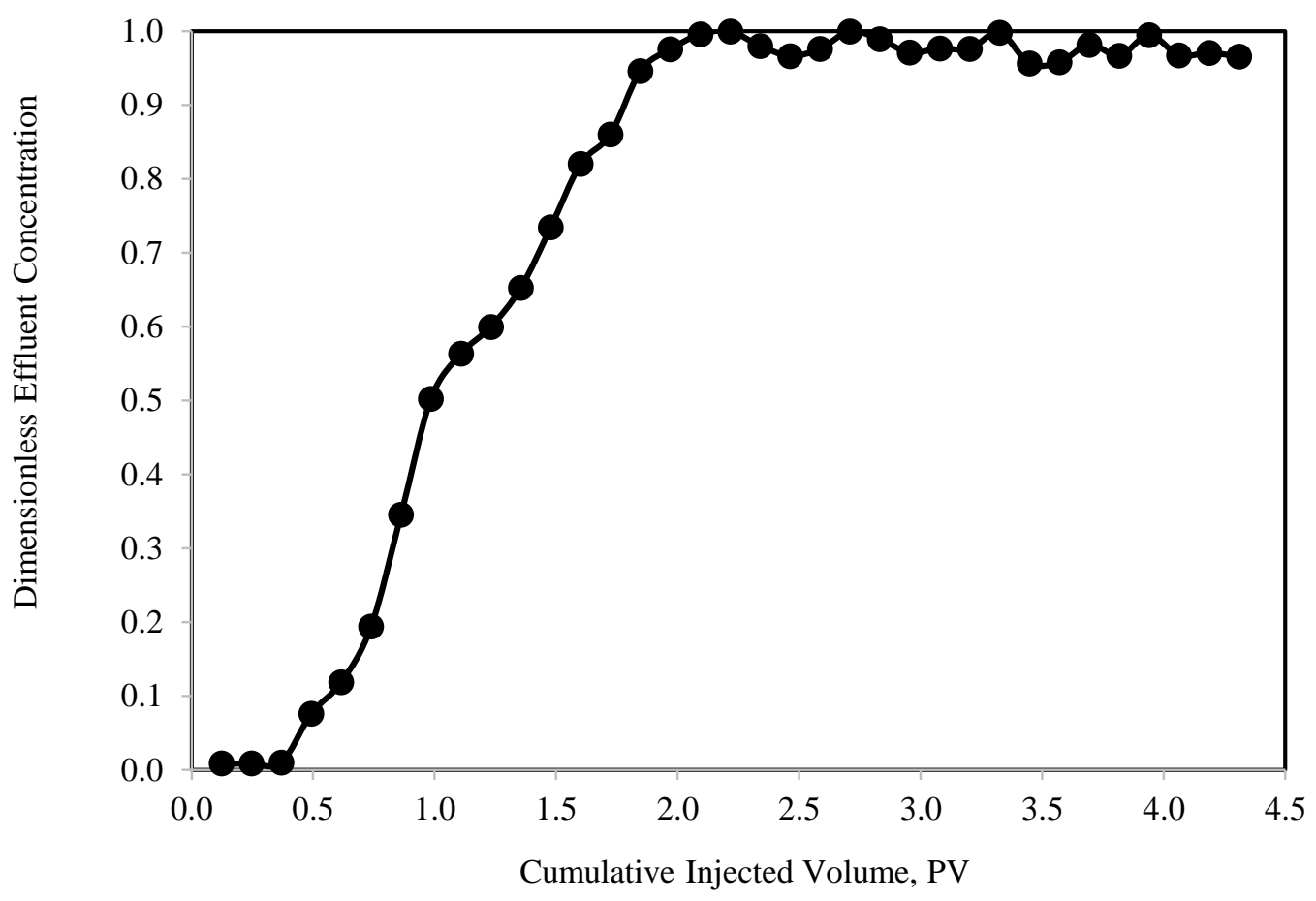

Figure 10: Tracer concentration of Indiana limestone core 2. 


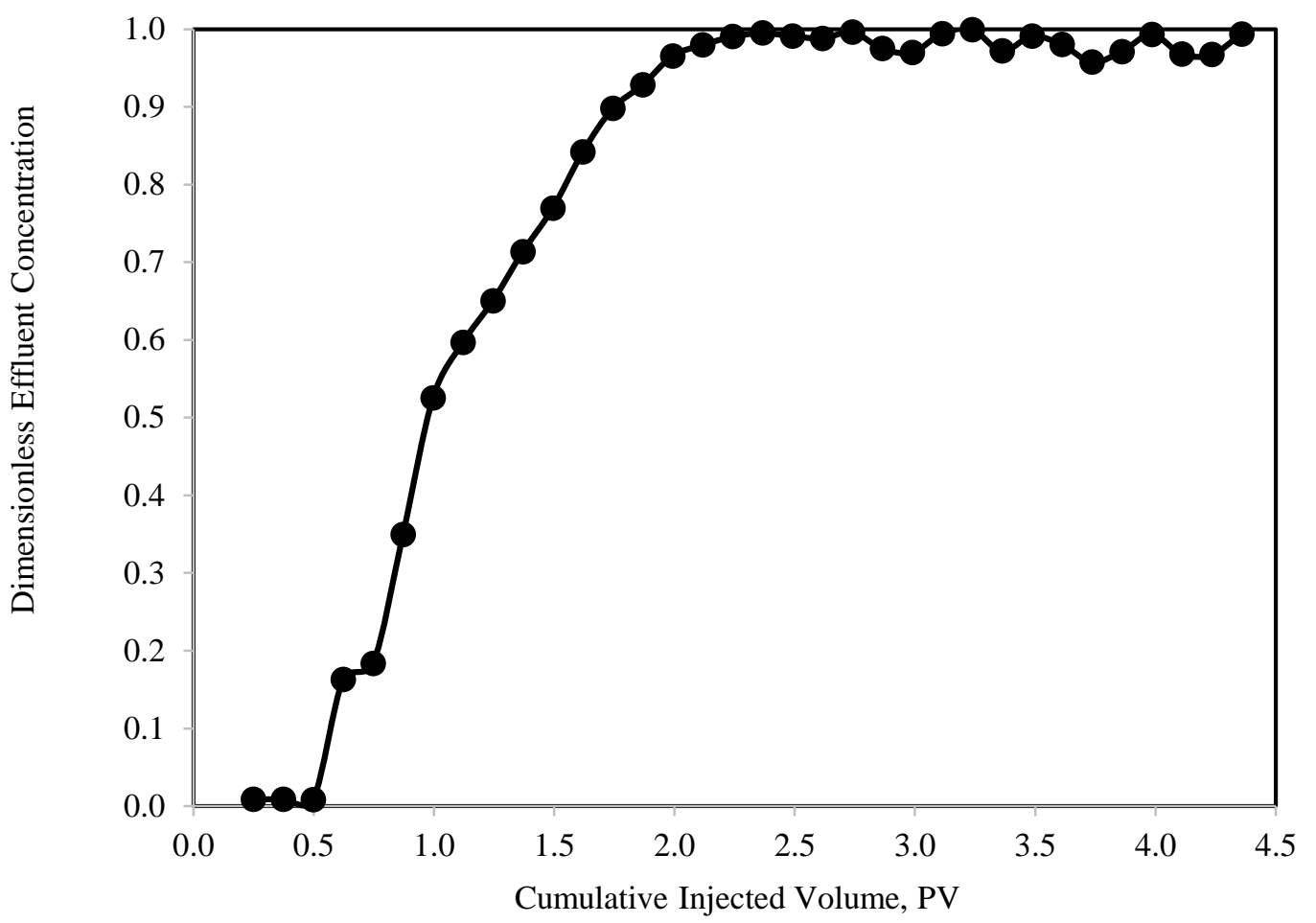

Figure 11: Tracer concentration of Indiana limestone core 3.

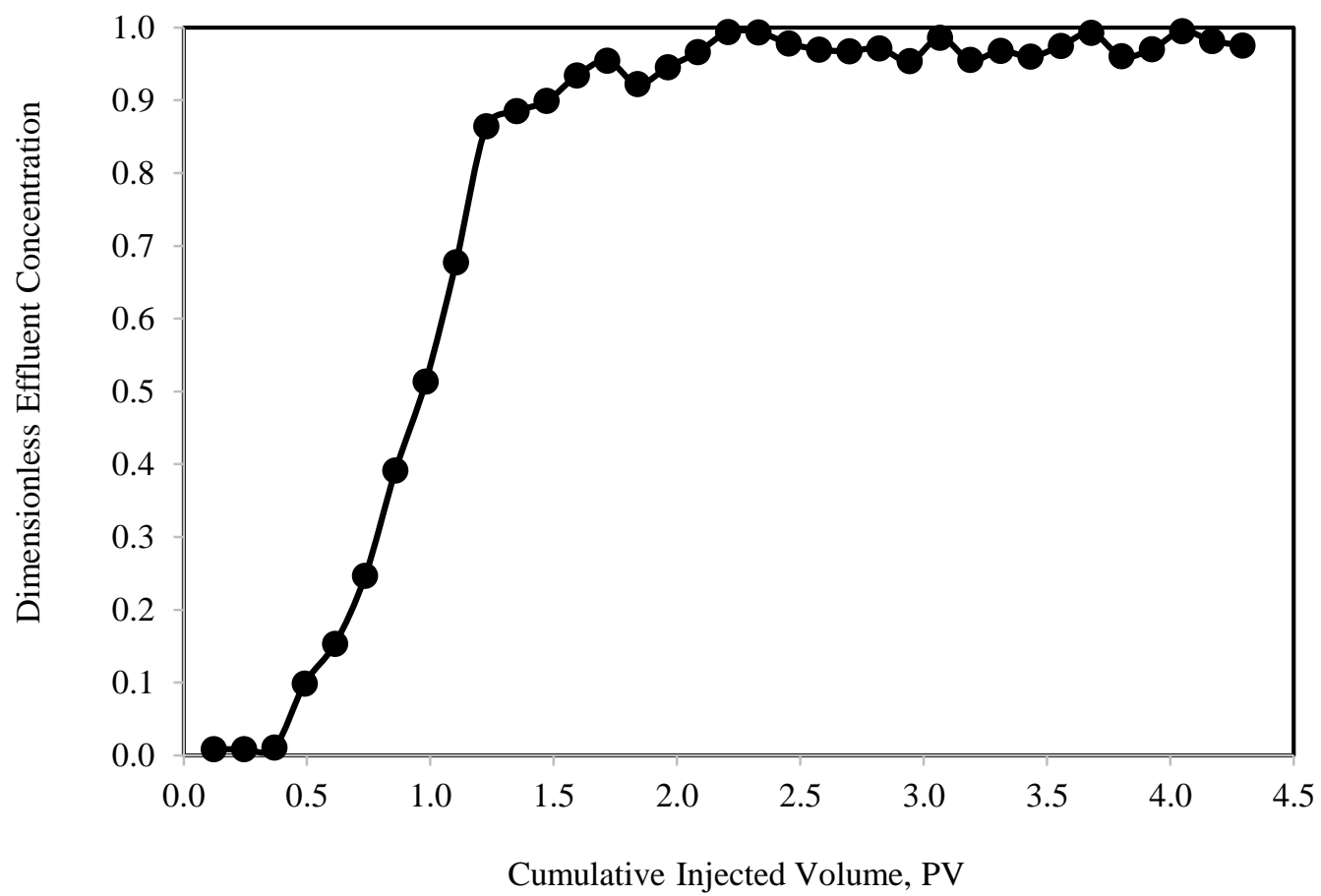

Figure 12: Tracer concentration of Indiana limestone core 4.

19 
Tracer profiles for Austin chalk presented in Figure 13 through Figure 16. This rock has lower and more varies flowing fraction compared to Indiana limestone, with $f=$ $0.89 \pm 0.02$. It needs 0.89 cumulative injected volume of tracer to achieve 0.5 dimensionless effluent concentrations. With flowing fraction lower than homogeneous Indiana liestone, it proved that Indiana limestone has better pore connectivity than this rock.

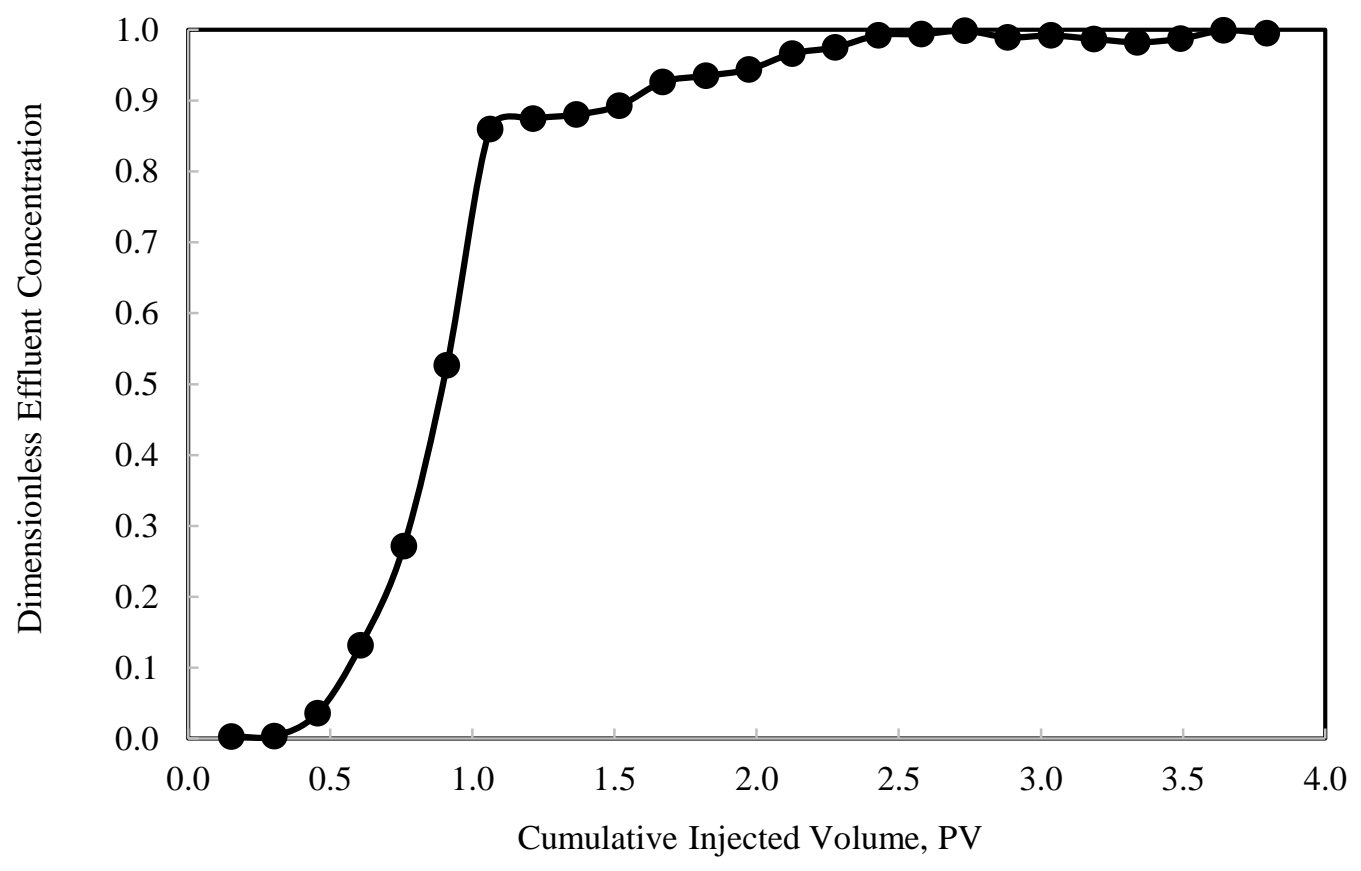

Figure 13: Tracer concentration of Austin chalk core 1. 


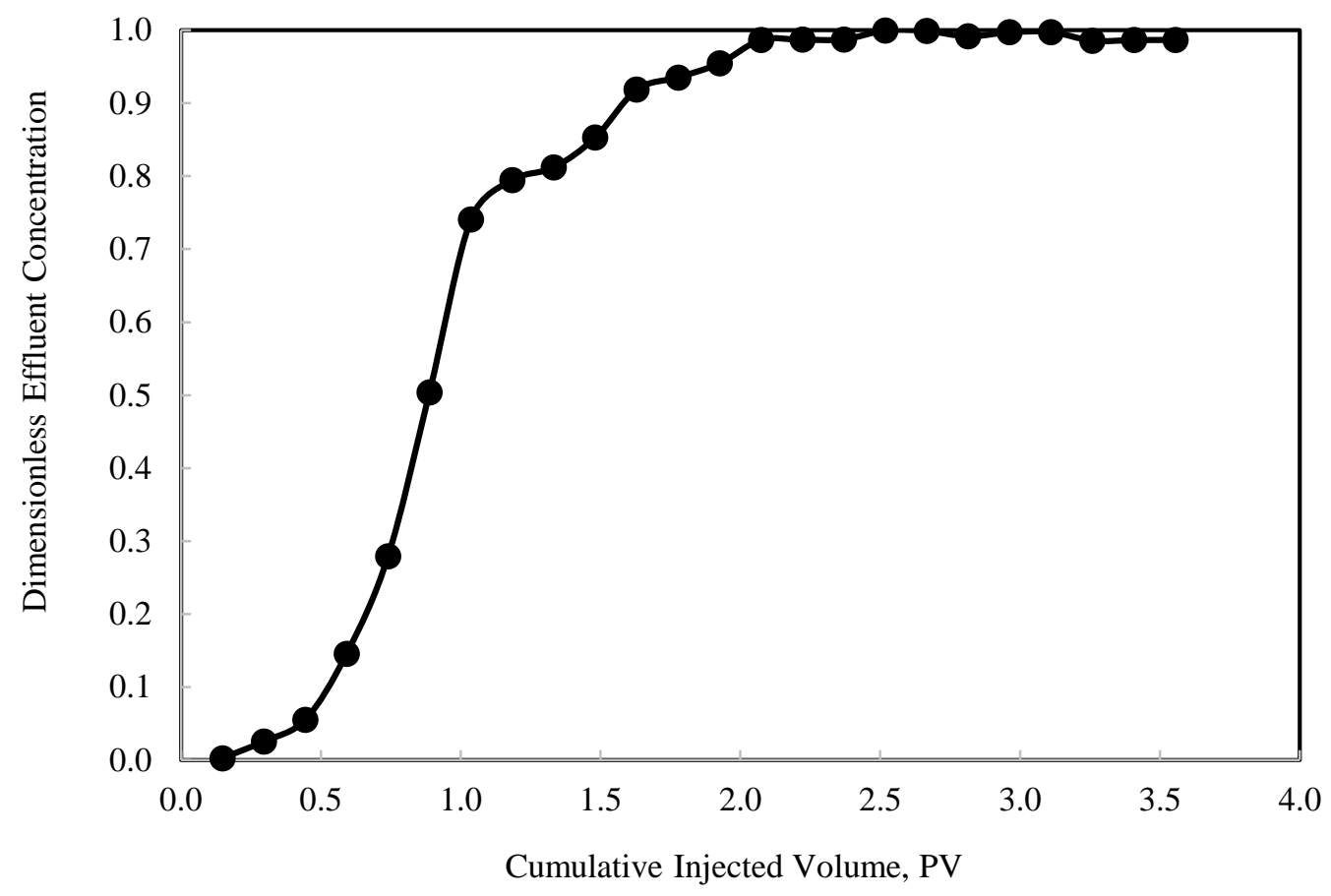

Figure 14: Tracer concentration of Austin chalk core 2.

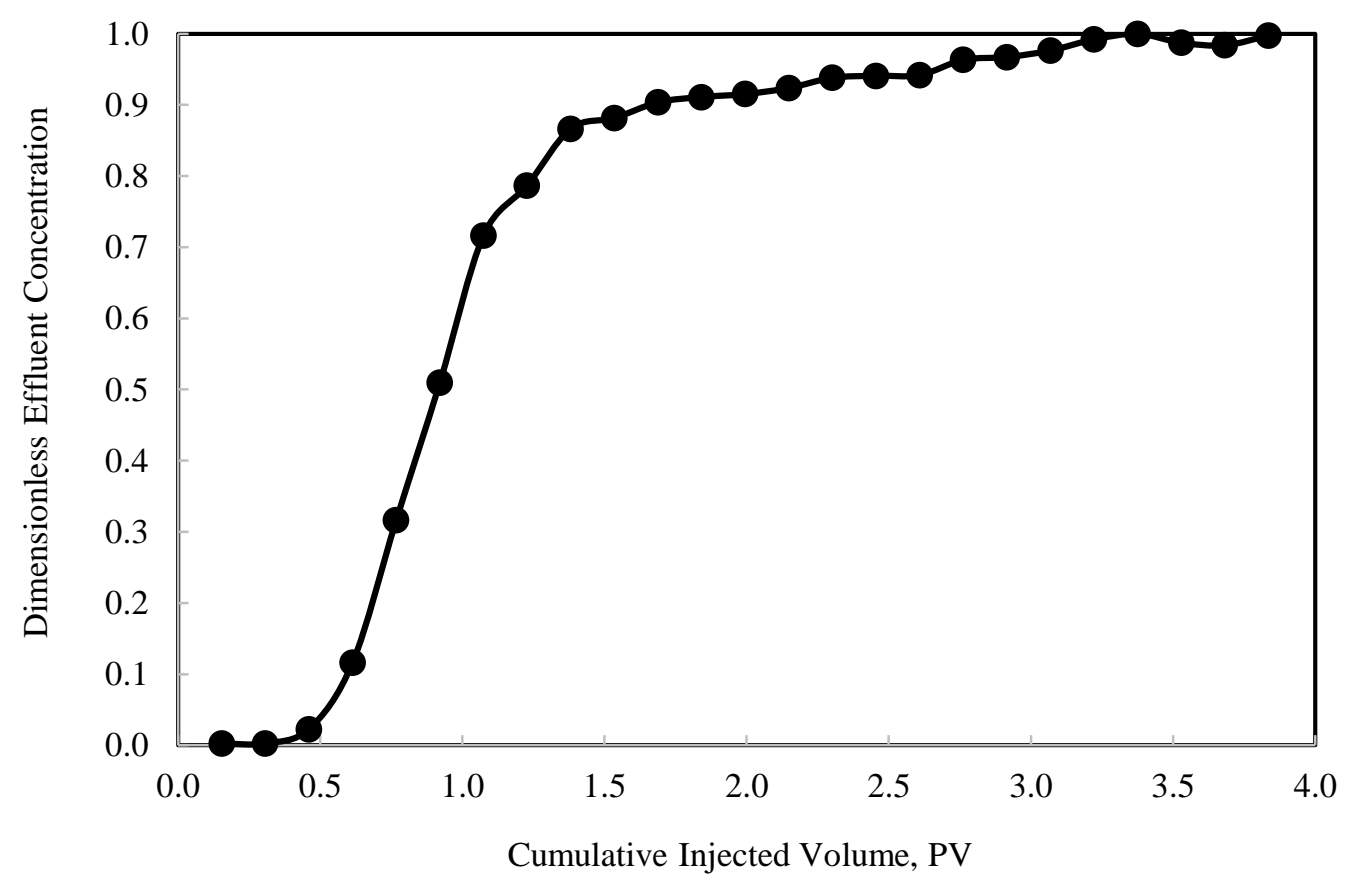

Figure 15: Tracer concentration of Austin chalk core 3. 


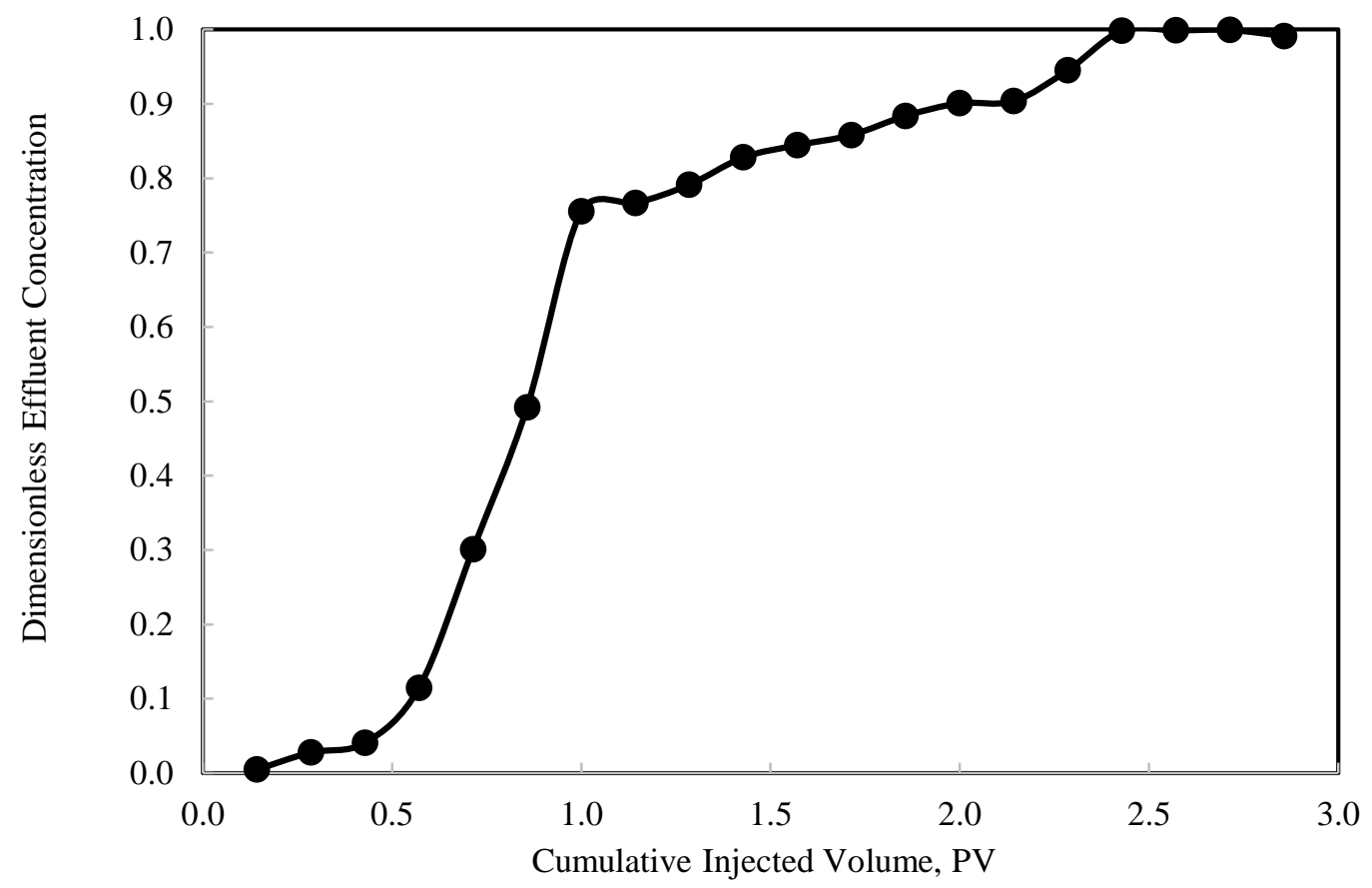

Figure 16: Tracer concentration of Austin chalk core 4.

Tracer profiles for Edwards yellow showed in Figure 17 through Figure 20 with flowing fractions $f=0.86 \pm 0.02$. It needs averagely 0.86 cumulative injected volume of tracer to achieve 0.5 dimensionless effluent concentrations. This number less than Austin chalk, or it can be said that Austin chalk has better pore connectivity than Edwards yellow. 


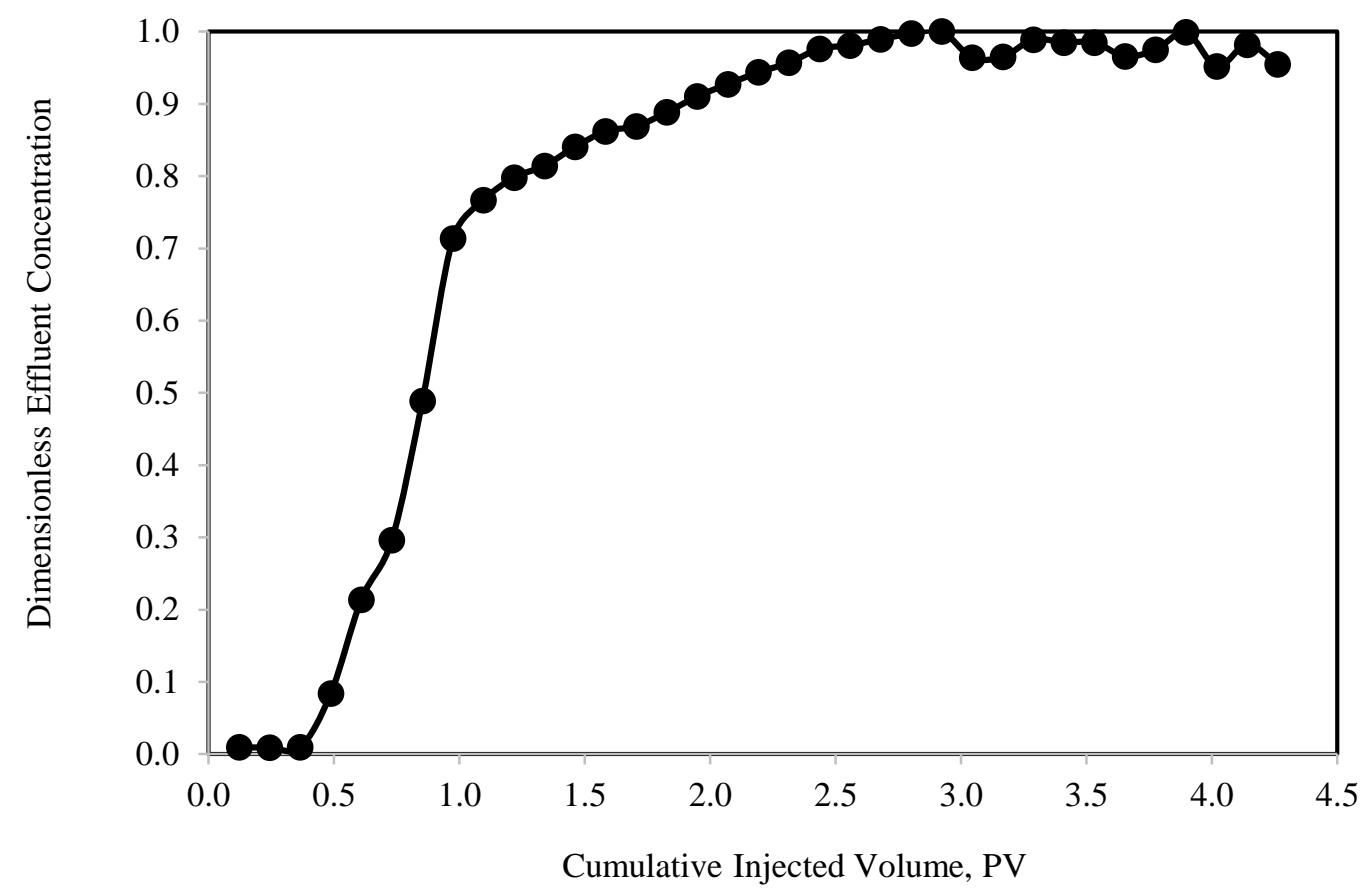

Figure 17: Tracer concentration of Edwards yellow core 1.

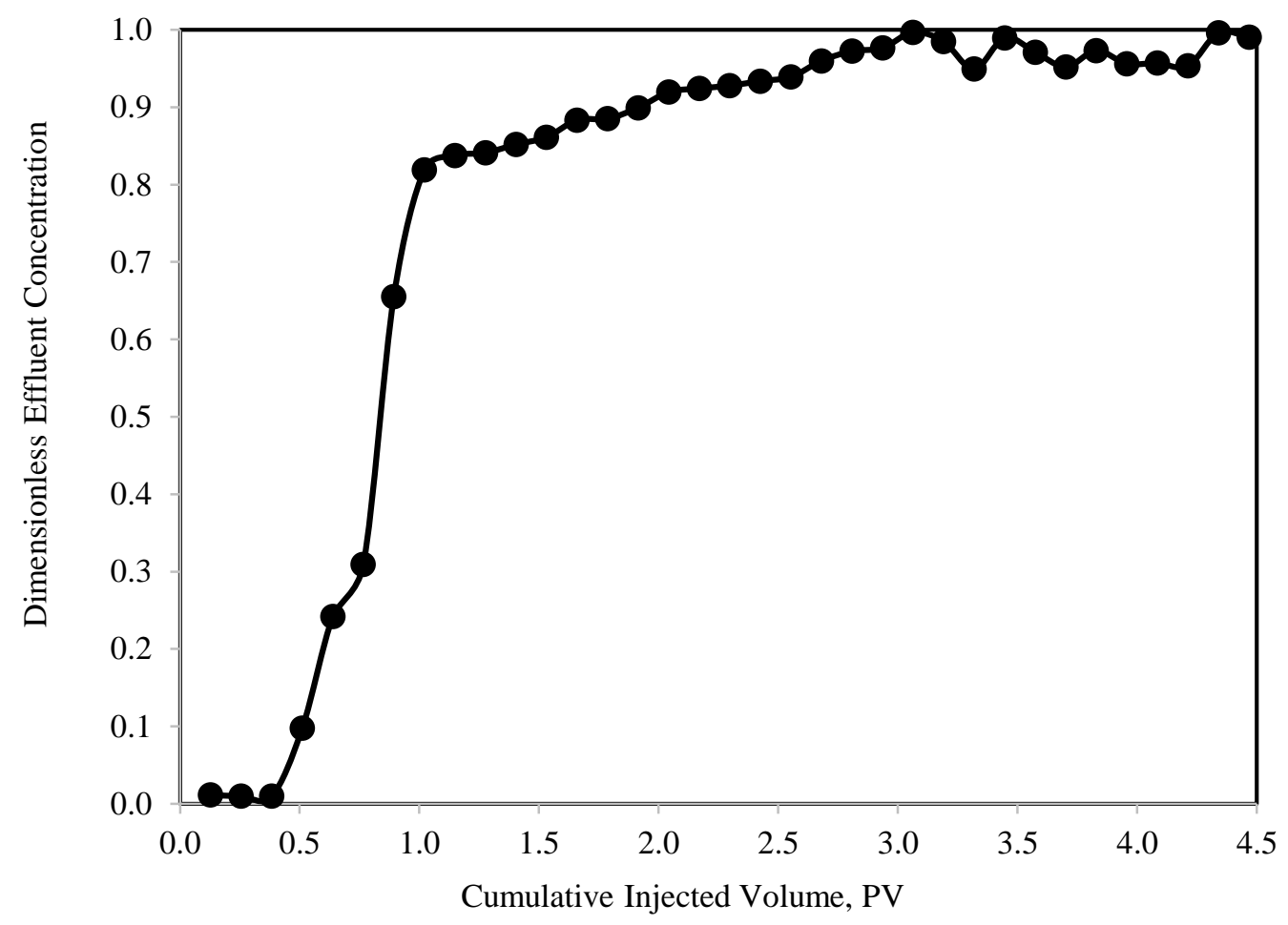

Figure 18: Tracer concentration of Edwards yellow core 2. 


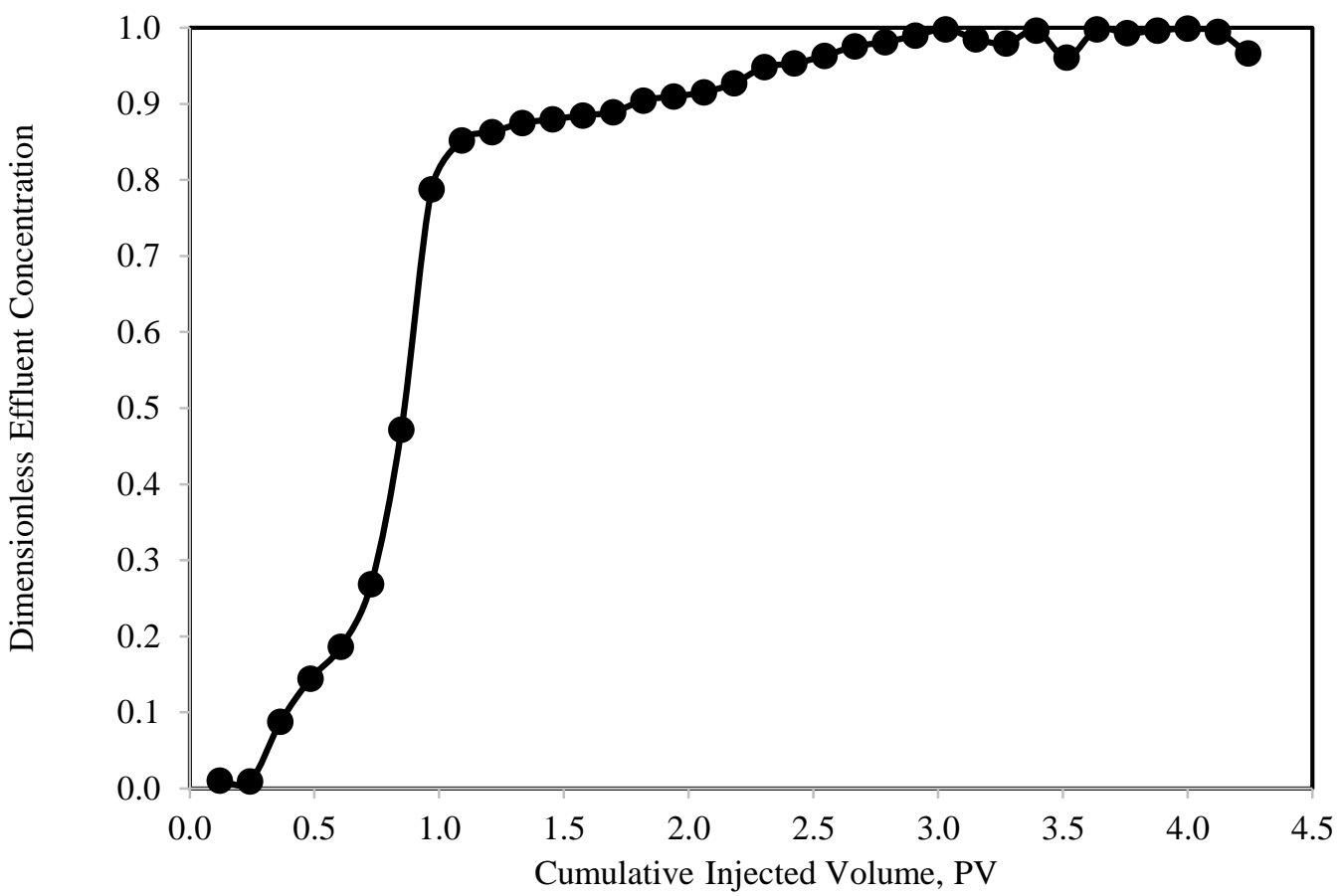

Figure 19: Tracer concentration of Edwards yellow core 3.

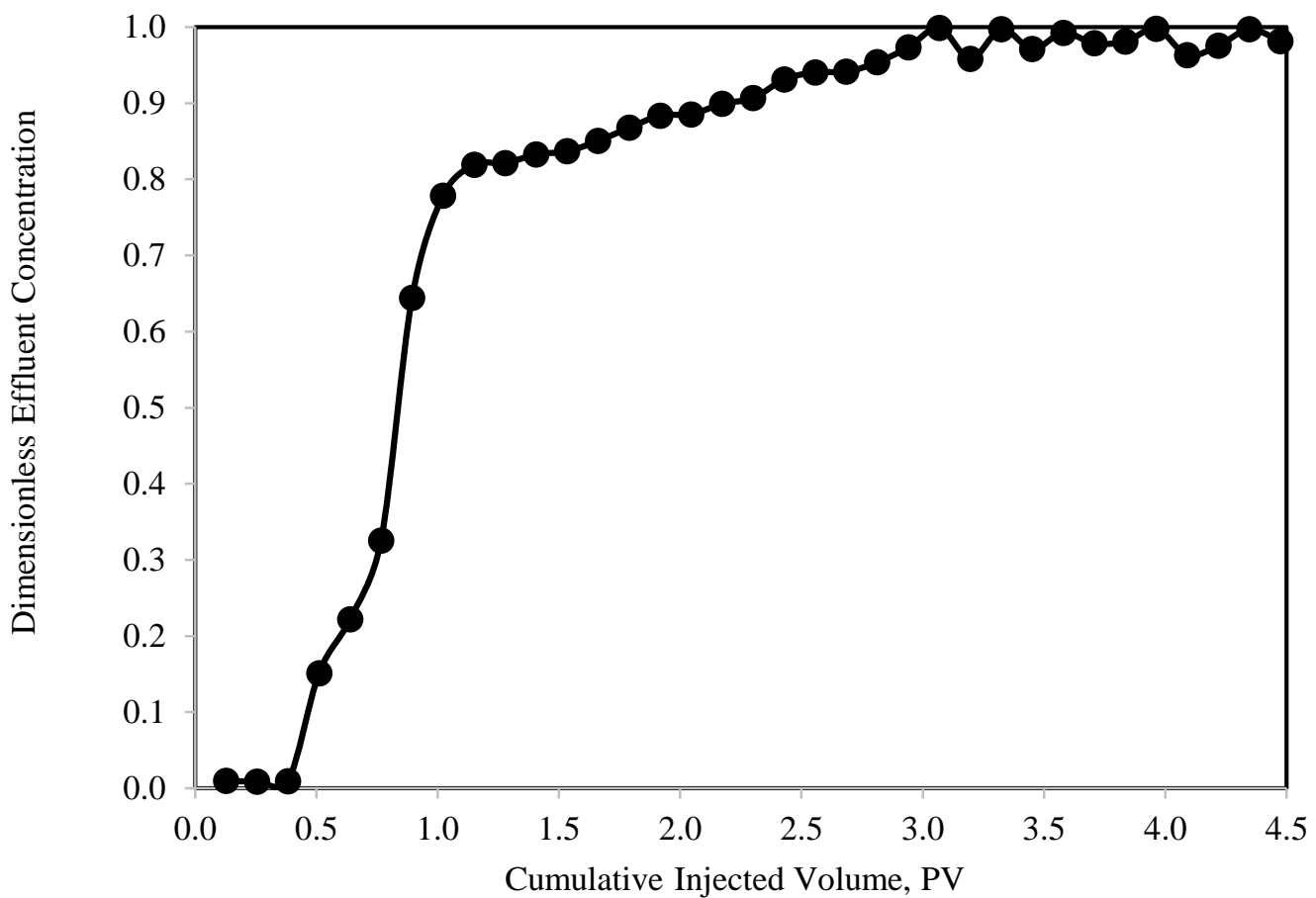

Figure 20: Tracer concentration of Edwards yellow core 4.

24 


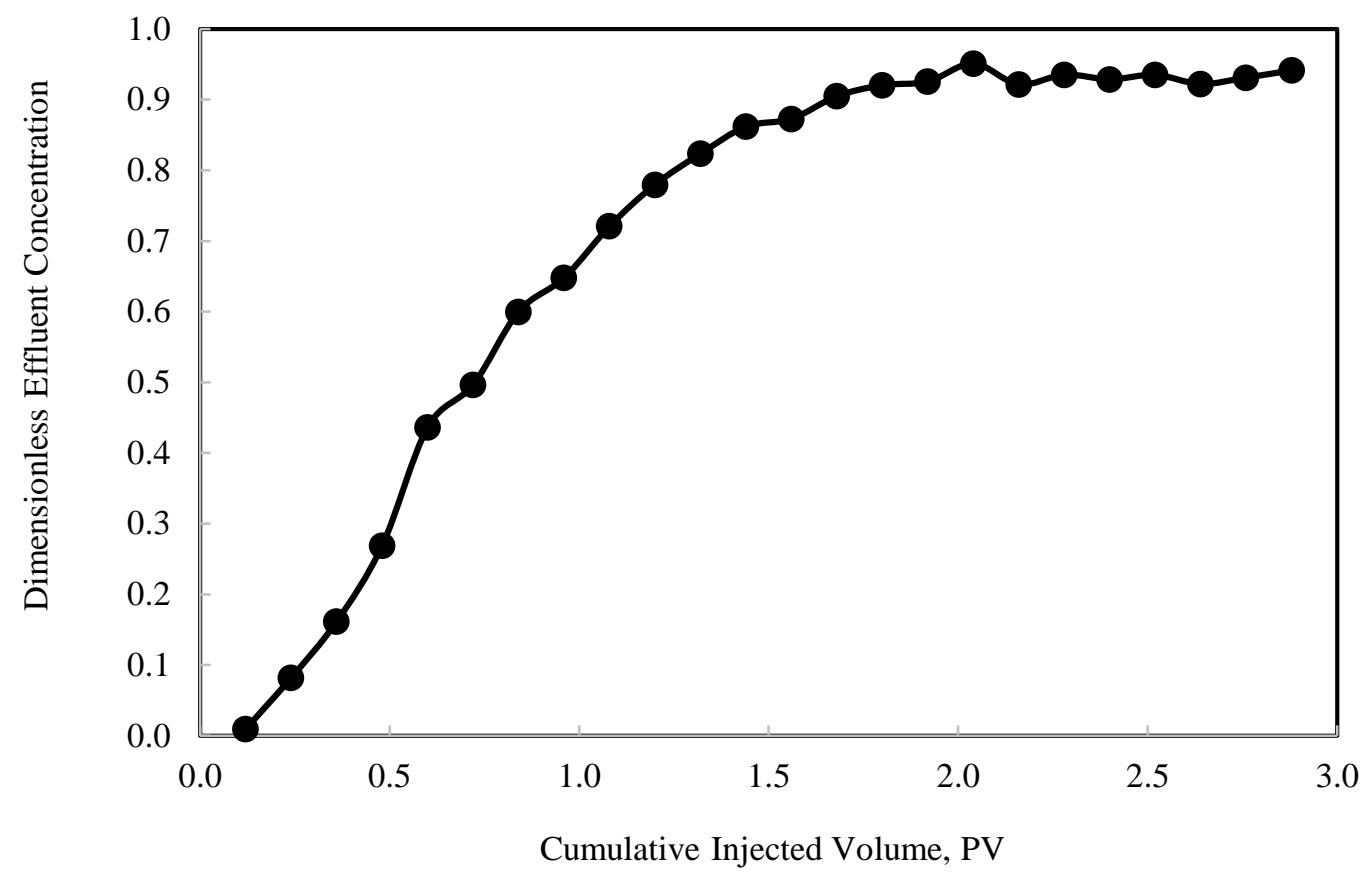

Figure 21: Tracer concentration of Pink desert core 1.

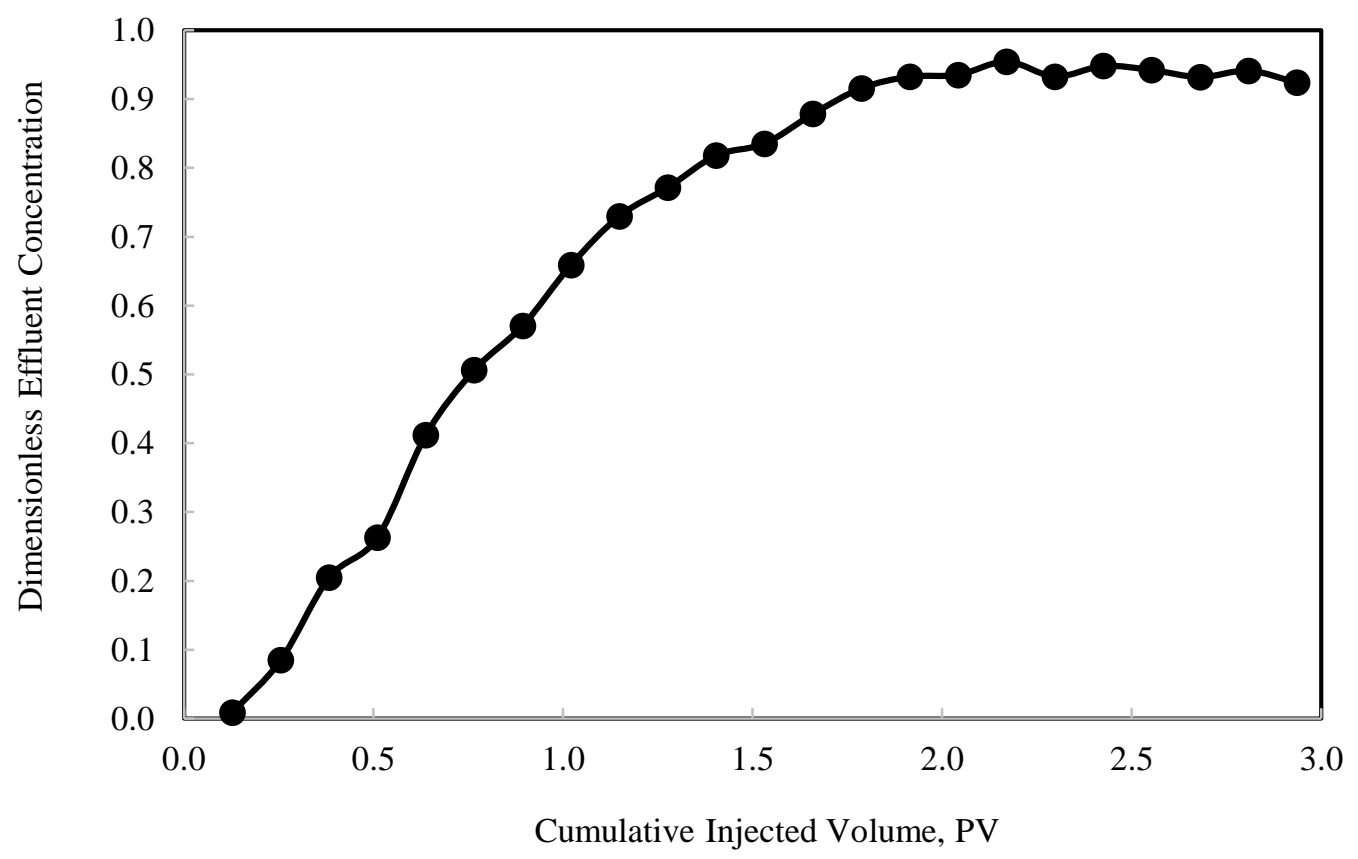

Figure 22: Tracer concentration of Pink desert core 2. 


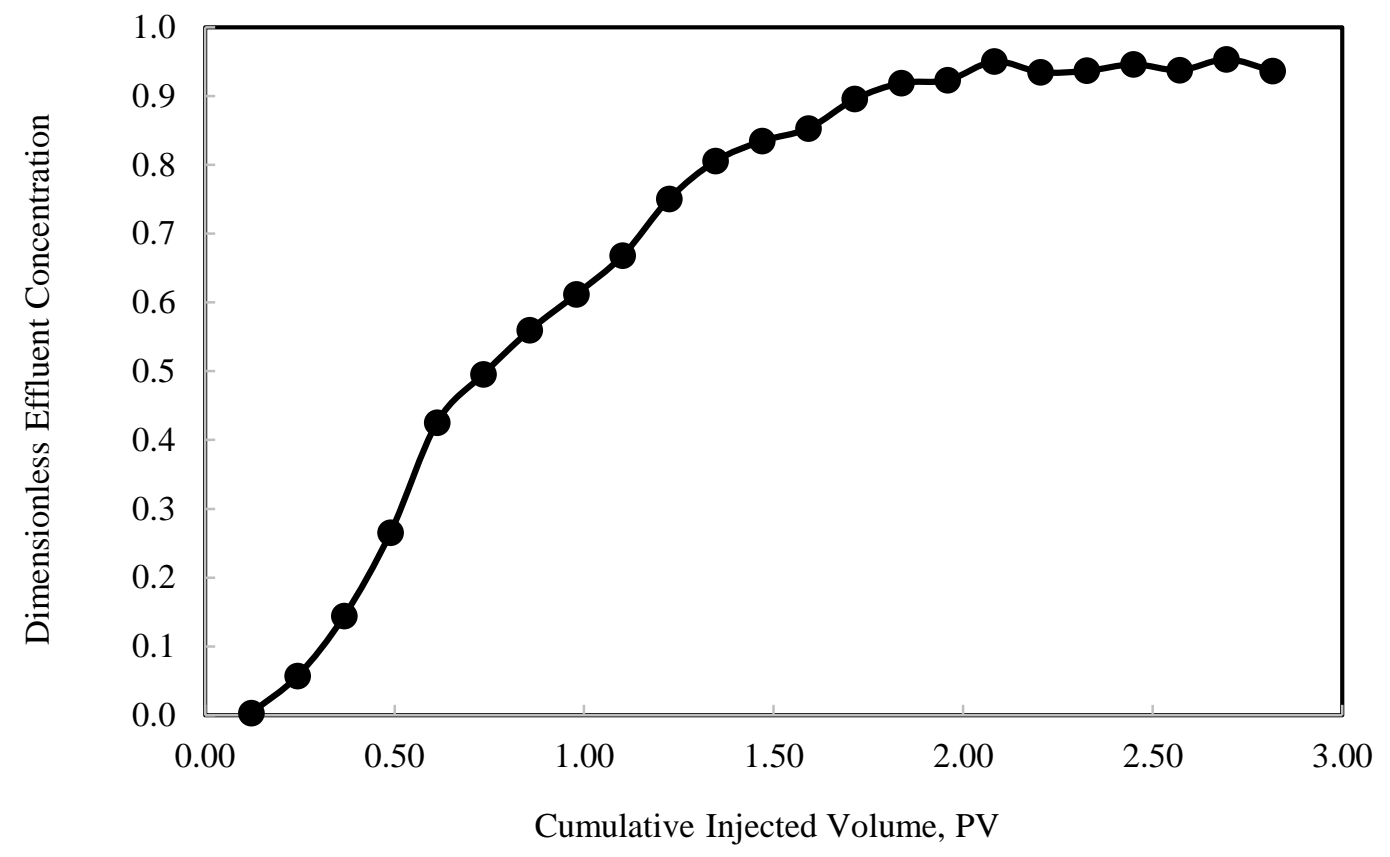

Figure 23: Tracer concentration of Pink desert core 3.

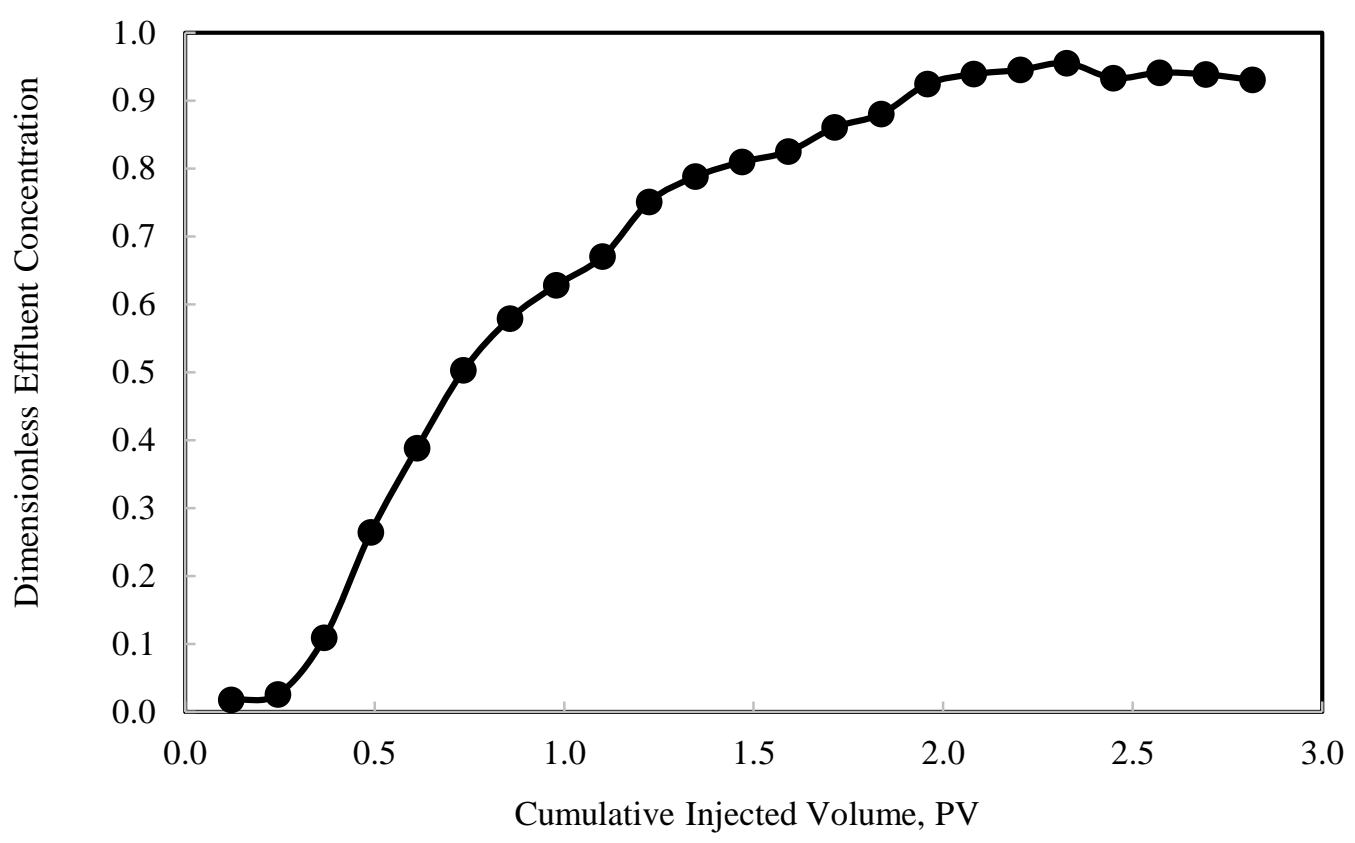

Figure 24: Tracer concentration of Pink desert core 4. 
Early breakthrough of tracer concentration occured with Pink desert, as shown in tracer profile Figure 21 through Figure 24. With flowing fraction less than other 3 rocks $f=0.73 \pm 0.02$, this rock has less of pore connectivity, that led to earlier concentration build-up during tracer experiments.

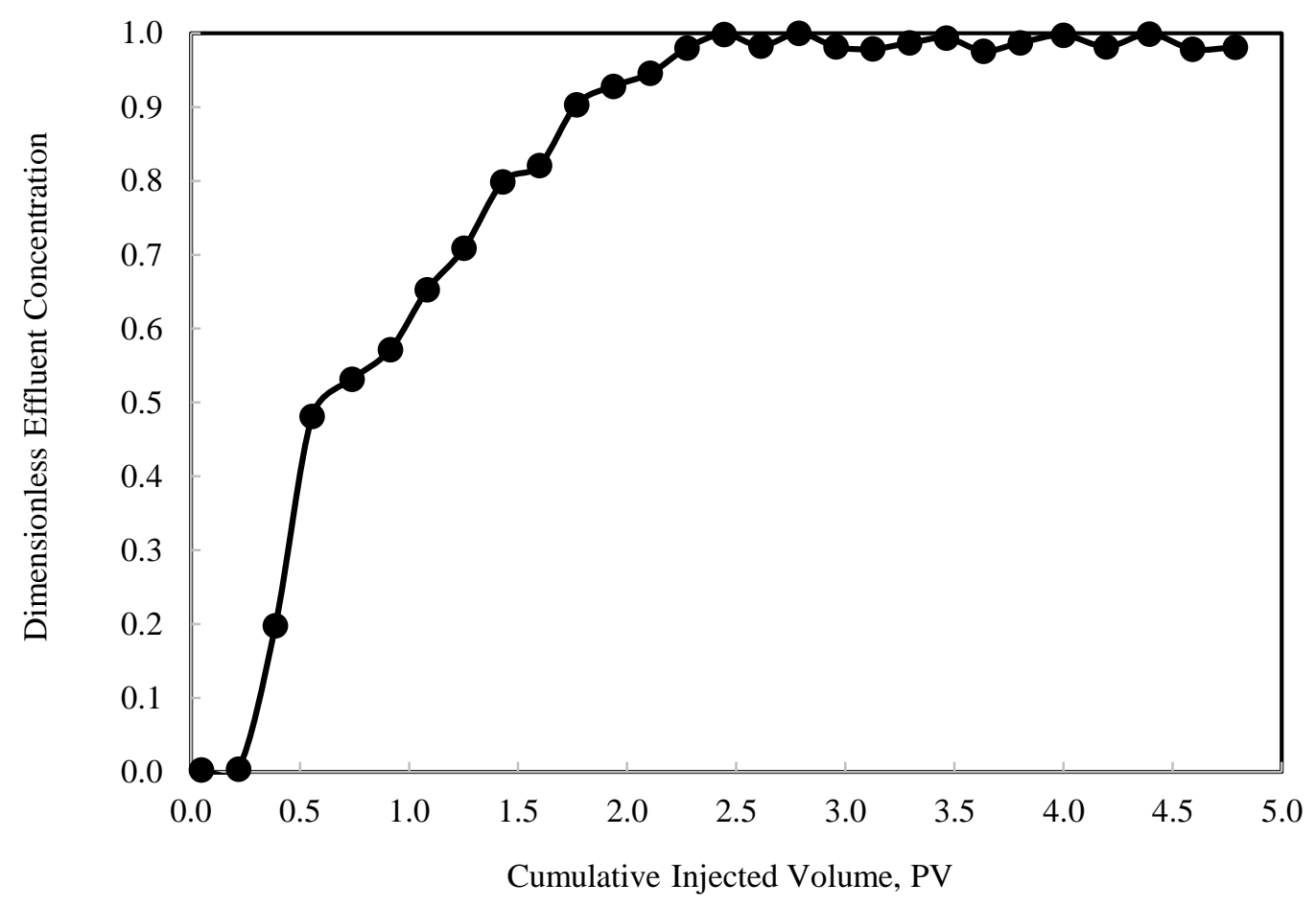

Figure 25: Tracer concentration of Winterset limestone core 1.

Tracer profiles of Winterset limestone were shown in Figure 25 through Figure 28 with early breakthrough, cause tracer concentration reach dimensionless effluent concentrations $\left(\mathrm{C} / \mathrm{C}_{\mathrm{o}}\right)$ at flowing fraction, $f=0.61 \pm 0.03$. These results revealed that this is heterogeneous rock according to Berthier and Fleury (2000). 


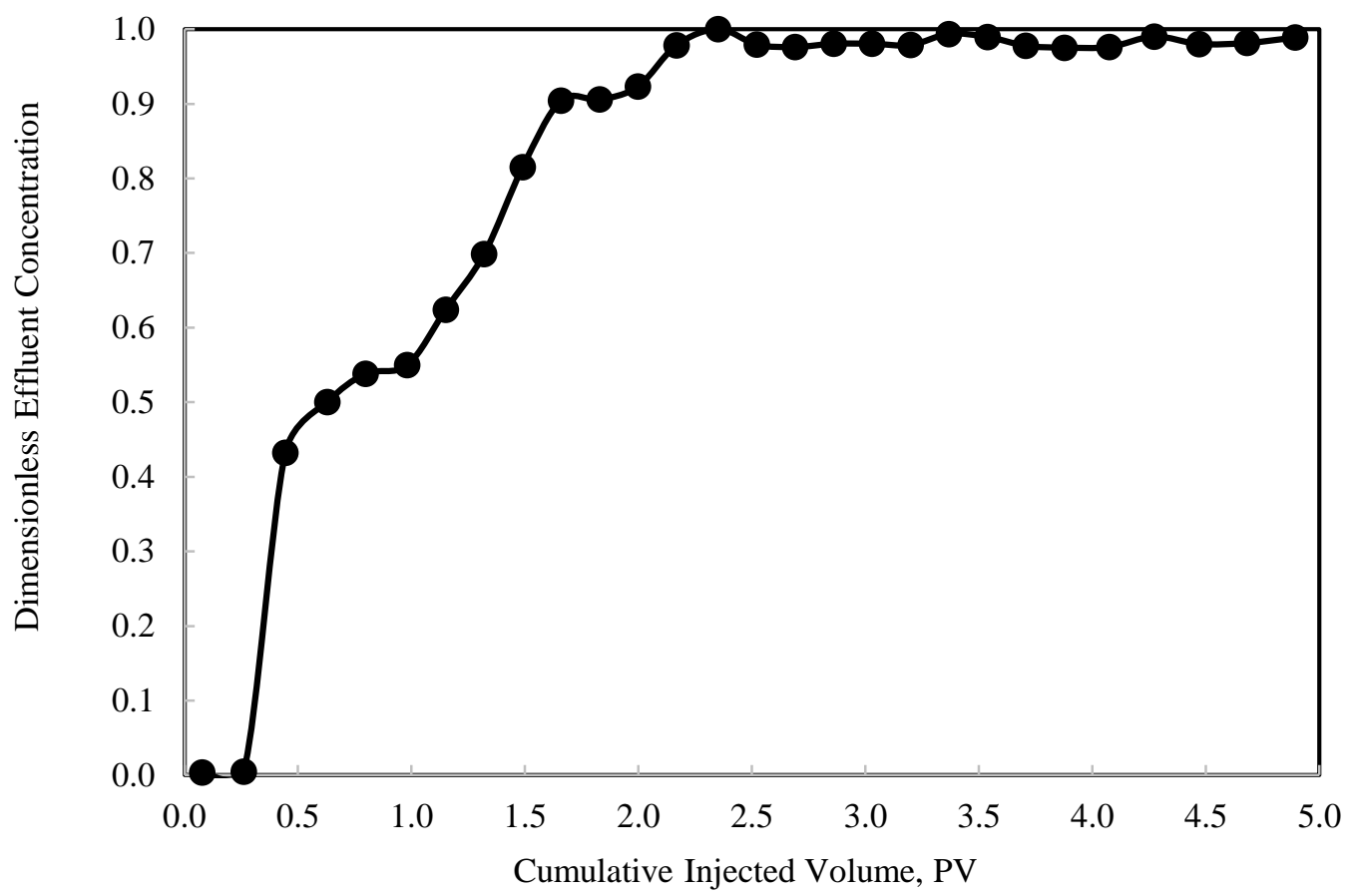

Figure 26: Tracer concentration of Winterset limestone core 2.

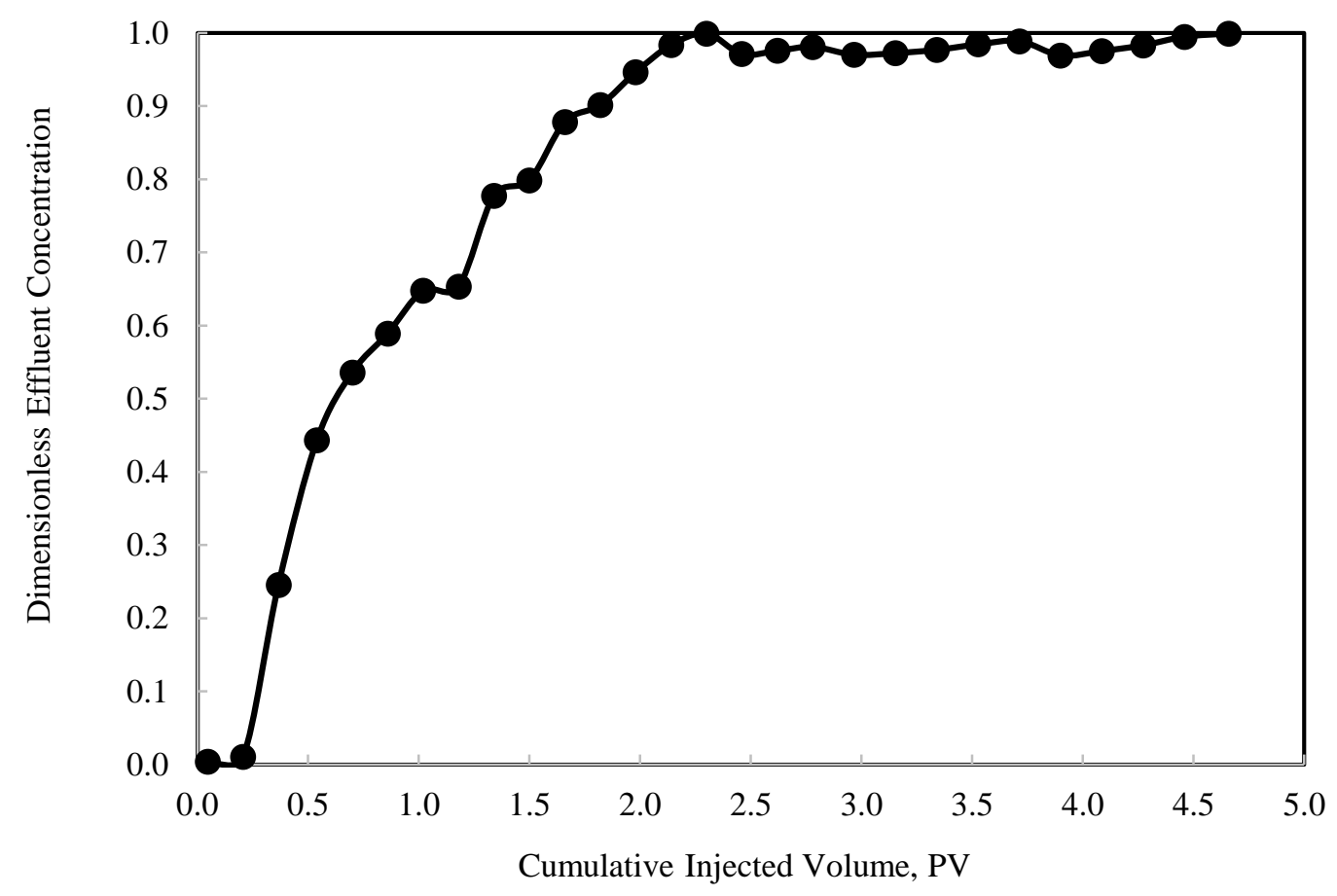

Figure 27: Tracer concentration of Winterset limestone core 3. 


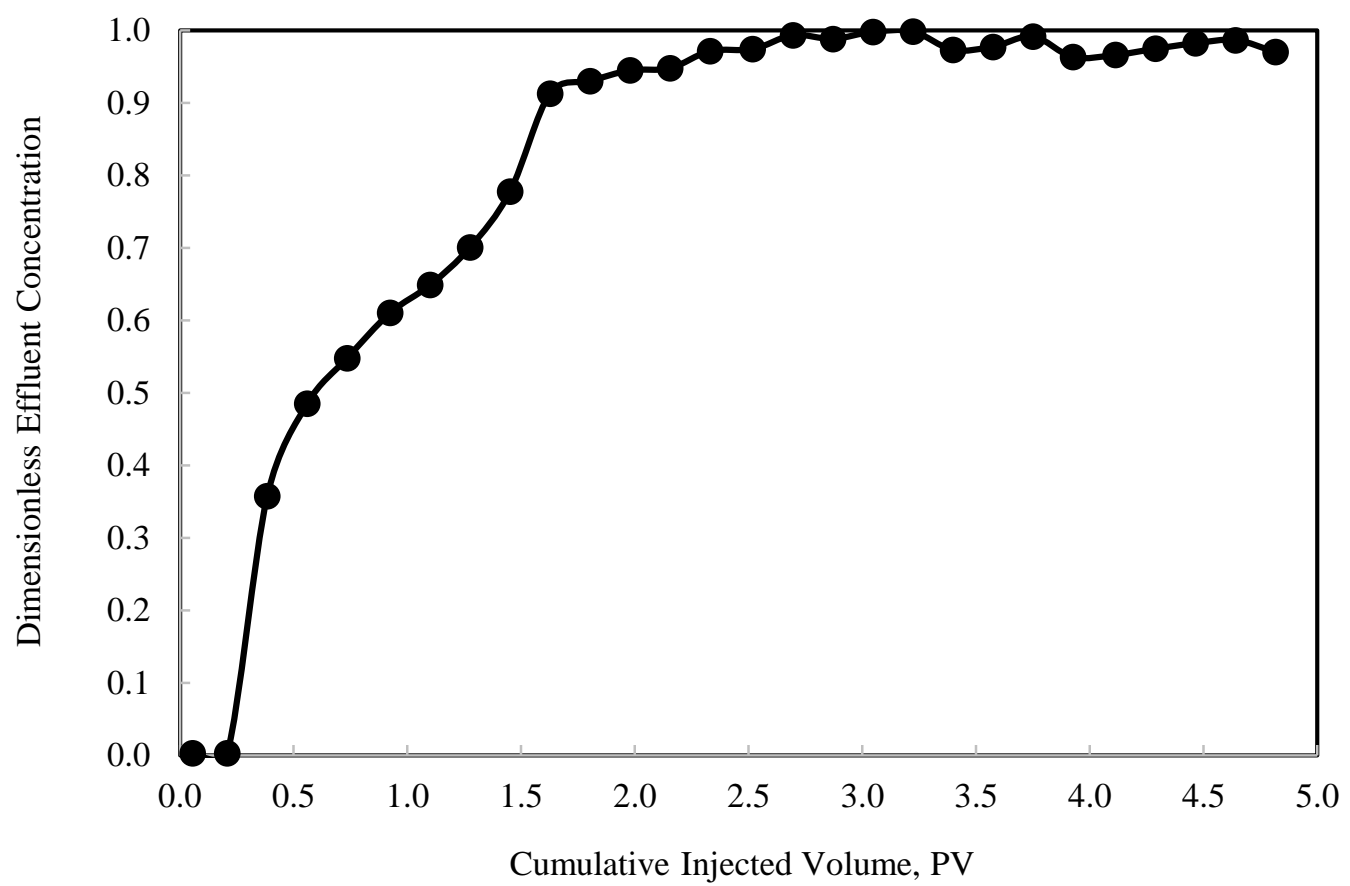

Figure 28: Tracer concentration of Winterset limestone core 4.

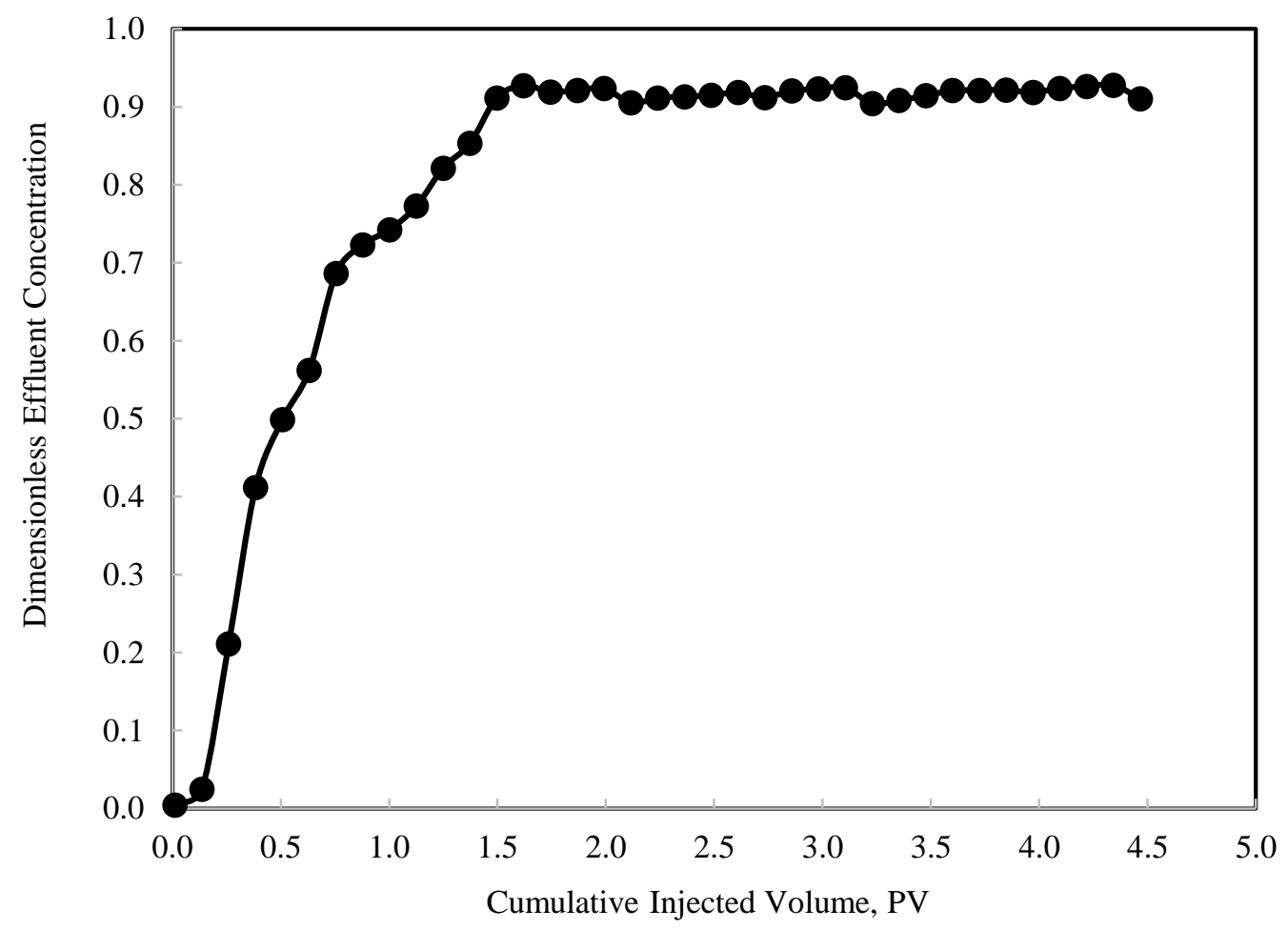

Figure 29: Tracer concentration of Edwards white core 1. 


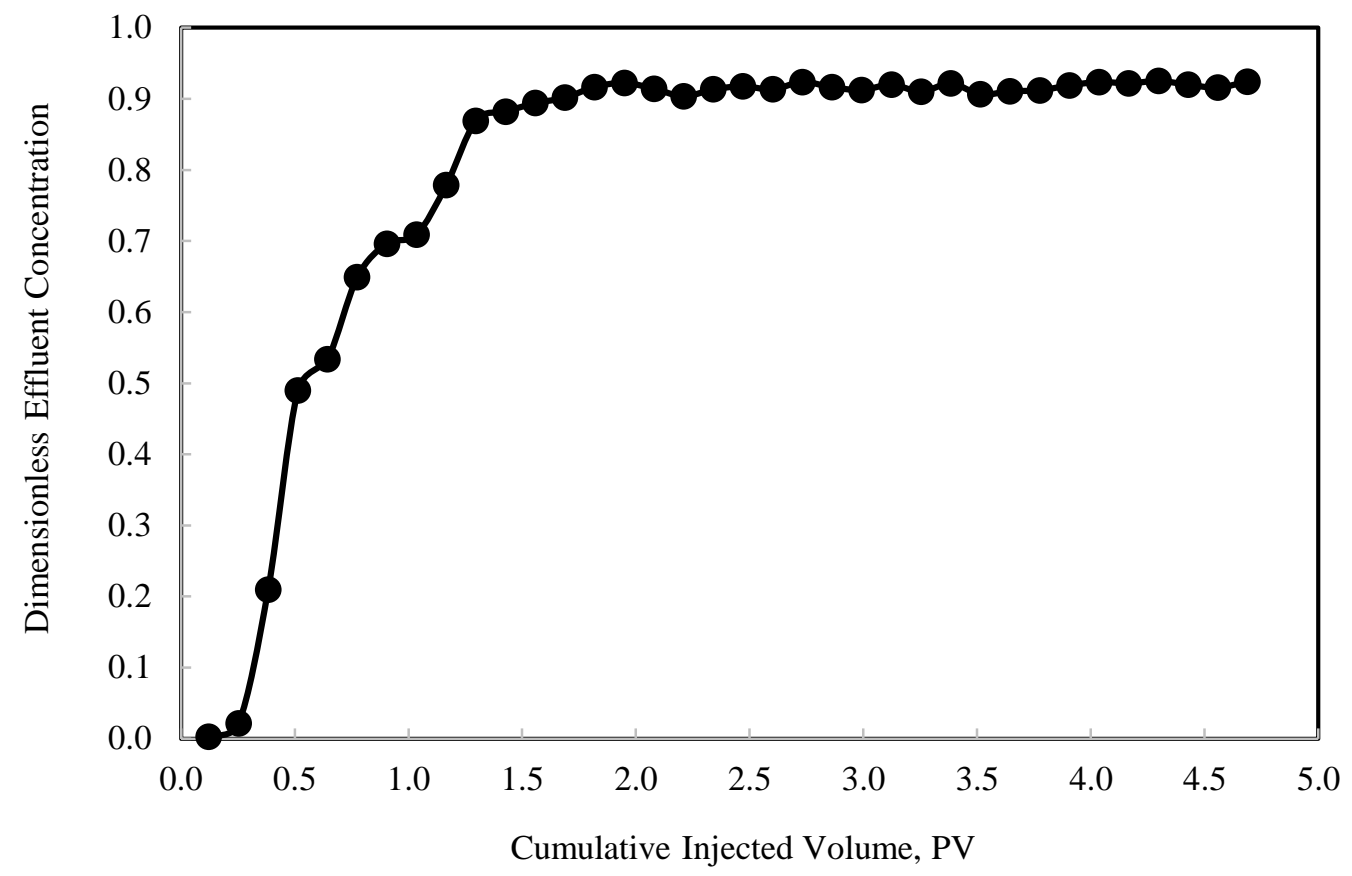

Figure 30: Tracer concentration of Edwards white core 2.

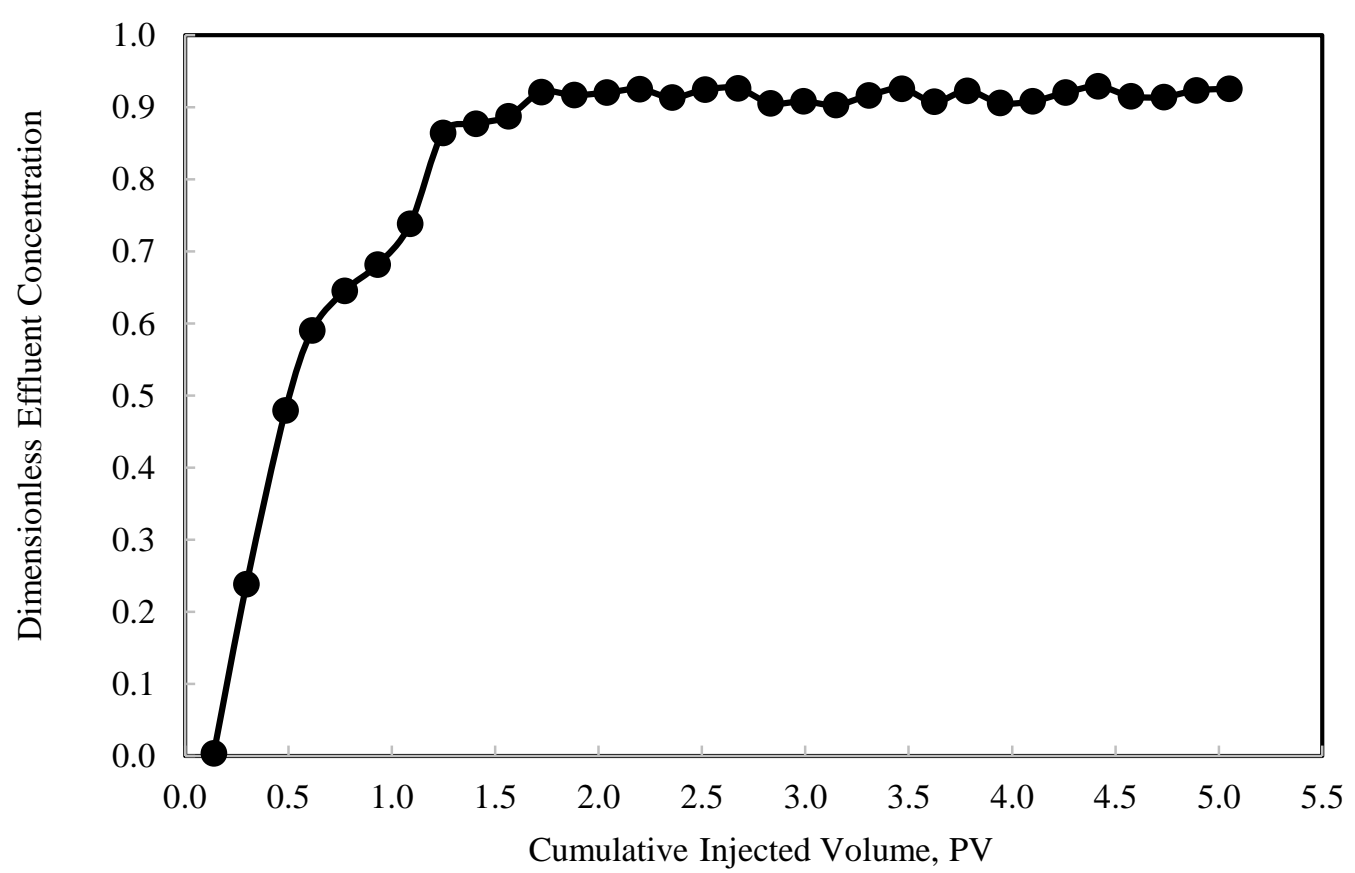

Figure 31: Tracer concentration of Edwards white core 3. 


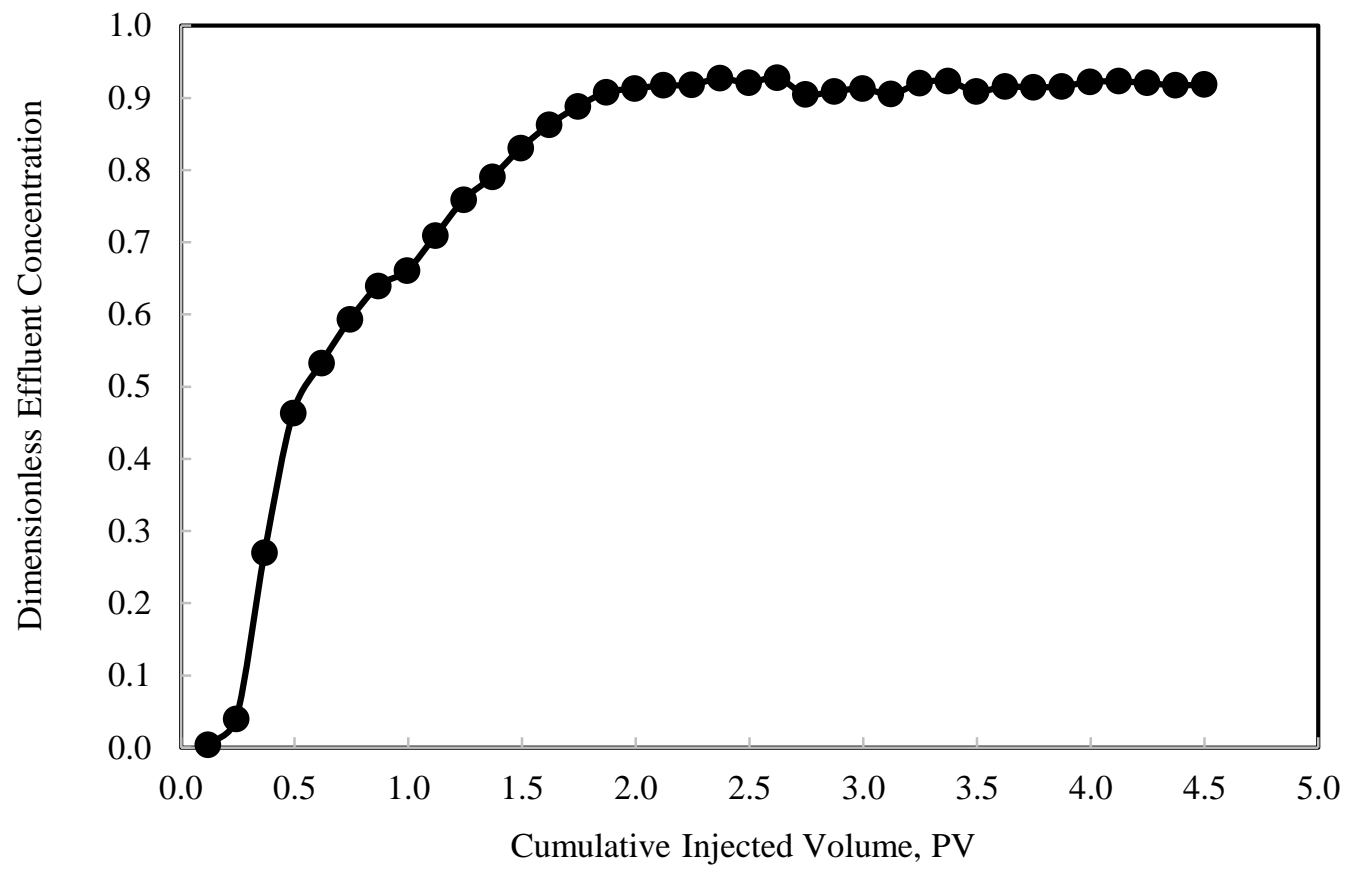

Figure 32: Tracer concentration of Edwards white core 4.

Edwards white limestone has an early breakthrough as well with $f=0.53 \pm 0.03$

(Figure 29 through Figure 32). Among other type of rocks, Edwards white has the lowest flowing fraction number, the most heterogeneous rock that was selected for this study.

\subsection{VES-Based Acid Experiments}

The amount of acid $\mathrm{PV}_{\mathrm{bt}}$ was determined from the pressure drop profiles, as presented in Figure 33 through Figure 38. As the acid entered and reacted with carbonate rocks, the viscosity increased due to micelle structure entanglement. An increase in the viscosity during VES acid injection improved fluid diversion, and is a main reason for the pressure drop build-up. The increase of pressure drop, from pressure base line (DI water was injected) to the time when VES acid touch the core was varies for different rocks. For 
Indiana limestone this pressure drop build up around 120-140 psi. Edwards yellow had a pressure drop build up of 10-30 psi, and Winterset limestone had a pressure drop build-up of 20-30 psi. The pressure base line of each rock depends on its initial permeability.
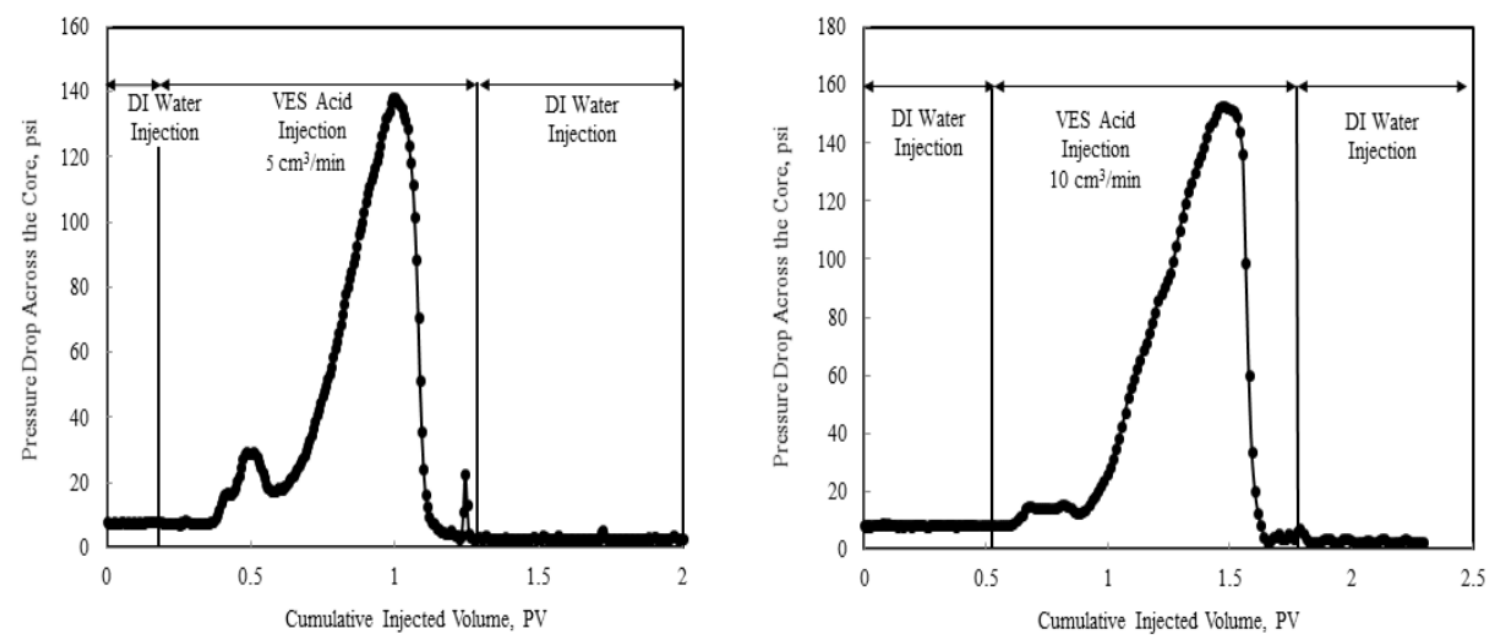

Figure 33: Pressure drop profiles of Indiana limestone.
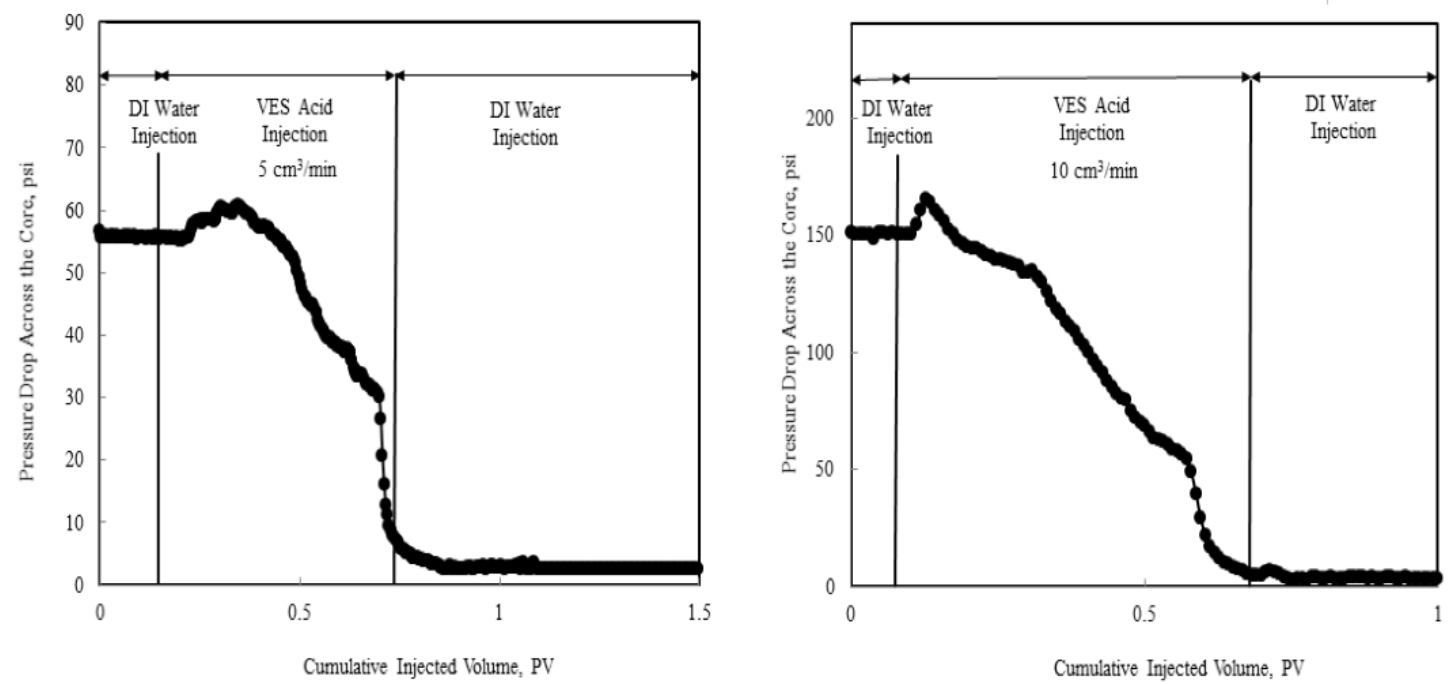

Figure 34: Pressure drop profiles of Austin chalk. 

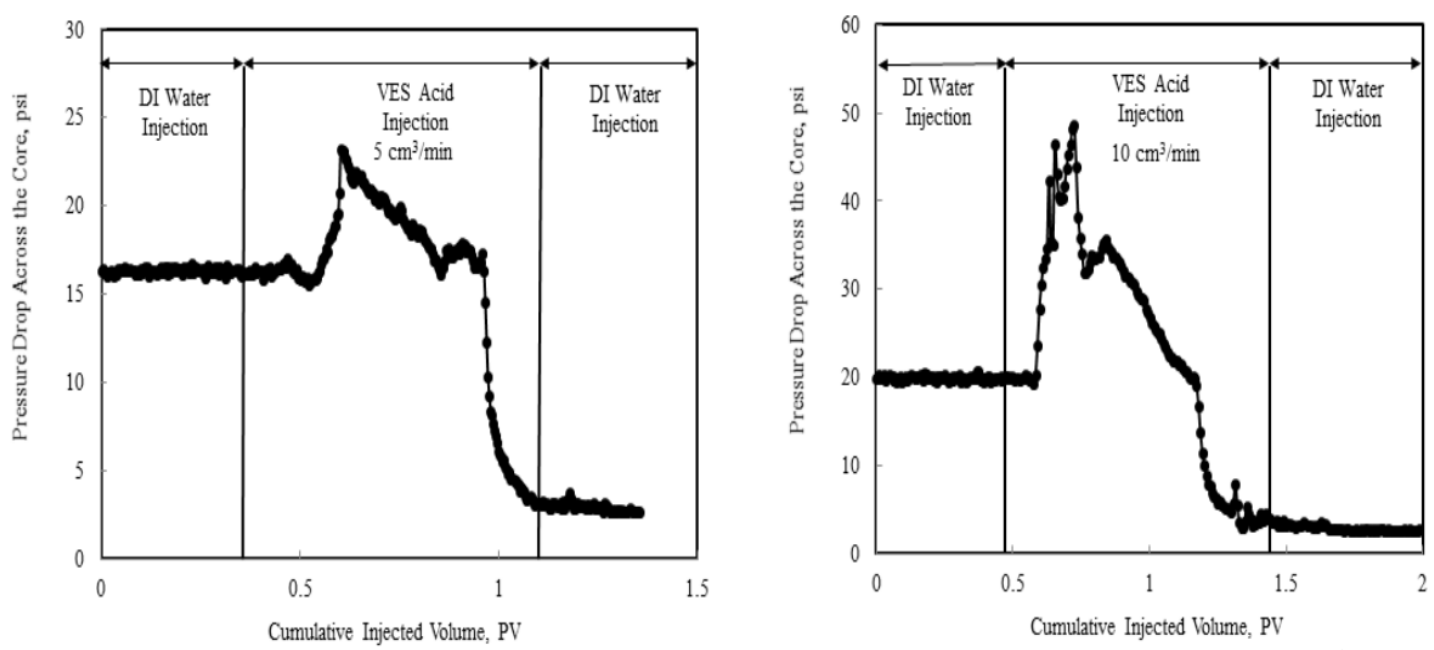

Figure 35: Pressure drop profiles of Edwards yellow.
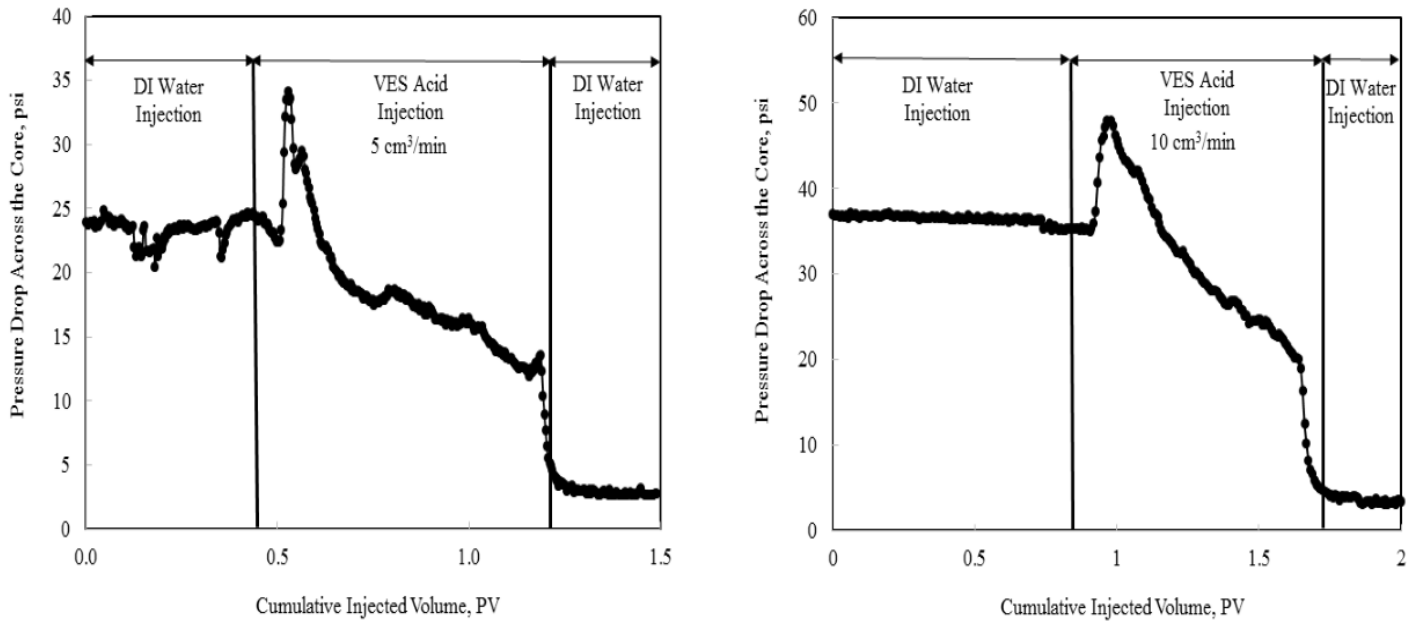

Figure 36: Pressure drop profiles of Pink desert. 

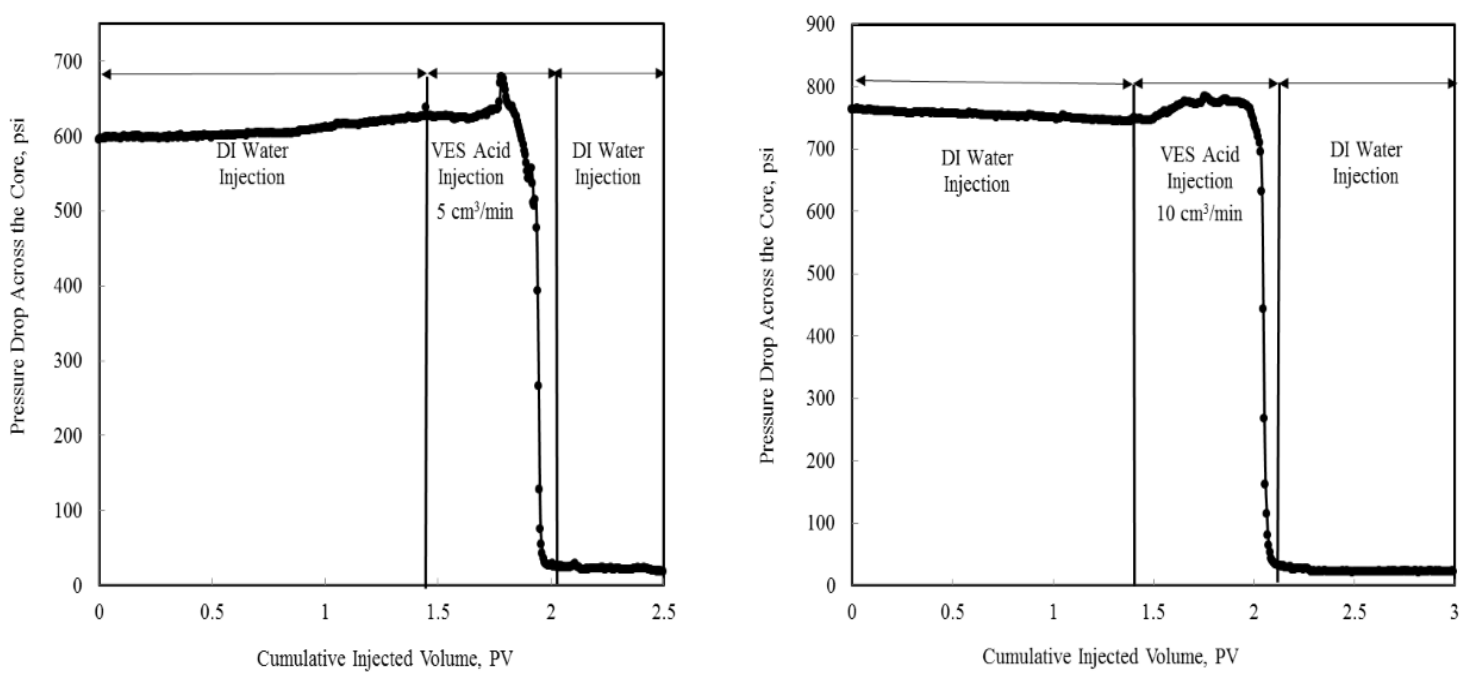

Figure 37: Pressure drop profiles of Winterset limestone.
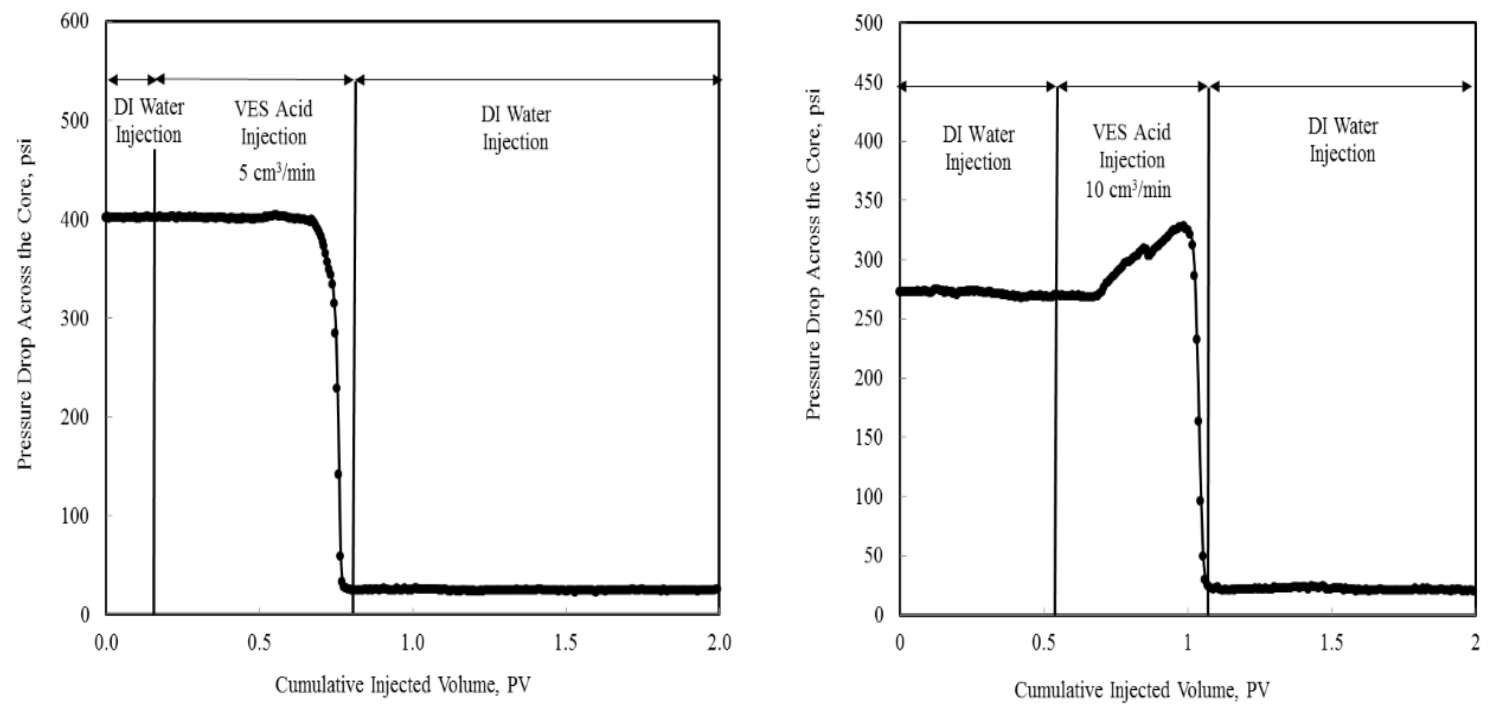

Figure 38: Pressure drop profiles of Edwards white.

Figure 39 shows the pore volume to breakthrough as a function of injection rate in different carbonate rocks. Indiana limestone with $f=1$ had $\mathrm{PV}_{\mathrm{bt}}$ ranging from 0.60 to 0.84, Edwards yellow with $f=0.86$ had $\mathrm{PV}_{\mathrm{bt}}$ ranging from 0.46 to 0.73 , and Edwards white with $f=0.53$ had $\mathrm{PV}_{\mathrm{bt}}$ ranging from 0.2 to 0.36 . The higher flowing fraction for Indiana 
limetone showed that the rock with better pore connectivity than Edwards yellow and Edwards white. The better pore connectivity proved that the rock has more flow paths for the VES acid propagation, and consequently more acid was consumed to dissolve the carbonate rocks. Edwards yellow that has less flowing fraction showed that less pore connectivity than Indiana limestone, hence less VES acid contacted with carbonate rock. For the rock that has tailing tracer profile such as Edwards white, the early breakthrough occured due to inaccessible pores and dead-end pores. The presence of these pores causing less VES acid contacted with the rock and as a result less acid $\mathrm{PV}_{\mathrm{bt}}$ was required. This investigation resolved that the lower flowing fraction correspond to higher magnitude of pore heterogeneity. Once the heterogeneity of the rock is conclusive, the acid $\mathrm{PV}_{\mathrm{bt}}$ could be predicted.

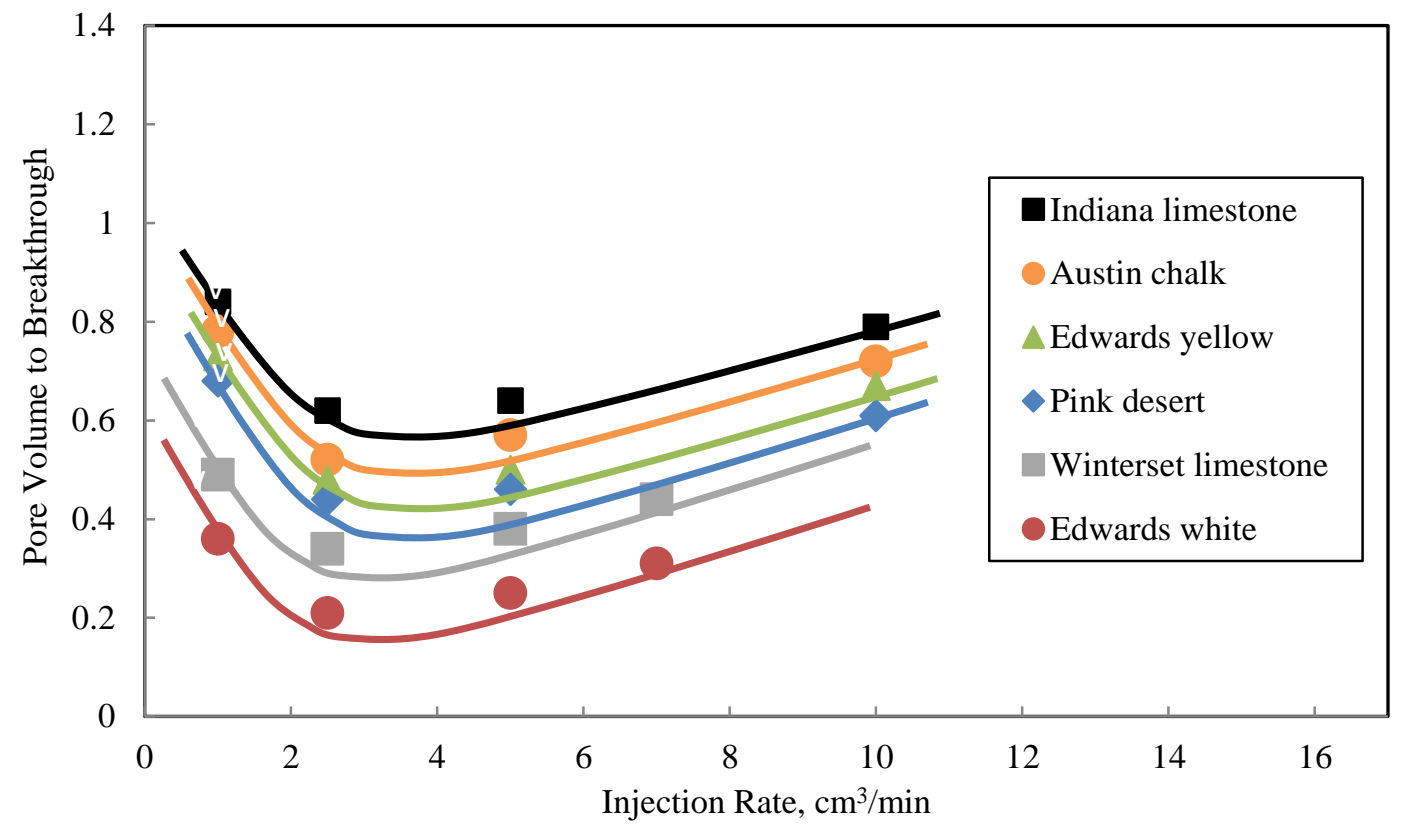

Figure 39: Acid volume to breakthrough as a function of acid injection rates. 


\subsection{Wormhole Patterns Analysis}

The CT Scan images before acid injection were made to observe porosity distribution in different rocks, while CT Scan images after acid injection were conducted to examine wormhole patterns as the impact of pore-structure (Figure 40 through Figure 51). The dominant wormholes with less branches were formed at an optimum acid injection rate for each rock type, when the velocity of wormhole propagation is less affected by the injection velocity. At higher than optimal injection rates, the dissolution rate is lower, branched wormholes are formed, and this could increase the surface area and reduce the rate of channel propagation.

Overall, fewer branched wormholes were produced with the rocks which early breakthough occured during tracer experiments. In addition, the CT scan images showed that the diameters of the wormhole were smaller at the outlet of the core compared to diameters of wormholes near the inlet of the core. Some of the acid in the solution is spent in the reaction with carbonate rocks to create wormhole patterns. As the acid flows from the inlet to the outlet of the core, the concentration of acid decreases. Therefore, less acid was able to react with carbonate rocks, resulting in smaller wormhole diameters generated towards the outlet of the core. 


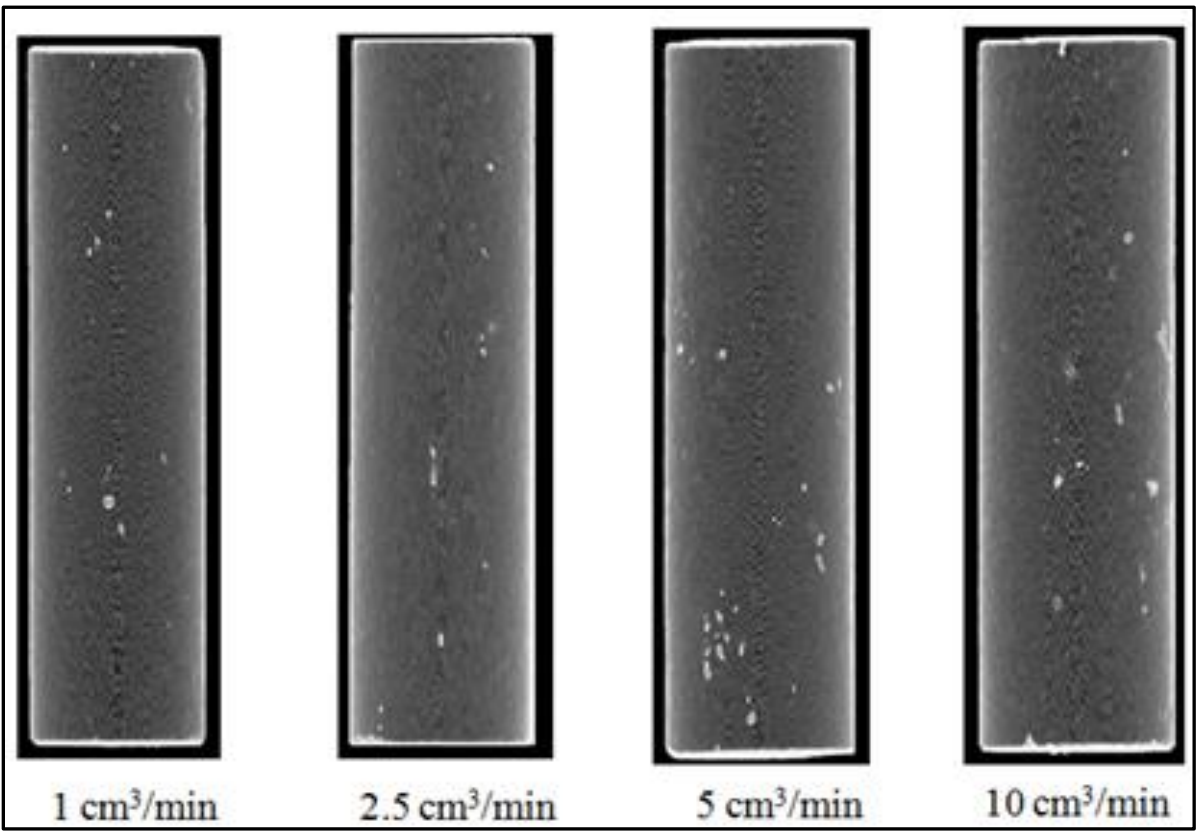

Figure 40: CT scan images of Indiana limestone before acidizing.

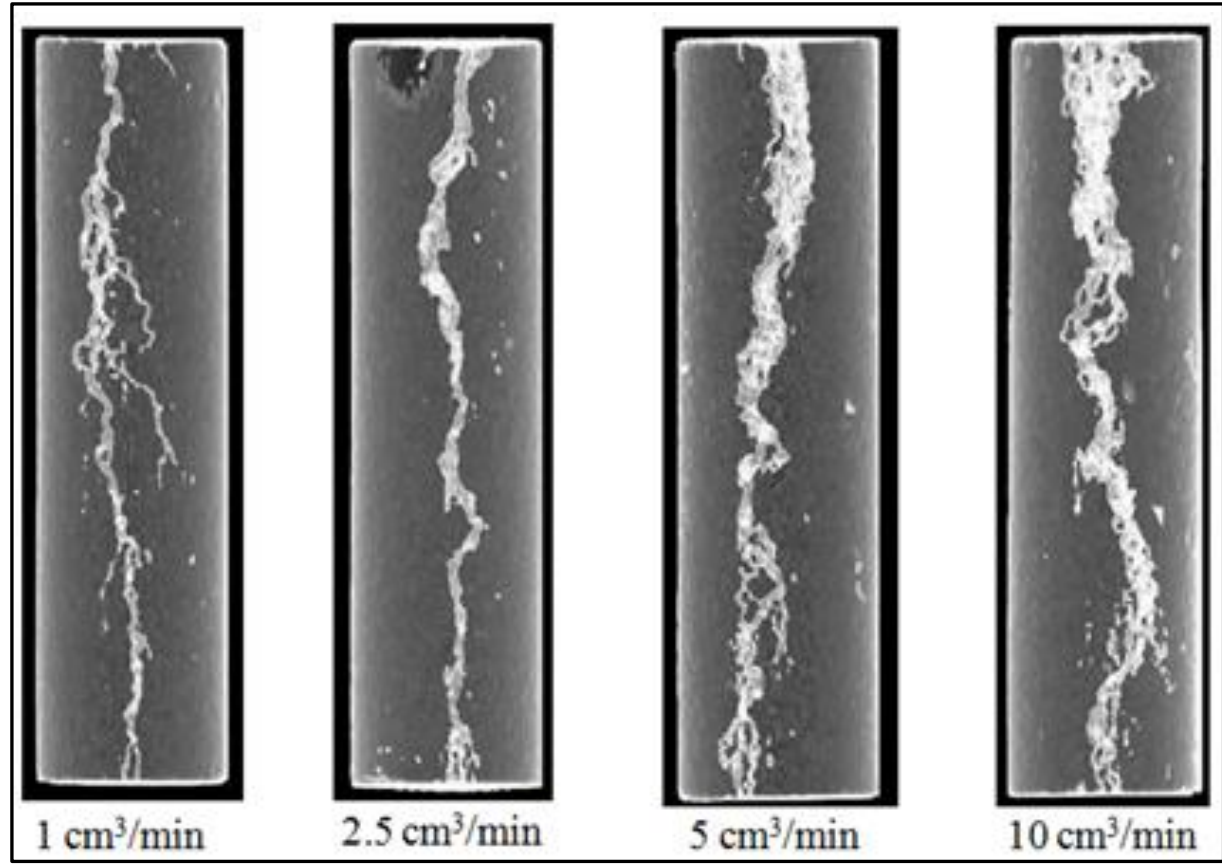

Figure 41: Wormhole pattern of Indiana limestone. 


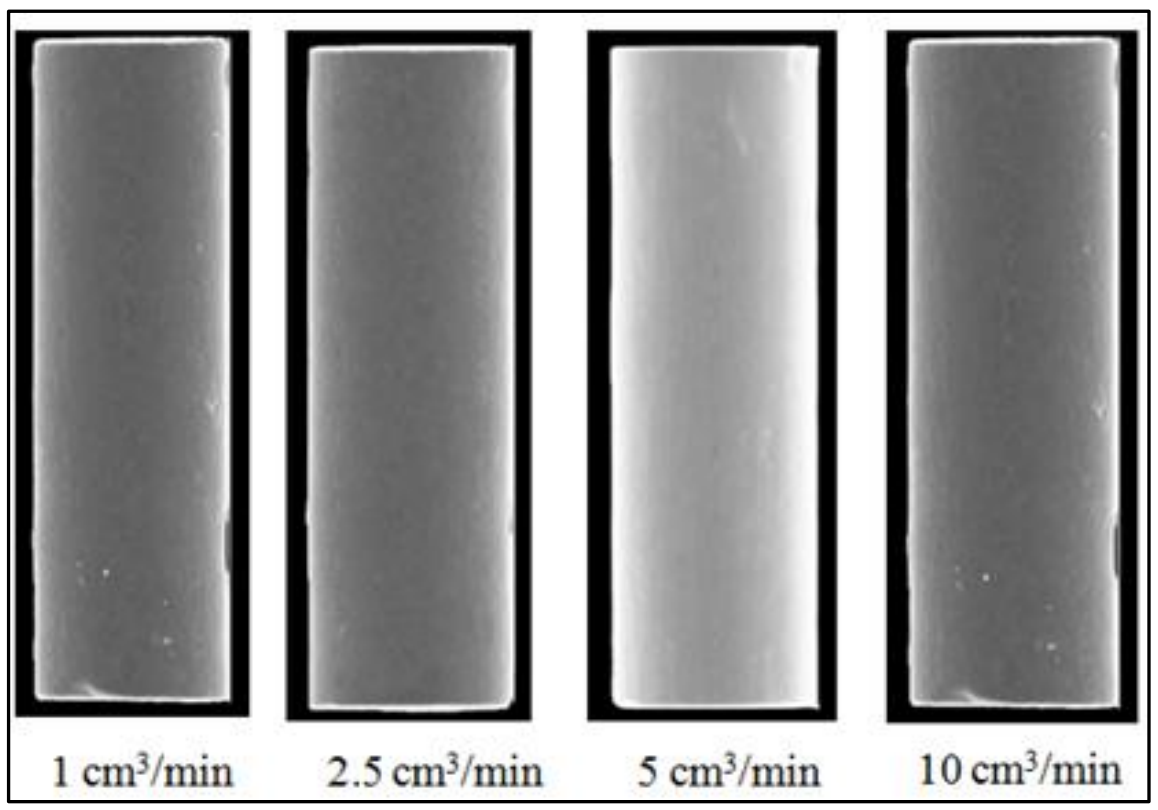

Figure 42: CT scan images of Austin chalk before acidizing.

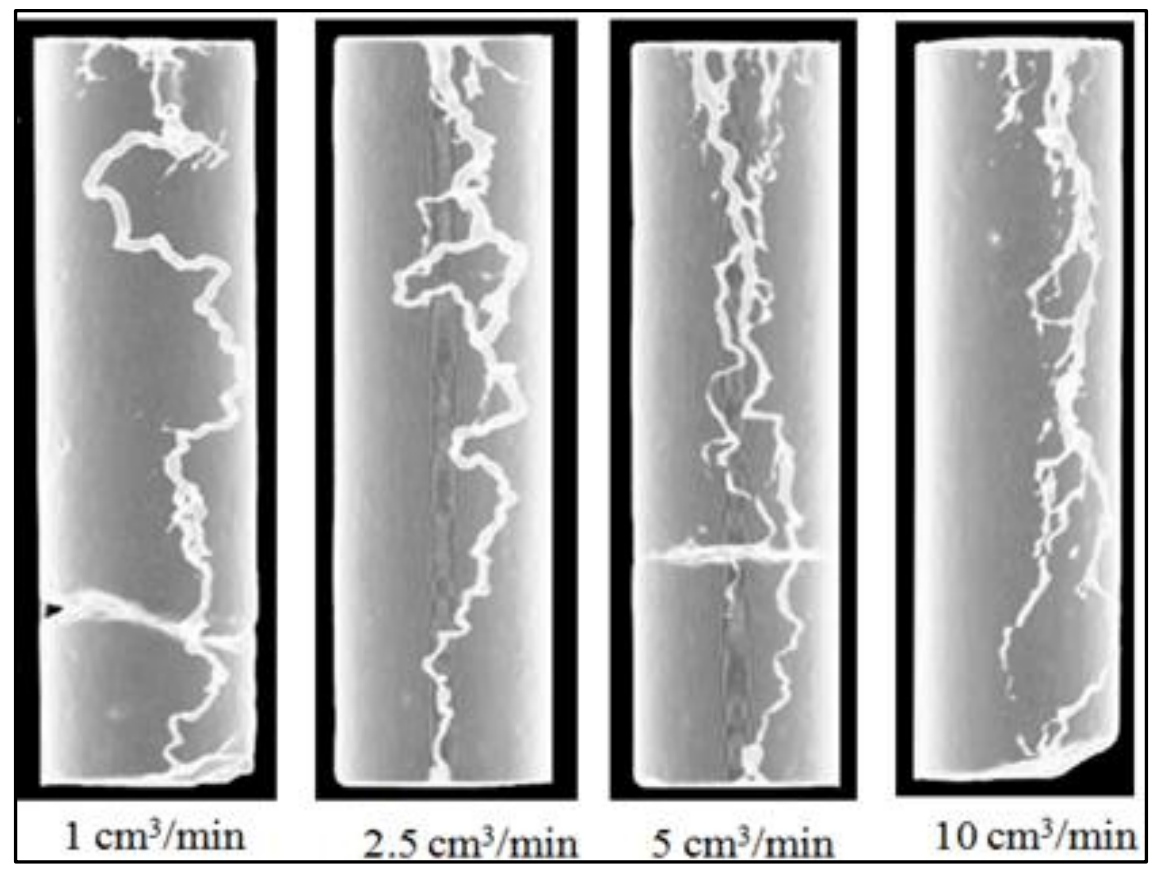

Figure 43: Wormhole pattern of Austin chalk. 


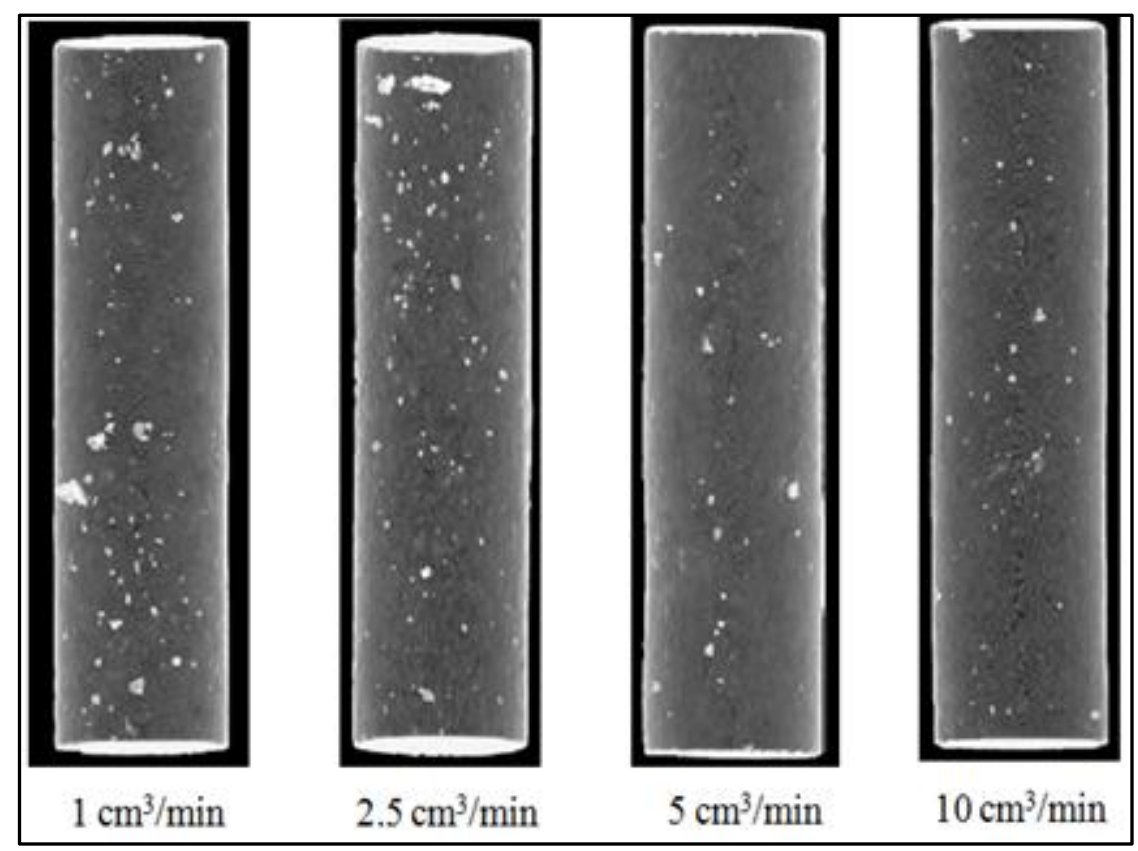

Figure 44: CT scan images of Edwards yellow before acidizing.

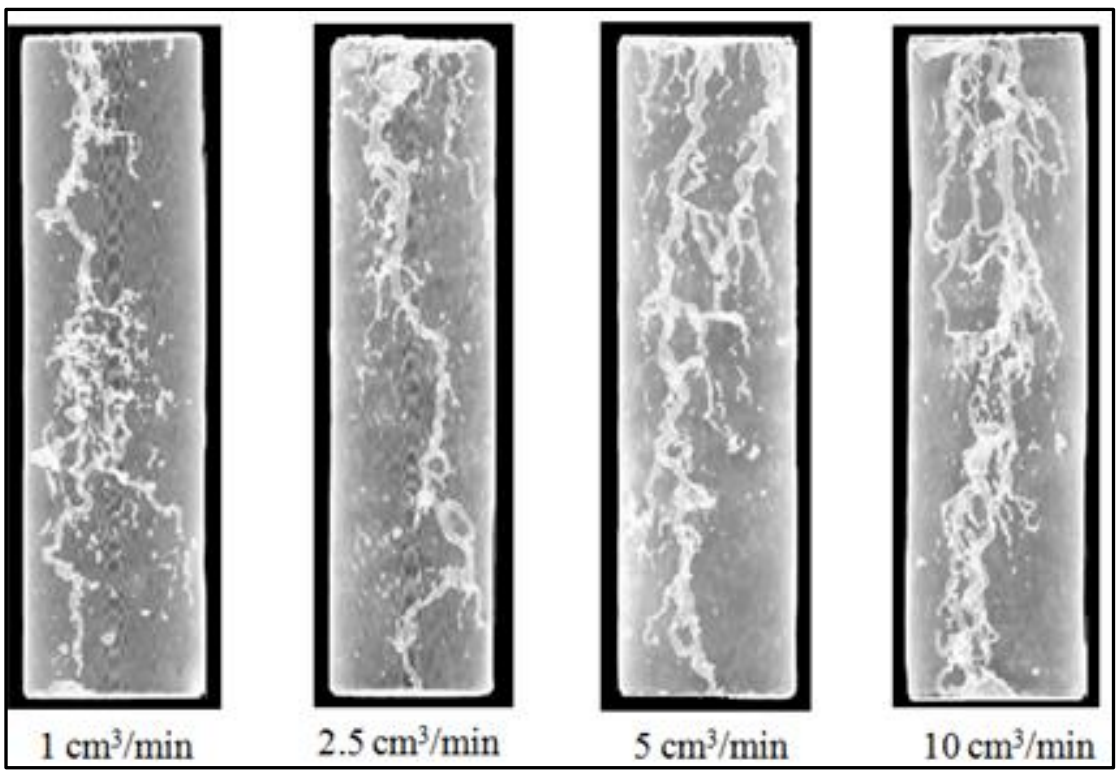

Figure 45: Wormhole pattern of Edwards yellow. 


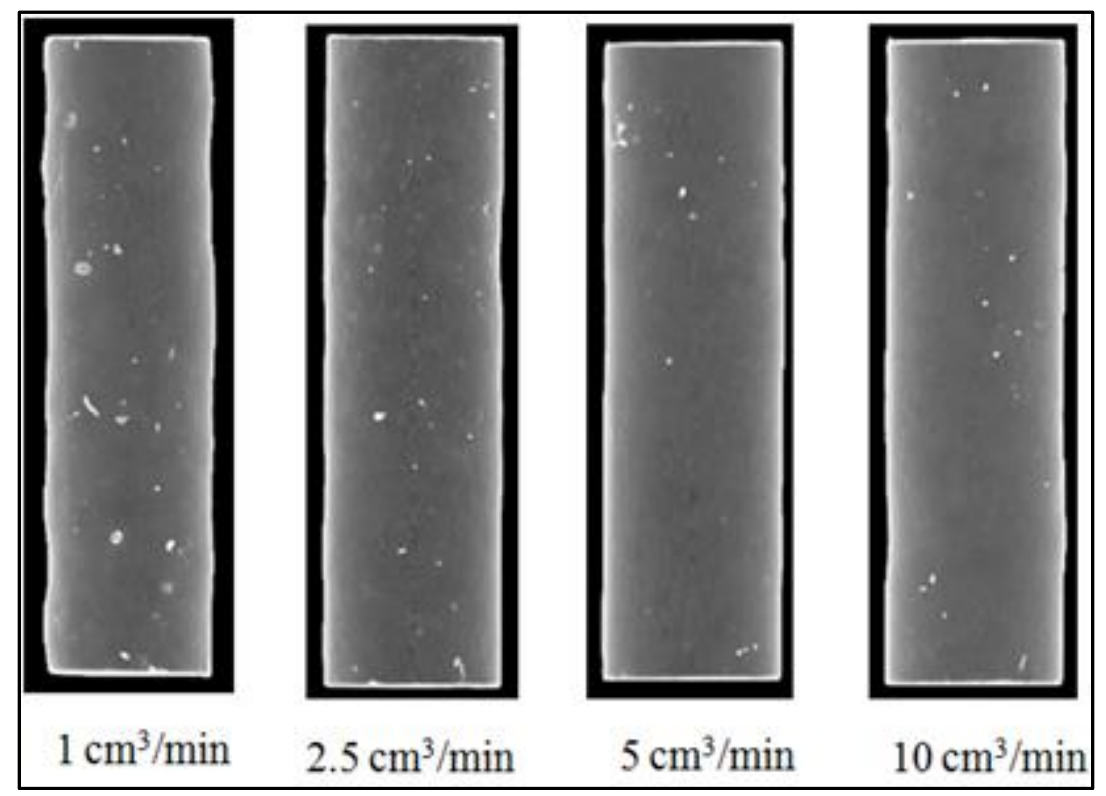

Figure 46: CT scan images of Pink desert before acidizing.

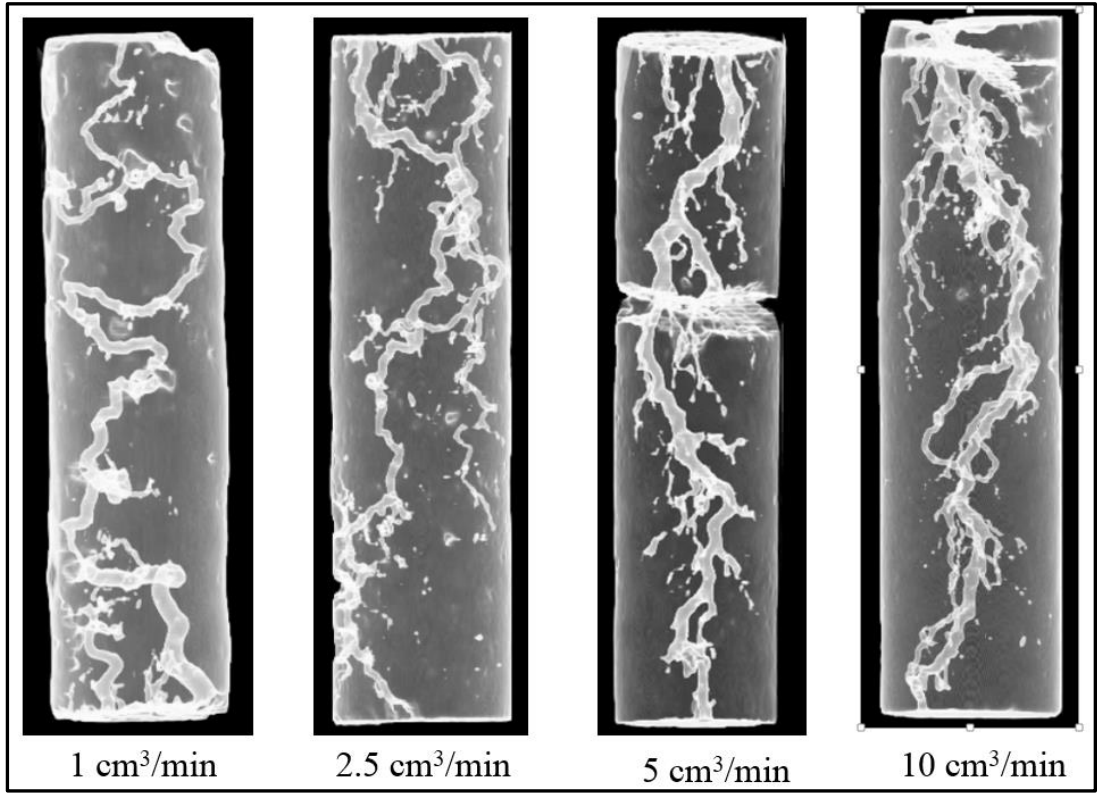

Figure 47: Wormhole pattern of Pink desert. 


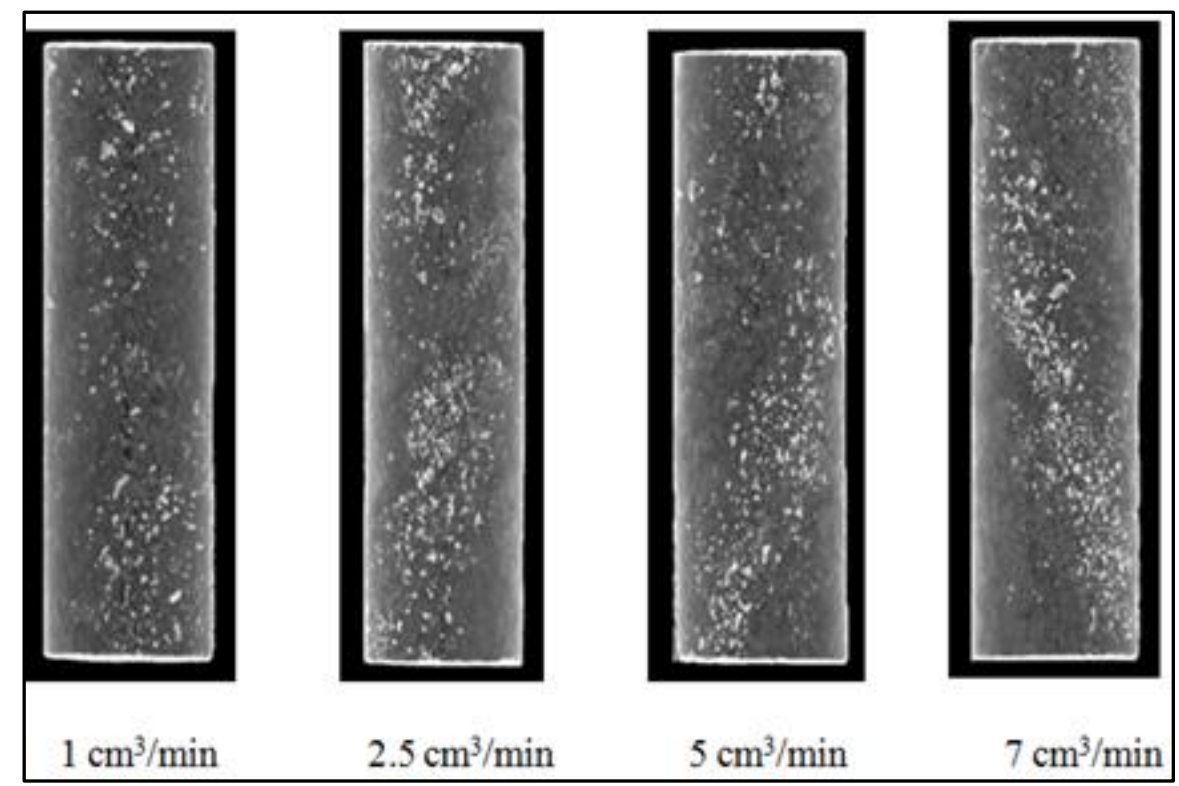

Figure 48: CT scan images of Winterset limestone before acidizing.

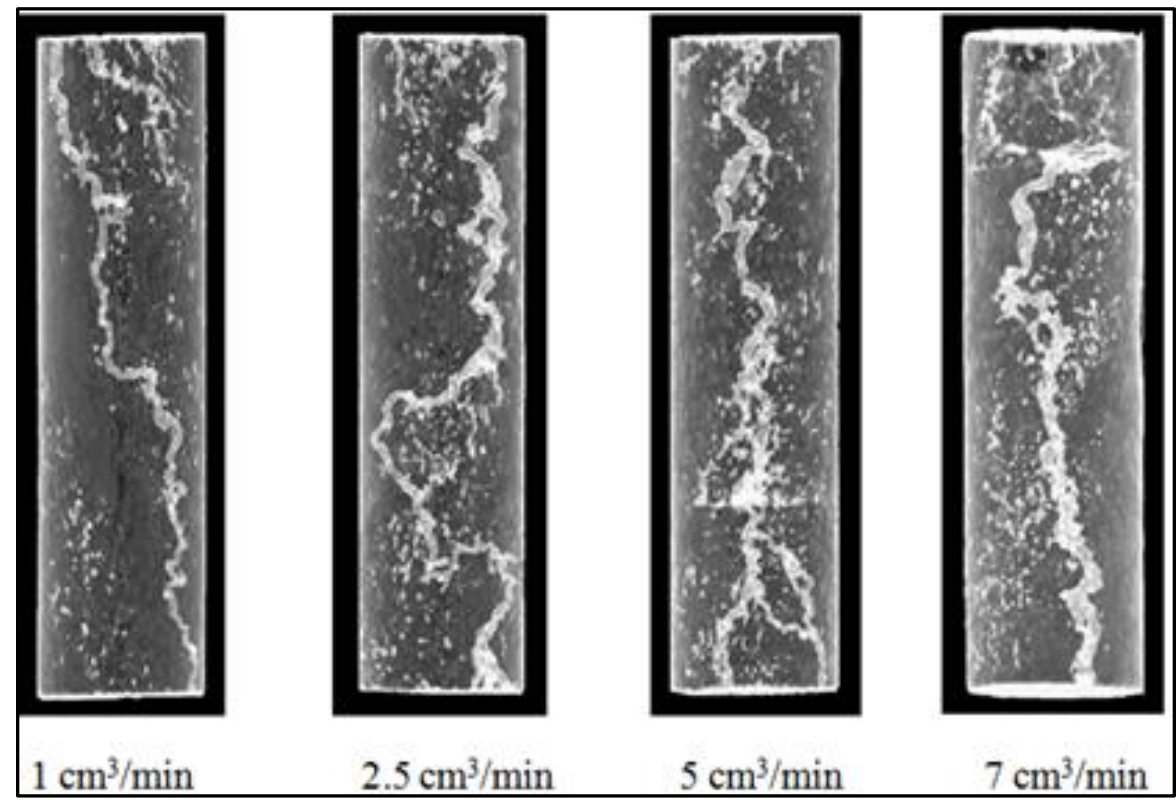

Figure 49: Wormhole pattern of Winterset limestone. 


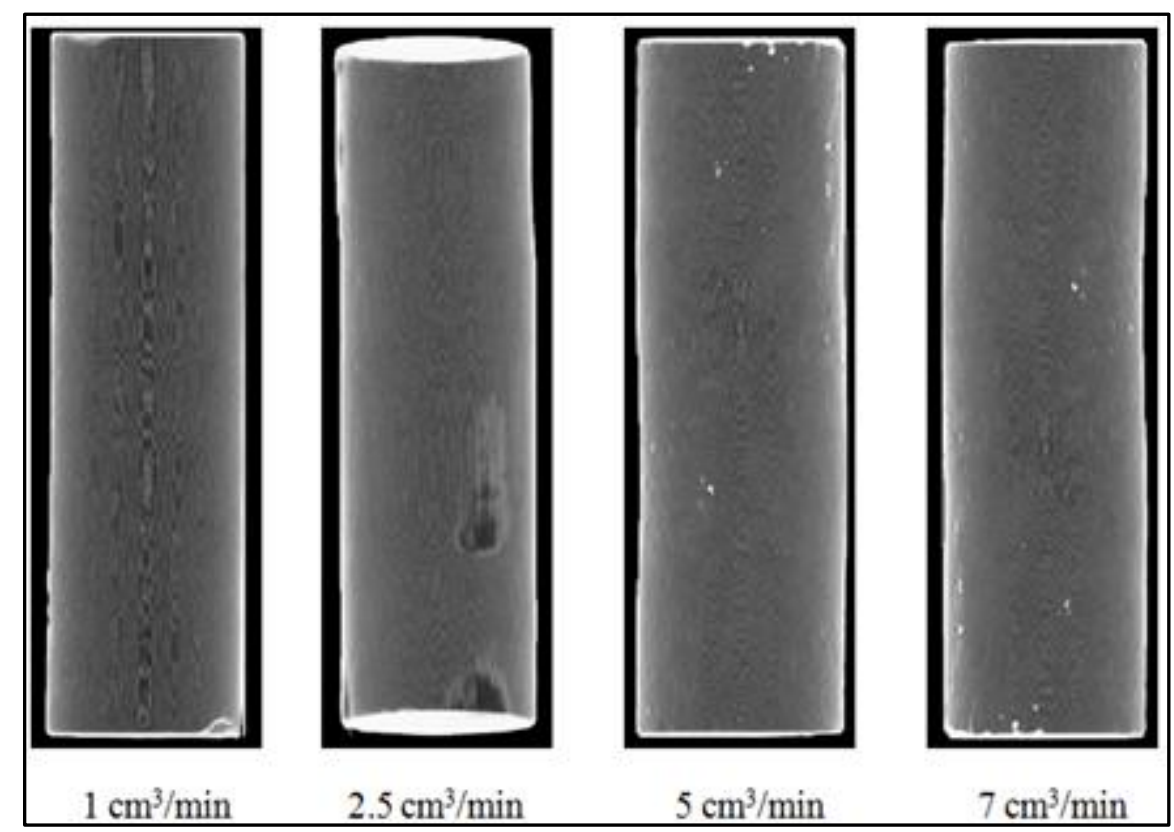

Figure 50: CT scan images of Edwards white before acidizing.

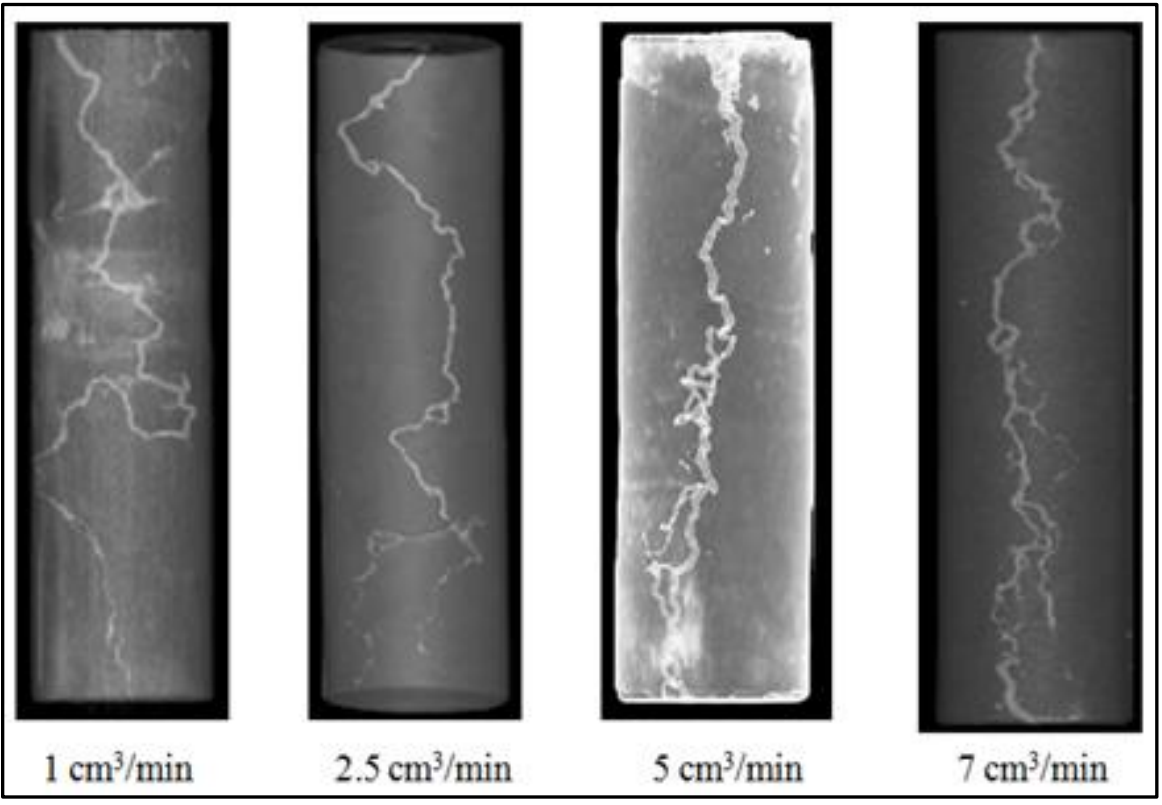

Figure 51: Wormhole pattern of Edwards white. 
The complexity of wormhole patterns were represented by fractal dimension index. As a fractal dimension is used to analyze the growth of the wormhole, the smaller number represents the wormhole with the fewest branches, the dissolution pattern that is more preferable. These numbers for wormhole patterns that were generated at optimum acid injection rates were presented in Table 2.

Table 2: Fractal dimension of different rock types.

\begin{tabular}{|c|c|}
\hline Rock Type & Fractal Dimension Numer \\
\hline Indiana limestone & 1.28 \\
\hline Austin chalk & 1.43 \\
\hline Edwards yellow & 1.42 \\
\hline Pink desert & 1.41 \\
\hline Winterset limestone & 1.35 \\
\hline Edwards white & 1.13 \\
\hline
\end{tabular}

Edwards yellow with $f=0.86$, had acid $\mathrm{PV}_{\mathrm{bt}}$ of 0.46 and fractal dimension of 1.39. While Edwards white with $f=0.53 \mathrm{PV}_{\mathrm{bt}}$ of 0.20 and fractal dimension of 1.13 . As the pore heterogeneity is higher for the rock, the flowing fraction is lower. The lower flowing fraction represent less pore connectivity, hence, less carbonates were dissolved during acid treatment, and less complex dissolution patterns were generated.

\subsection{Calcium Dissolved Analysis}

Figure 52 through Figure 57 show the calcium concentration at various acid rates for the six types of carbonate rocks investigated in this study. As the acid $\mathrm{PV}_{\mathrm{bt}}$ depends on 
the acid injection rate, the more acid was required to reach breakthrough, the more carbonate rocks were dissolved. Thus, amount of calcium in the effluent samples were affected by the acid injection rate. The maximum calcium concentrations for most of the rock type were achieved at the highest acid injection rates, 7 or $10 \mathrm{~cm}^{3} / \mathrm{min}$. The fluctuations of calcium concentration occured when the gelled were broken, so that the calcium dissolved were able to flow within the effluent samples.

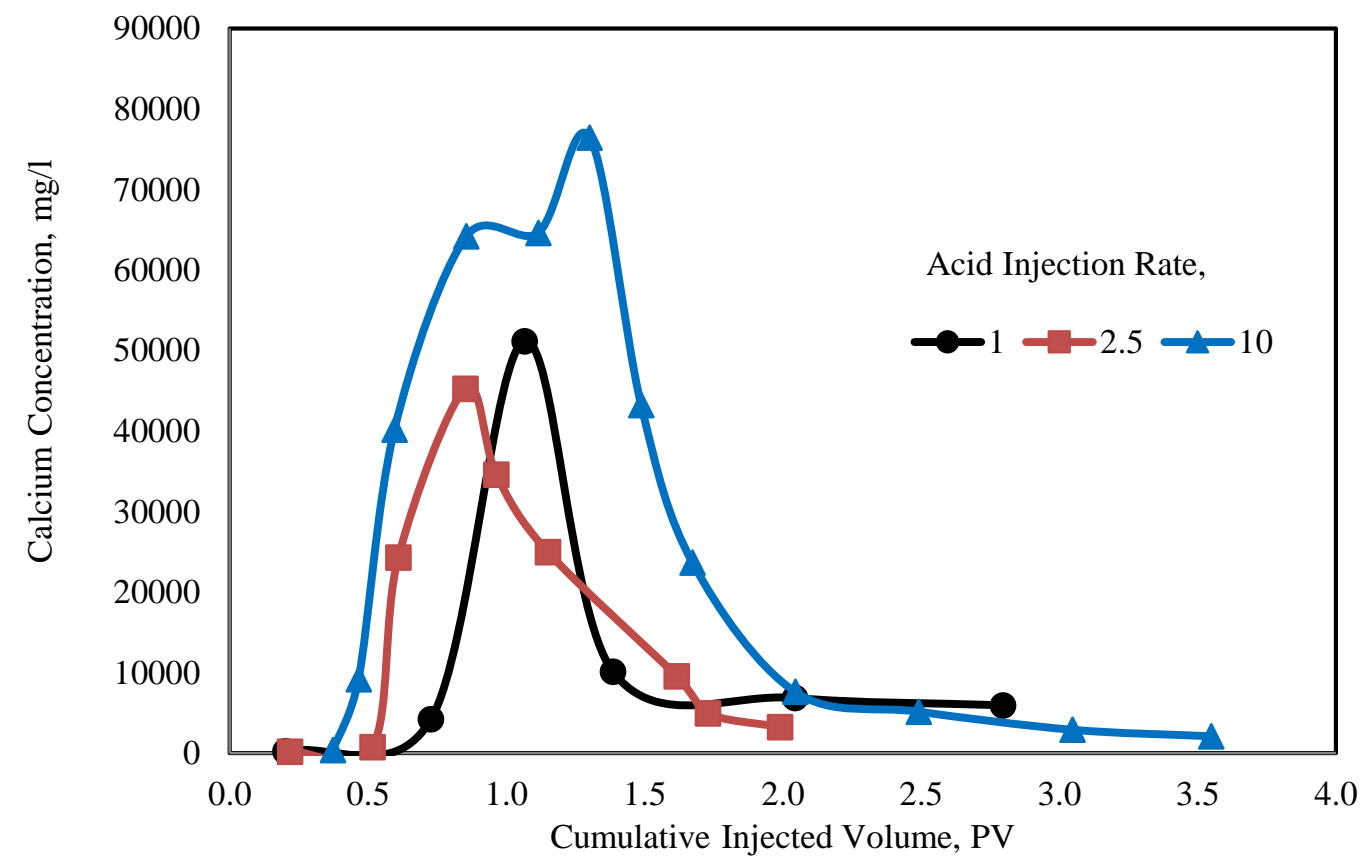

Figure 52: Calcium concentration in the core effluent samples of Indiana limestone. 


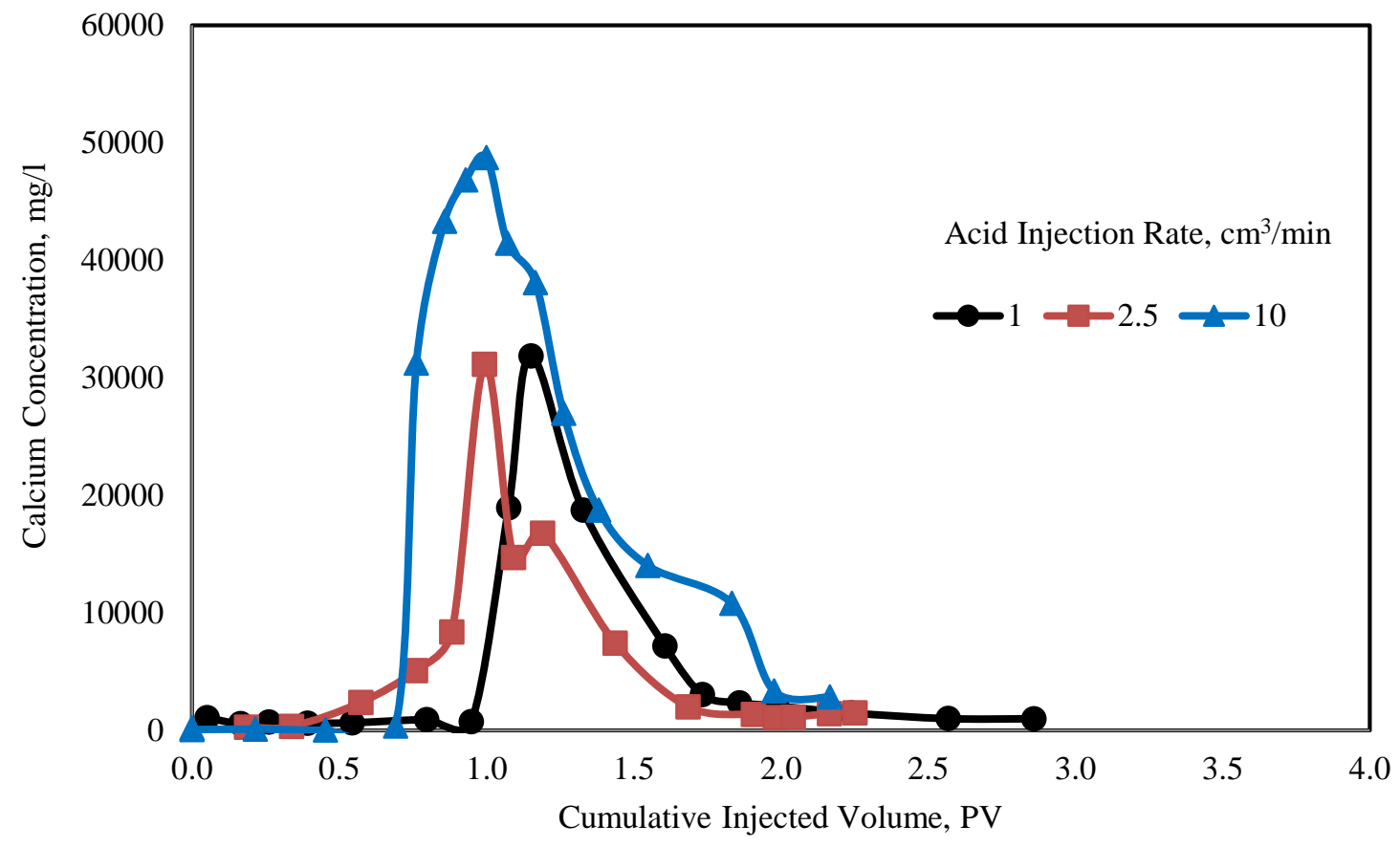

Figure 53: Calcium concentration in the core effluent samples of Austin chalk.

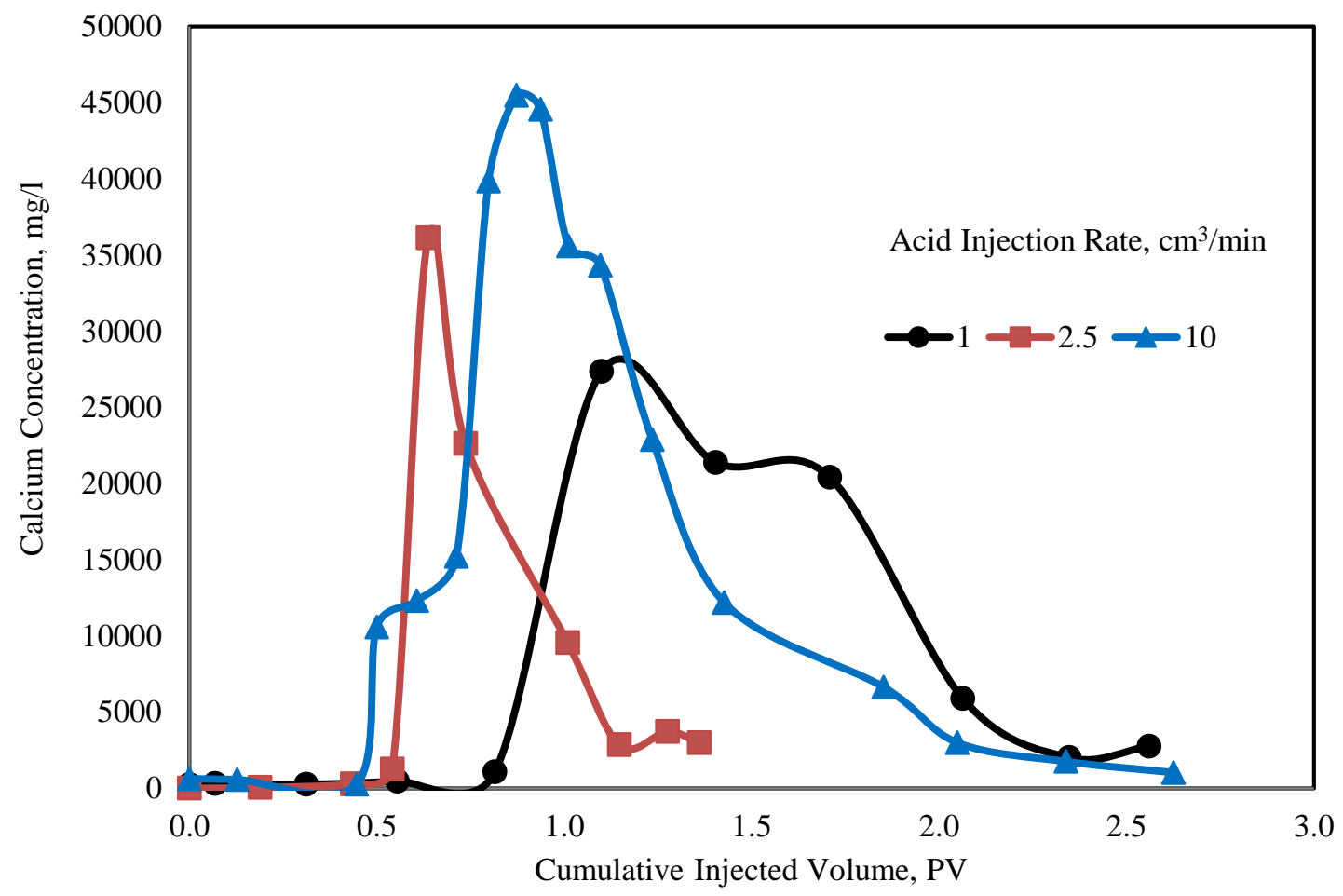

Figure 54: Calcium concentration in the core effluent samples of Edwards yellow. 


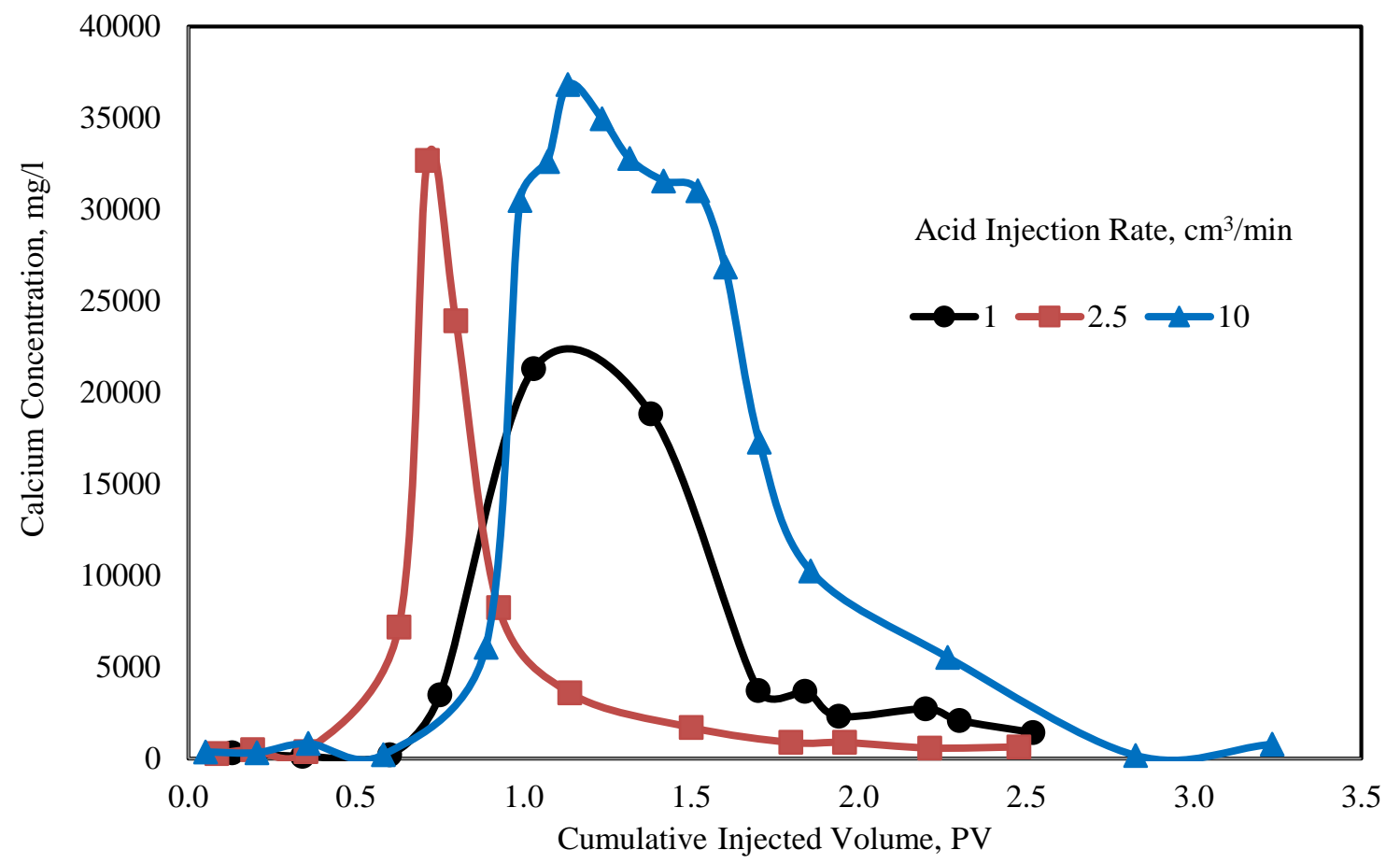

Figure 55: Calcium concentration in the core effluent samples of Pink desert.

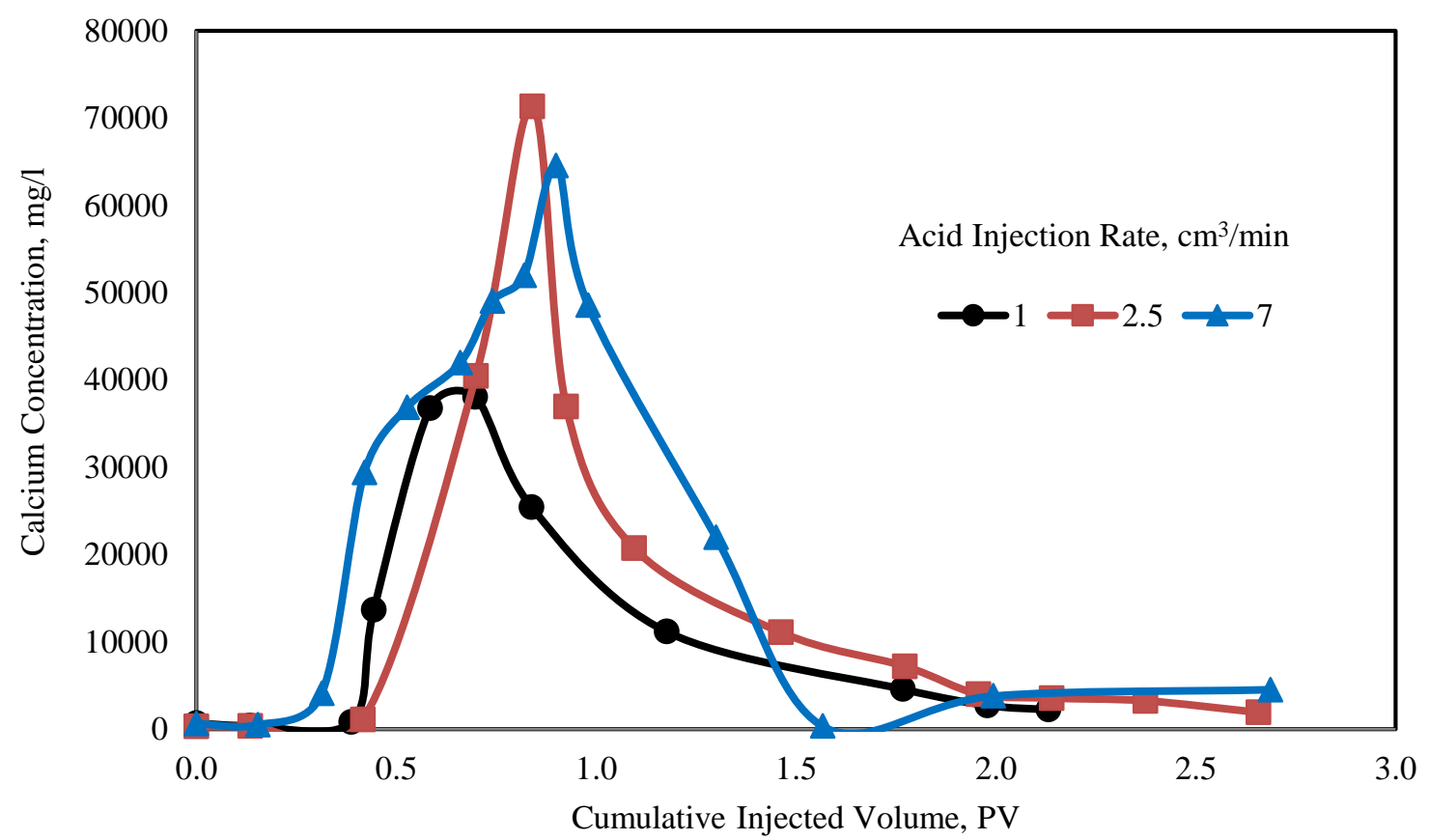

Figure 56: Calcium concentration in the core effluent samples of Winterset limestone. 


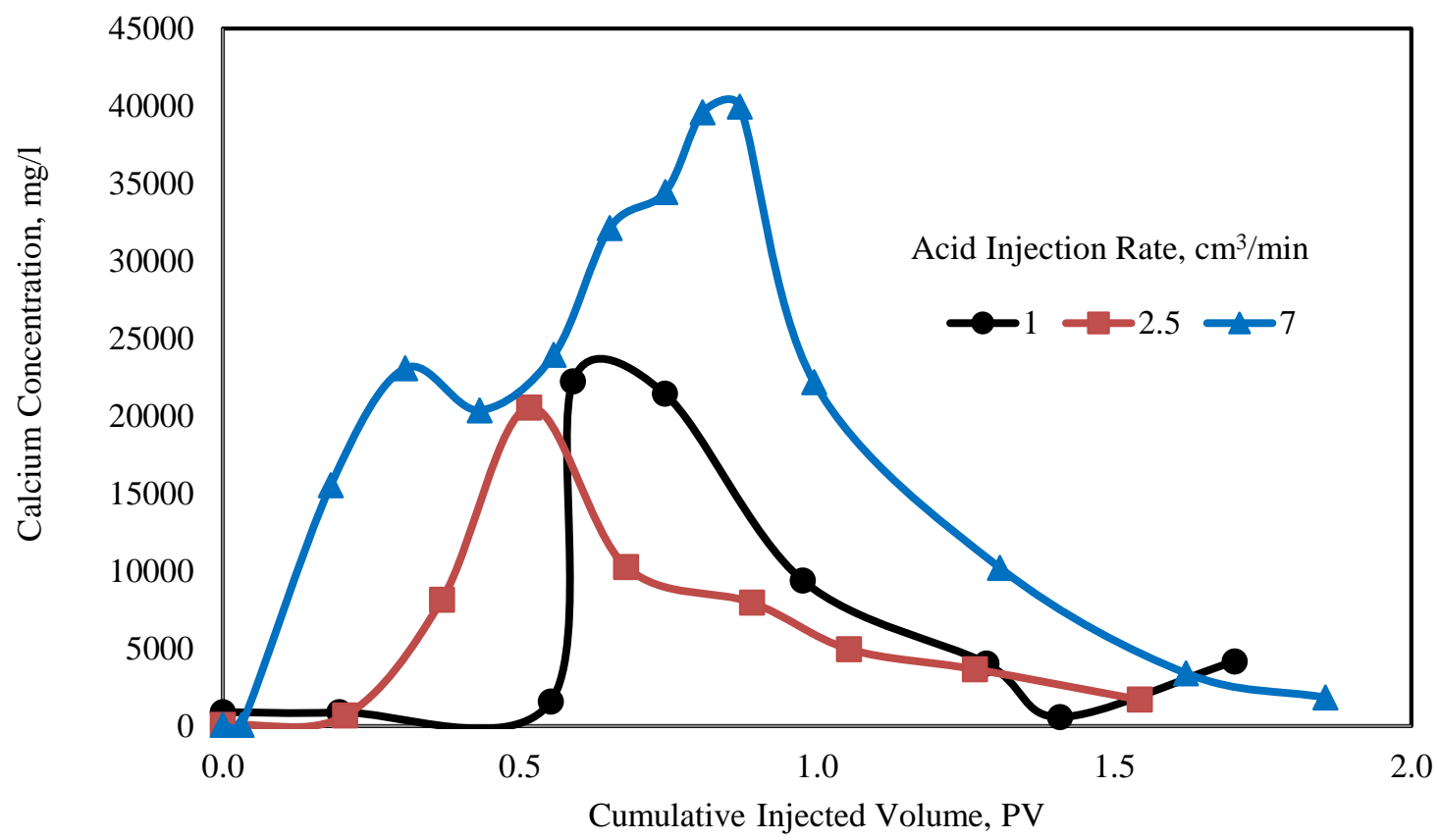

Figure 57: Calcium concentration in the core effluent samples of Edwards white.

Table 3: Total calcium dissolved for different rock types.

\begin{tabular}{|c|c|c|}
\hline Rock Type & $\begin{array}{c}\text { Injection Rate } \\
\left(\mathrm{cm}^{3} / \mathrm{min}\right)\end{array}$ & $\begin{array}{c}\text { Mass } \mathrm{Ca}^{2+} \\
(\mathrm{mg})\end{array}$ \\
\hline \multirow{3}{*}{ Indiana limestone } & 1 & 844 \\
\cline { 2 - 3 } & 2.5 & 747 \\
\cline { 2 - 3 } & 10 & 1995 \\
\hline \multirow{4}{*}{ Austin chalk } & 1 & 504 \\
\cline { 2 - 3 } & 2.5 & 497 \\
\cline { 2 - 3 } & 10 & 1384 \\
\hline \multirow{4}{*}{ Edwards yellow } & 1 & 1195 \\
\cline { 2 - 3 } & 2.5 & 455 \\
\cline { 2 - 3 } & 10 & 1343 \\
\hline \multirow{4}{*}{ Pink desert } & 1 & 818 \\
\cline { 2 - 3 } & 2.5 & 475 \\
\cline { 2 - 3 } & 10 & 1525 \\
\hline Winterset limestone & 1 & 493 \\
\cline { 2 - 3 } & 2.5 & 893 \\
\cline { 2 - 3 } & 7 & 1060 \\
\hline Edwards white & 1 & 311 \\
\cline { 2 - 3 } & 2.5 & 304 \\
\cline { 2 - 3 } & 7 & 942 \\
\hline
\end{tabular}


Table 3 presents total calcium dissolved of each rock type. This number were calculated as an area under the curve. A higher calcium dissolved mostly showed at a higher acid injection rates, where a higher acid $\mathrm{PV}_{\mathrm{bt}}$ required to reach breakthrough. 


\section{CHAPTER IV}

\section{ANALYSIS AND CONCLUSIONS}

\subsection{Thin Section Analysis}

X-Ray-Diffraction (XRD) and X-Ray Fluorescence (XRF) analyses have been done in previous study to investigate these mineral compositions and elemental composition. These analyses revealed that rocks did not contain clays and anhydrites. Thus, the response of the rocks from experimental works were due to heterogeneity in the pore-structure (Zakaria et al. 2015). Thin section analysis also has been conducted to observe pore heterogeneity qualitatively. The images at $2.5 \mathrm{X}$ and $10 \mathrm{X}$ magnification showed that Indiana limestone has well-connected intergranular pores; Austin chalk has micropores and fine intergranular pores; Edwards yellow has moldic pores that are formed by the leaching of intergranular pores and fossils; Pink desert has dominant moldic pores; Winterset limestone has fairly connected moldic pores that are formed by the leaching of grainstone; and Edwards white has micropores within the micritized matrix, fewer intergranular pores, and moldic pores. This characterization helps to determine the magnitude of pore heterogeneity from tracer experiments.

\subsection{Magnitude of Pore Heterogeneity}

Tracer experiments were conducted for each rock to obtain flowing fraction, and this number was used to quantify rock heterogeneity. The flowing fraction from tracer experiments of this study presented in Table 4. 
Table 4: Flowing fraction of carbonate rocks.

\begin{tabular}{|c|c|}
\hline Rock Type & Flowing Fraction \\
\hline Indiana limestone & 1 \\
\hline Austin chalk & $0.89 \pm 0.02$ \\
\hline Edwards yellow & $0.86 \pm 0.02$ \\
\hline Pink desert & $0.73 \pm 0.02$ \\
\hline Winterset limestone & $0.61 \pm 0.03$ \\
\hline Edwards white & $0.46 \pm 0.03$ \\
\hline
\end{tabular}

Indiana limestone has the highest flowing fraction than other rocks. This number corresponds to thin section analysis, where well-connected pores have multiple paths for the fluid to flow, since the fluid could explore various ways to propagate, this led delay on tracer fluid to breakthrough. While, Winterset limestone and Edwards white with lower flowing fraction responded to thin section image, which the presence of dead-end pores and inaccessible pores generating the tailing profile, and early reakthrough happened due to inaccessible pores. The existence of these type of pores increase the magnitude of the pore heterogeneity.

\subsection{Correlation of Flowing Fraction and Acid PV}

Figure 58 shows $\mathrm{PV}_{\mathrm{bt}}$ as a function of flowing fraction at different acid injection rates for VES-based $\mathrm{HCl}$. Indiana limestone with $f=1$ had $\mathrm{PV}_{\mathrm{bt}}$ ranging from 0.6 to 0.84 , Edwards yellow with $f=0.86$ had $\mathrm{PV}_{\mathrm{bt}}$ ranging from 0.46 to 0.73 , and Edwards white with $f=0.53$ had $\mathrm{PV}_{\mathrm{bt}}$ ranging from 0.2 to 0.36 . A higher flowing fraction for Indiana limetone corresponds to more pores that contributed to the flow of fluid compared to Edwards 
yellow and Edwards white. The better pore connectivity provided more paths for the VES acid to flow, and, consequently, more acid was consumed to dissolve the carbonate rocks. For the rocks that have tailing tracer profiles, such as Winterset limestone and Edwards white, the large pores were distributed in a manner that allow a faster wormhole propagation, and thus less acid $\mathrm{PV}_{\mathrm{bt}}$ is required. The presence of these pores provides preferential paths. This investigation proved that the acid $\mathrm{PV} \mathrm{bt}_{\mathrm{bt}}$ in carbonate rocks depends on their pore heterogeneity. Heterogeneous rock with preferential paths possessed a lower flowing fraction, and thus less acid was consumed during treatment. Once the heterogeneity of the rock is conclusive, the acid $\mathrm{PV}_{\mathrm{bt}}$ could be predicted.

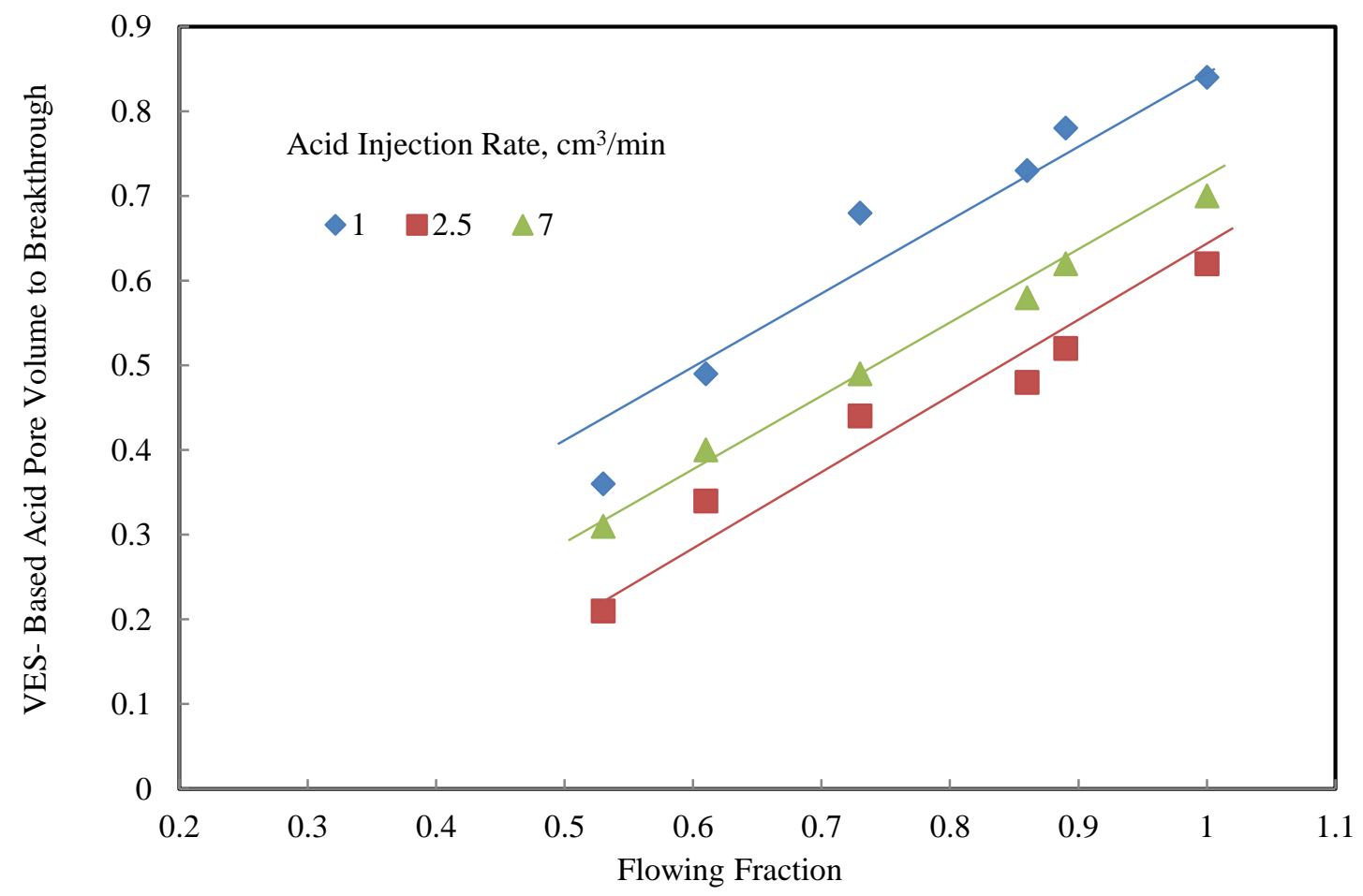

Figure 58: PVbt for VES-based $\mathrm{HCl}$ as a function of the flowing fraction at different acid injection. 
Comparing the response of Edwards white to VES acid and regular acid that was studied by Zakaria et al. (2015), this in-situ gelled could reduce acid pore volume to reach breakthrough up to $20 \%$ less than regular acid. Only $80 \%$ of the acid was needed to reach breakthough for VES-based $\mathrm{HCl}$. The additionVES in acid system was efficient to decrease the need of acid during stimulation treatment and it allows the acid to travel and penetrate deeper into the intervals before spending, such that less acid is required to complete the treatments.

\subsection{Wormhole Patterns Behavior}

The dominant wormhole patterns are formed at an optimum acid injection rate, when the velocity of wormhole propagation is less affected by the injection velocity. At higher than optimal injection rates, the dissolution rate is lower, wormholes that have more branches are formed, and this could increase the surface area and reduce the rate of channel propagation. The study of Ziauddin and Bize (2007) helped with rock classification based on porosity spatial distribution. The wormhole patterns presented in Figure $\mathbf{5 9}$ are the response of the carbonate rocks to VES-based $\mathrm{HCl}$. Rock type 1 consists of Austin chalk and Edwards white. These rocks were classified into a rock type, in which fine grain and micropores exist. Edwards yellow, Pink desert, and Winterset limestone were grouped in rock type 2 , in which porosity system is dominated by moldic pores. The carbonate rocks in each rock type exhibit similar dissolution patterns.

In addition, the CT scan images showed that diameters of the wormhole were smaller at the outlet of the core compared to the diameters of wormholes near the inlet of 
the core. Some of the acid in the solution was spent in the reaction with carbonate rocks. As the acid flows from the inlet to the outlet of the core, the concentration decreased.

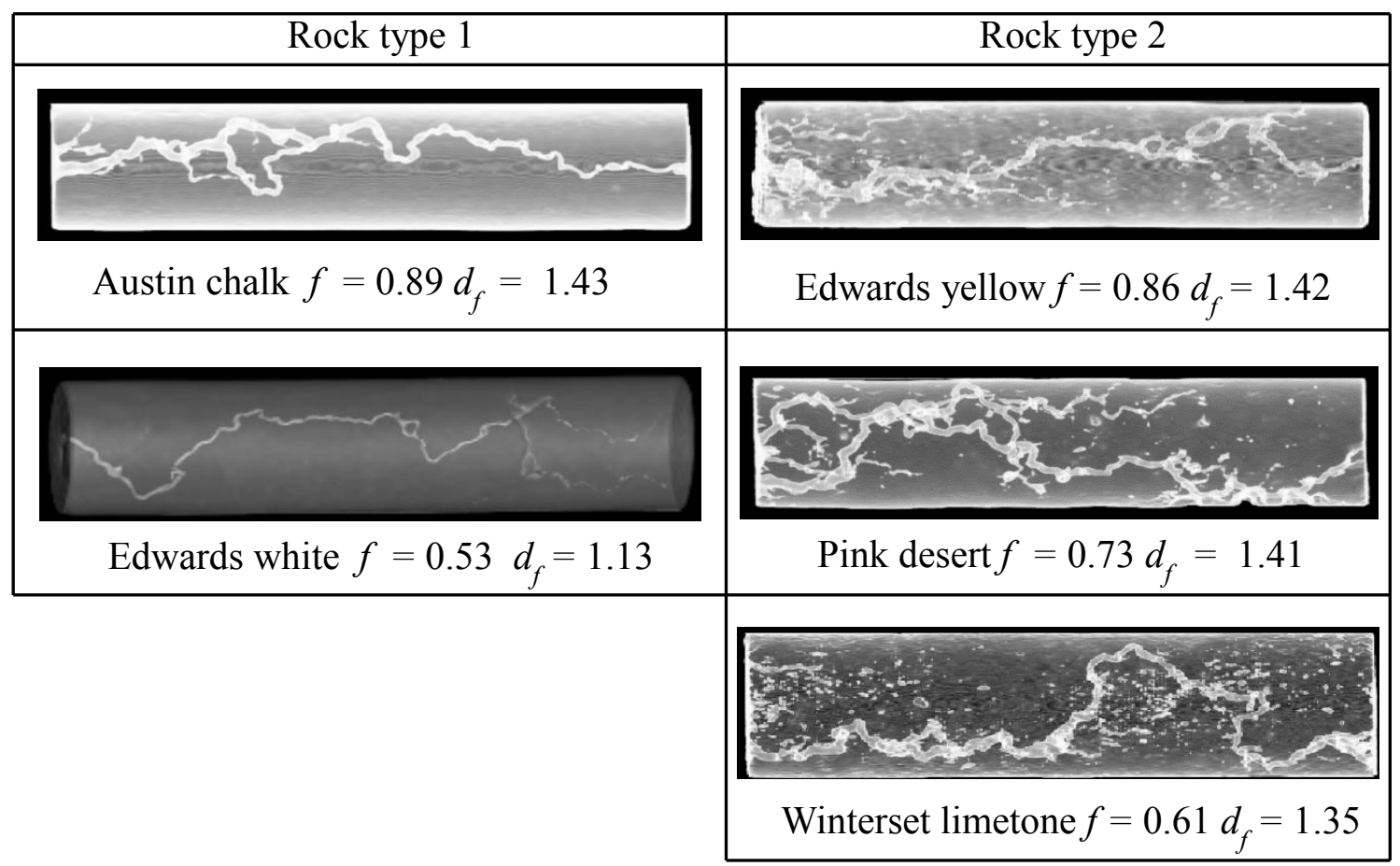

Figure 59: Wormhole patterns that are produced with VES-based HCl, grouped into each rock type.

Wormholes that have fewer branches were produced with VES-based $\mathrm{HCl}$. Wormhole pattern of the rock with well-connected pores, Indiana limestone (Figure 41) is uniform wormholes with fewer branches, while reaction of carbonates with regular $\mathrm{HCl}$ produced ramified wormholes (Zakaria et al. 2015). This occured because low viscosity regular $\mathrm{HCl}$ flows easily into leakoff zones or the zones which have higher permeability. These leakoff creating unwanted channels or branches, so the wormhole that was produced 
was not dominant conductive channel. Hence, fatty acid amidoalkyl betaine, was able to to act as a barrier, so less leakoff of acid occured during treatment.

\subsection{Correlation of Flowing Fraction and Wormhole Complexity}

The wormhole complexity represented by fractal dimension number. As a fractal dimension is used to analyze the growth of the wormhole, the smaller number represents the wormhole with the fewest branches, the dissolution pattern that is more preferable. These numbers for wormhole patterns that were generated at optimum acid injection rates were presented in Table 2.

In an attempt to correlate pore heterogeneity with wormhole patterns and their complexity, the flowing fraction and fractal dimension of carbonate rocks that have similar porosity spatial distribution in Figure 59 are compared. In rock type 1, Austin chalk that has a higher flowing fraction $(f=0.89)$ produced a wormhole that has more branches and a higher fractal dimension $\left(d_{f}=1.43\right)$ compared to Edwards white $\left(d_{f}=1.13\right)$. For rock

type 2, Edwards yellow with a higher flowing fration $(f=0.86)$ has a higher fractal dimension number $\left(d_{f}=1.42\right)$ than Pink desert $\left(d_{f}=1.41\right)$ and Winterset limestone $\left(d_{f}=\right.$ $1.35)$. 


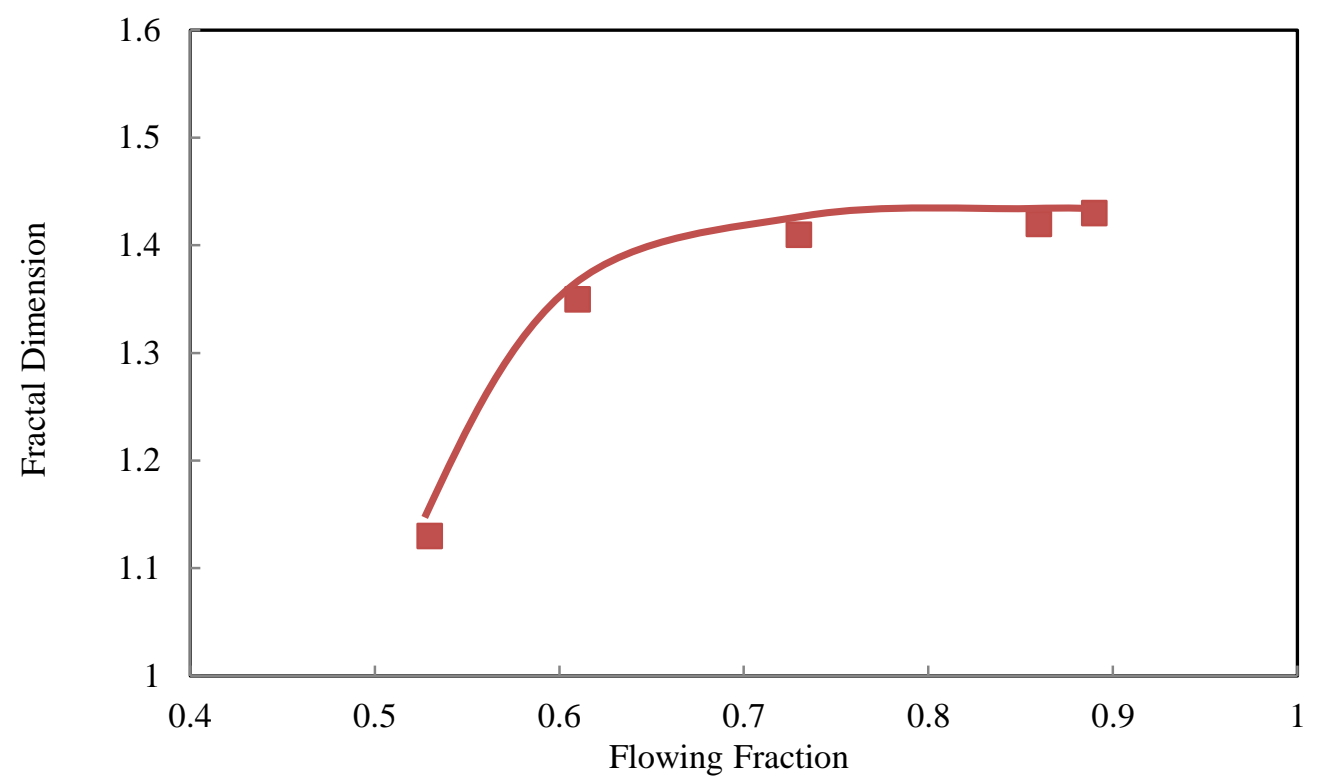

Figure 60: Fractal dimension as a function of flowing fraction.

Carbonate rocks that have a higher flowing fraction in each rock type, produced more complex wormholes and, therefore, a higher fractal dimension. In an attempt to correlate pore heterogeneity and wormhole complexity, fractal dimension is plotted against flowing fraction (Figure 60). At lower flowing fractions, the decrease in magnitude heterogeneity gave a big difference in wormhole dissolution patterns. While at the higher flowing fractions, the increase in flowing fraction produced wormholes with less difference, until a point where rocks with better pore connectivity generate wormholes with similar complexity. This process happens when more branches keep appearing in the wormholes, producing fractal geometry similar to a surface. The lowest fractal dimension numbers were obtained at optimal $\mathrm{PV}_{\mathrm{bt}}$. Edwards white with the lowest fractal dimension number that is 1.13 , has the least complex wormhole. 


\subsection{Correlation of Flowing Fraction and Cleanup Characteristic}

In an attempt to evaluate the cleanup after VES-based $\mathrm{HCl}$ injection, DI water was injected to determine final permeability. The ratio of final permeability over initial permeability was plotted for different carbonate rocks as shown in Figure 61. The rock with a lower flowing fraction such as Winterset limestone and Edwards white have a better cleanup than the rock with a higher flowing fraction. Edwards white has final permeability $17 x$ of its initial rock permeability.

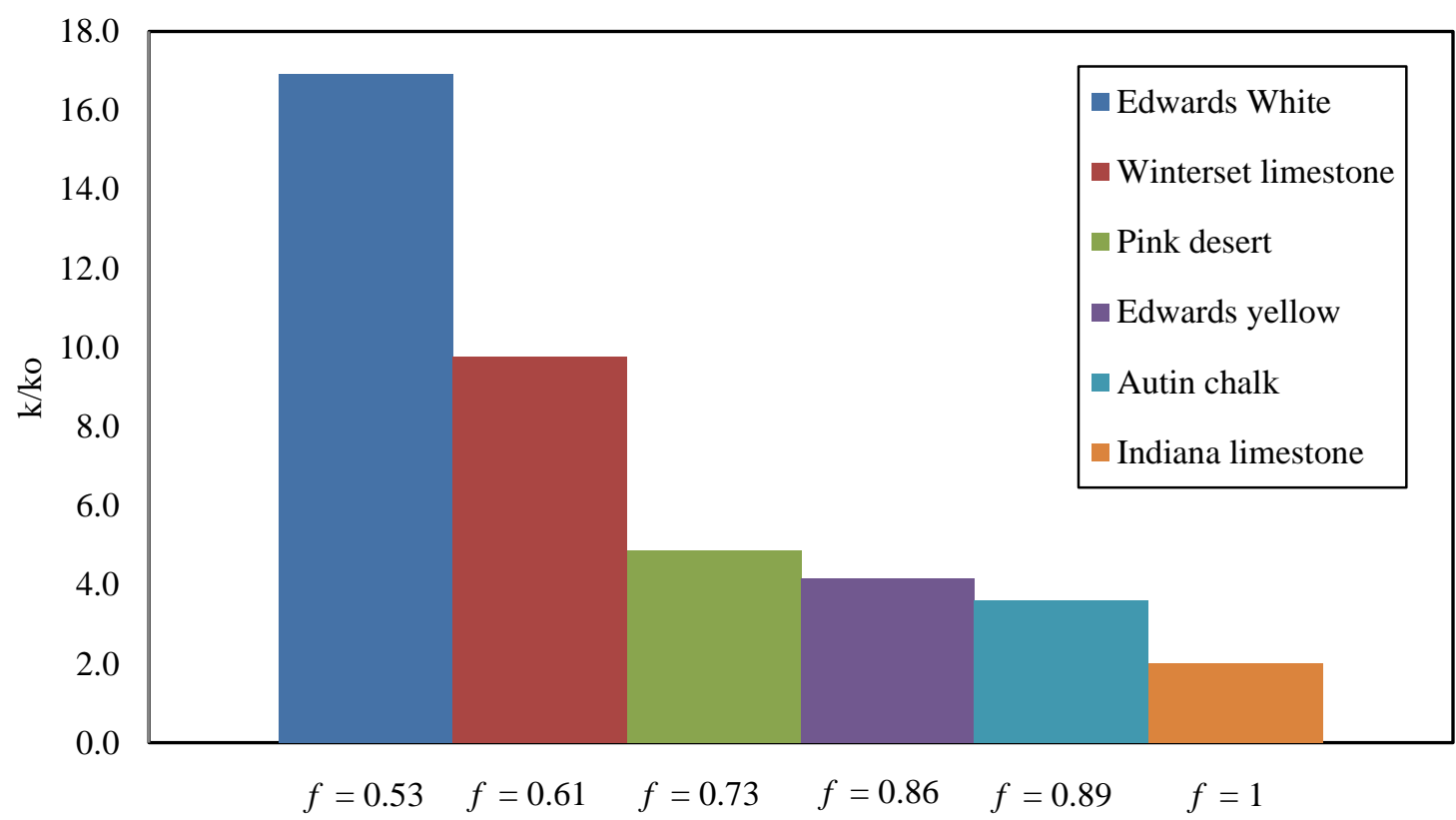

Figure 61: Regained permeability of different carbonate rock types after VESbased $\mathrm{HCl}$ injection.

The rock with better pore connectivity such as Indiana limestone and Austin chalk have higher flowing fraction. It means more acid coming in contact with carbonate rock or more surfactant flowing into the rock during treatment. This plot revealed that the rock 
with a lower flowing fraction had less remaining surfactants inside the core, hence, regained permeability was greater compared to the rock with a higher flowing fraction.

\subsection{Conclusions}

The experimental results from six carbonate rock types from this study showed that pore structure significantly affects the amount of acid needed to reach breakthrough during carbonate acidizing using VES-based $\mathrm{HCl}$. Pore structure of carbonate rocks significantly affects the amount of acid $\mathrm{PV}$ bt. The rock with better pore connectivity has a higher flowing fraction. This rock provides a greater fraction of pore volume that contributes to the fluid flow compared to the rock with a lower flowing fraction, consequently, a greater amount of VES-based $\mathrm{HCl}$ flows inside the core to reach breakthrough. Rock with preferential flow paths in pore-structure needed the least amount of acid to reach breakthrough.

The carbonate rocks that have similar pore class were grouped into a rock type, and they exhibit similar dissolution pattern. The wormhole that has more branches was produced from the rock with a higher flowing fraction. A higher flowing fraction generated a more complex dissolution pattern, which corresponds to a higher fractal dimension index.

The use of VES-based $\mathrm{HCl}$ was able to reduce acid $\mathrm{PV}_{\mathrm{bt}}$ to $20 \%$ less than regular $\mathrm{HCl}$ in more heterogeneous carbonate rocks. The rock with a greater degree of heterogeneity possessed preferential flow paths that lead to a faster wormhole propagation with even less required of acid $\mathrm{PV}_{\mathrm{bt}}$. This is because high-viscosity solution is able to 
lower the reaction rate of acid and the carbonate rock. Wormholes that have fewer branches were generated with VES-based $\mathrm{HCl}$ than regular $\mathrm{HCl}$. The high-viscosity solution was able to divert the acid so that less acid leakoff occured. Among all rock types, fewer branches were formed in the rock that has preferential flow paths at optimum acid injection rate. The rock with the lowest fractal dimension number has the most preferable wormhole pattern.

The rock with a lower flowing fraction has a better cleanup than the rock with a higher flowing fraction because this rock type had less remaining surfactants inside the core. A higher regained permeability was achieved for the rock with a lower flowing fraction, such as Edwards white, with 17X regained permeability. A better cleanup helps to reduce the cost of the field stimulation treatment and the rig time.

Based on these results, VES-based $\mathrm{HCl}$ is more efficient than regular $\mathrm{HCl}$ due to its diversion ability. Quantification of pore heterogeneity helps to estimate acid $\mathrm{PV}_{\mathrm{bt}}$, wormhole dissolution pattern and its complexity, and regained permeability. Thus, investigation of porosity systems is recommended to obtain a more successful field treatment. 


\section{REFERENCES}

Al-Ghamdi, A. H., Nasr-El-Din, H. A., Al-Qahtani, A. A. et al. 2004. Impact of Acid Additives on the Rheological Properties of Viscoelastic Surfactants and Their Influence on Field Application. Presented at the SPE/DOE Symposium on Improved Oil Recovery, Tulsa, Oklahoma, 17-21 April. SPE-89418-MS. http://dx.doi.org/10.2118/89418-MS.

Al-Ghamdi, A. H., Nasr-El-Din, H. A., and Hill, A. D. 2009. Propagation of Viscoelastic Surfactant Based Acid in Carbonate Cores. 2009. Presented at the SPE International Symposium on Oilfield Chemistry, The Woodlands, Texas, 20-22 April. SPE-121713-MS. http://dx.doi.org/10.2118/121713-MS.

Al-Nakhli, A. R., Nasr-El-Din, H. A., and Al-Baiyat, A. A. 2008. Interactions of Iron and Viscoelastic Surfactants During Well Stimulation: A New Formation Damage Mechanism. Presented at the SPE Saudi Arabia section Young Professionals Technical Symposium, Dhahran, Saudi Arabia, 29-30 March. SPE117060-MS. http://dx.doi.org/10.2118/117060-MS.

Al-Otaibi, M. A., Al-Muntasheri, G. A., Hussein, I. A. et al. 2011. Laboratory Evaluation of Viscoelastic Surfactant Acid Diversion for Carbonate Reservoirs. Presented at the SPE Middle East Oil and Gas Show and Conference, Manama, Bahrain, 25-28 September. SPE-141993-MS. http://dx.doi.org/10.2118/141993$\underline{\text { MS. }}$

Berthier, A. and Fleury, M. 2000. Permeability Mapping on Vuggy Core Sample Using Tracer Experiments and Stream-Line Simulations. Presented at the SPE International Petroleum Conference and Exhibition, Villahermosa, Mexico, 1-3 February. SPE-58992-MS. http://dx.doi.org/10.2118/58992-MS.

Bretz, R. E., Specter, R. M., and Orr, F. M. 1988. Experimental Study of a Viscoelastic Surfactant-Based in Situ Self-Diverting Acid System: Results and Interpretation. SPE Res Eng 3 (3): 857-866. SPE-15017-PA. http://dx.doi.org/10.2118/15017$\underline{\text { PA. }}$

Bulgakova, G. T., Kharisov, R. Y., Pestrikov, A. V. et al. 2013. Experimental Study of a Viscoelastic Surfactant-Based in Situ Self-Diverting Acid System: Results and Interpretation. Presented at the 14th International Conference on Petroleum Phase Behavior and Fouling, Malmaison, France, 10-13 June. 
Chang, F., Qu, Q., and Frenier, W. 2001. A Novel Self-Diverting-Acid Developed for Matrix Stimulation of Carbonate Reservoirs. Presented at the 2001 SPE International Symposium on Oilfield Chemistry, Houston, Texas, 13-16 February. SPE-65033-MS. http://dx.doi.org/10.2118/65033-MS.

Coats, K. H. and Smith, B. D. 1964. Dead-End Pore Volume and Dispersion in Porous Media. SPE J. 4 (1): 73-84. SPE-647-PA. http://dx.doi.org/10.2118/647-PA.

Fredd, C. N. and Fogler, H. S. 1999. Optimum Conditions for Wormhole Formation in Carbonate Porous Media: Influence of Transport and Reaction. SPE J. 4 (3): 196205. SPE-56995-PA. http://dx.doi.org/10.2118/56995-PA.

Gomaa, A. M., Wang, G., and Nasr-El-Din, H. A. 2011. An Experimental Study of a New VES Acid System: Considering the Impact of CO2 Solubility. Presented at the SPE International Symposium on Oilfield Chemistry, The Woodlands, Texas, 11-13 April. SPE-141298-MS. http://dx.doi.org/10.2118/141298-MS.

Hoefner, M. L. and Fogler, H. S. 1989. Fluid-Velocity and Reaction-Rate Effects During Carbonate Acidizing: Application of Network Model. SPE Prod Eng 4 (1): 56-62. SPE-15573-PA. http://dx.doi.org/10.2118/15573-PA.

Huang, T., Hill, A. D., and Schechter, R. S. 1997. Reaction Rate and Fluid Loss: The Keys to Wormhole Initiation and Propagation in Carbonate Acidizing. SPE J. 5 (3): 287-292. SPE-65400-PA. http://dx.doi.org/10.2118/65400-PA.

Karperien, A. 2004. Fraclac Advance User's Manual, 5. Sydney, Austrralia: Charles Sturt University.

Li, L., Nasr-El-Din, H. A., and Cawiezel, K. E. 2009. Rheological Properties of a New Class of Viscoelastic Surfactant. Presented at the SPE International Symposium on Oilfield Chemistry, The Woodlands, Texas, 20-22 April. SPE-121716-MS. http://dx.doi.org/10.2118/121716-MS.

Liu, P., Xue, H., Zhao, L. Q. et al. 2015. Analysis and Simulation of Rheological Behavior and Diverting Mechanism of In Situ Self-Diverting Acid. J Pet Sci and Technol 132 (2015) : 39-52. http://dx.doi.org/10.1016/j.petrol.2015.04.042.

Lucia, F. J. 1983. Petrophysical Parameters Estimated from Visual Description of Carbonate Rocks: A Field Classification of Cabonate Pore Space. J Pet Technol 35 (3) : 39-52. http://dx.doi.org/10.2118/10073-PA. 
Lucia, F. J. 2010. Carbonate Reservoir Characterization, 2nd edition. New York: Springer-Verlag.

Lungwitz, B. R., Fredd, C. N., Brady, M. E. et al. 2004. Diversion and Cleanup Studies of Viscoelastic Surfactant-Based Self-Diverting Acid. Presented at the SPE International Symposium and Exhibition on Formation Damage Control, Lafayette, Louisiana, 18-20 February. SPE-86504-MS. http://dx.doi.org/10.2118/86504-MS.

Lynn, J. D. and Nasr-El-Din, H. A. 2001. A Core Based Comparison Of The Reaction Characteristics Of Emulsified And In-Situ Gelled Acids In Low Permeability, High Temperature, Gas Bearing Carbonates. Presented at the SPE International Symposium on Oilfield Chemistry, Houston, Texas, 13-16 February. SPE-65386MS. http://dx.doi.org/10.2118/65386-MS.

Maheshwari, P. and Balakotaiah, V. 2013. Comparison of Carbonate $\mathrm{HCl}$ Acidizing Experiments with 3D Simulations. SPE Prod \& Oper 28 (4): 402-413. SPE164517-PA. http://dx.doi.org/10.2118/164517-PA.

Mou, J., Liu, M., Zheng, K. et al. 2015. Diversion Conditions for ViscoelasticSurfactant-Based Self-Diversion Acid in Carbonate Acidizing. SPE Prod \& Oper 30 (2): 121-129. SPE-173898-PA. http://dx.doi.org/10.2118/173898-PA.

Nasr-El-Din, H. A., Al-Ghamdi, A. W. H., Al-Qahtani, A. A. et al. 2008. Impact of Acid Additives on the Rheological Properties of Viscoelastic Surfactants and Their Influence on Field Application. SPE J. 13 (1): 35-47. SPE-89418-PA. http://dx.doi.org/10.2118/89418-PA.

Nasr-El-Din, H. A., Al-Mohammed, A. M., Al-Aamri, A. D. et al. 2009. Quantitative Analysis of Reaction-Rate Retardation in Surfactant-Based Acids. SPE Prod \& Oper 24 (1): 107-116. SPE-107451-PA. http://dx.doi.org/10.2118/107451-PA.

Nasr-El-Din, H. A., Chesson, J. B., Cawiezel, K. E. et al. 2006. Lessons Learned and Guidelines for Matrix Acidizing With Viscoelastic Surfactant Diversion in Carbonate Formations. Presented at the SPE Annual Technical Conference and Exhibition, San Antonio, Texas, 24-27 September. SPE-102468-MS. http://dx.doi.org/10.2118/102468-MS.

Nasr-El-Din, H. A. and Samuel, M. 2007. Lesson Learned From Using Viscoelastic Surfactants in Well Stimulation. SPE Prod \& Oper 22 (1): 112-120. SPE-90383PA. http://dx.doi.org/10.2118/90383-PA. 
Pepin, A. H., Bize-Forest, N., Montoya Padilla, S. J. et al. 2014. Pre-Salt Carbonate Reservoir Analog Selection for Stimulation Optimization. Presented at the International Petroleum Technology Conference, Kuala Lumpur, Malaysia, 1012 December. SPE-18023-MS. http://dx.doi.org/10.2523/IPTC-18023-MS.

Shimizu, I., Itachida, O., Kobayashi, O. et al. 2005. Surfactant-Based Self-Diverting Acid System Maximises Acid Coverage and Eliminates Flowback in an Openhole Horizontal Injection Well Offshore Qatar. Presented at the International Petroleum Technology Conference, Doha, Qatar, 21-23 November. SPE-10445-MS. http://dx.doi.org/10.2523/IPTC-10445-MS.

Shu, Y., Wang, G., Nasr-El-Din, H. A. et al. 2015. Interactions of Fe(III) and Viscoelastic-Surfactant-Based Acids. SPE Prod \& Oper. SPE-165149-PA. http://dx.doi.org/10.2118/165149-PA.

Skauge, A., Vik, B., Pourmohammadi, S. et al. 2006. Dispersion Measurements Used in Special Core Analysis of Carbonates. Presented at the International Symposium of the Society of Core Analysts, Trondheim, Norway, 12-16 September.

Turk, N., Greig, M. J., Dearman, W. R. et al. 1987. Characterization of Rock Joint Surfaces by Fractal Dimension. Presented at the 28th US Symposium on Rock Mechanics, Tucson,Arizona, 29 June - 1 July.

Wang, Y., Hill, A. D., and Schechter, R. S. 1993. The Optimum Injection Rate for Matrix Acidizing of Carbonate Formations. Presented at the SPE Annual Technical Conference and Exhibition, Houston, Texas, 3-6 October. SPE-26578MS. http://dx.doi.org/10.2118/26578-MS.

Yu, M., Mahmoud, M. A., and Nasr-El-Din, H. A. 2009. Quantitative Analysis of an Amphoteric Surfactant in Acidizing Fluids and Coreflood Effluent. Presented at the SPE International Symposium on Oilfield Chemistry, The Woodlands, Texas, 20-22 April. SPE-121715-MS. http://dx.doi.org/10.2118/121715-MS.

Yu, M., Mahmoud, M. A., and Nasr-El-Din, H. A. 2011. Propagation and Retention of Viscoelastic Surfactants Following Matrix-Acidizing Treatments in Carbonate Cores. SPE J 16 (4): 993-1001. SPE-128047-PA. http://dx.doi.org/10.2118/128047-PA.

Zakaria, A. S., Nasr-El-Din, H. A., and Ziauddin, M. 2015. Predicting the Performance of the Acid-Stimulation Treatments in Carbonate Reservoirs with Nondestructive 
Tracer Tests. SPE J. Preprint. SPE-174084-PA.

http://dx.doi.org/10.2118/174084-PA.

Ziauddin, M. and Bize, E. 2007. The Effect of Pore-Scale Heterogeneities on Carbonate Stimulation Treatments. Presented at the SPE Middle East Oil \& Gas Show and Conference, Kingdom of Bahrain, 11-14 March. SPE-104627-MS.

http://dx.doi.org/10.2118/104627-MS. 